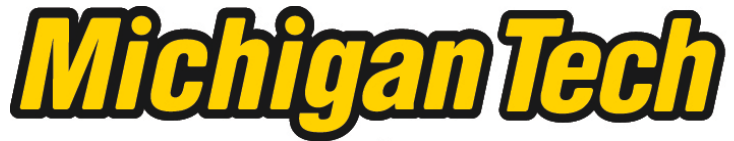 \\ Michigan Technological University Create the Future Digital Commons @ Michigan Tech
}

2015

\section{MODELING OF BIOMASS TORREFACTION AND PYROLYSIS AND ITS APPLICATIONS}

Jordan L. Klinger

Michigan Technological University

Follow this and additional works at: https://digitalcommons.mtu.edu/etds

Part of the Chemical Engineering Commons, and the Energy Systems Commons Copyright 2015 Jordan L. Klinger

\section{Recommended Citation}

Klinger, Jordan L., "MODELING OF BIOMASS TORREFACTION AND PYROLYSIS AND ITS APPLICATIONS", Dissertation, Michigan Technological University, 2015.

https://doi.org/10.37099/mtu.dc.etds/1013

Follow this and additional works at: https://digitalcommons.mtu.edu/etds

Part of the Chemical Engineering Commons, and the Energy Systems Commons 


\title{
MODELING OF BIOMASS TORREFACTION AND PYROLYSIS AND ITS APPLICATIONS
}

By

Jordan L. Klinger

\begin{abstract}
A DISSERTATION
Submitted in partial fulfillment of the requirements for the degree of DOCTOR OF PHILOSOPHY
\end{abstract}

In Mechanical Engineering-Engineering Mechanics

MICHIGAN TECHNOLOGICAL UNIVERSITY

(C) 2015 Jordan Klinger 
This dissertation has been approved in partial fulfillment of the requirements for the Degree of DOCTOR OF PHILOSOPHY in Mechanical Engineering - Engineering Mechanics.

Department of Mechanical Engineering - Engineering Mechanics

Dissertation Co-Advisor: Dr. Ezra Bar-Ziv

Dissertation Co-Advisor:

Dr. David Shonnard

Committee Member: Dr. Jeffrey Naber

Committee Member: $\quad$ Dr. Michael Mullins

Department Chair: Dr. William Predebon 


\section{Table of Contents}

List of Figures viii

List of Tables xii

Preface xiii

Acknowledgements xviii

Abstract .... XX

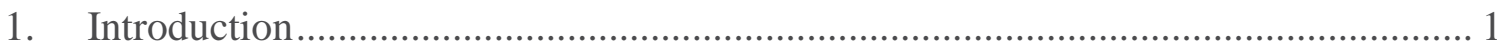

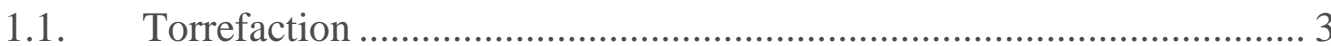

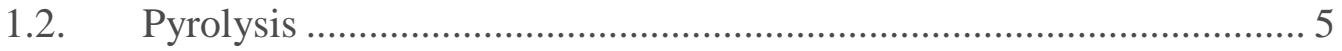

1.3. Kinetic Models for Torrefaction and Pyrolysis .................................. 8

1.3.1. Single Component Models ............................................................ 8

1.3.2. Multicomponent Models ............................................................. 11

1.3.3. Distributed Activation Energy Models (DAEM) .......................... 15

1.3.4. Modeling Summary and Knowledge Gaps .................................. 16

1.4. Research Objectives and Proposal Structure ................................... 17

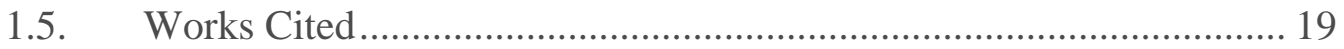

2. Development of Thermal Degradation Model ................................................... 29

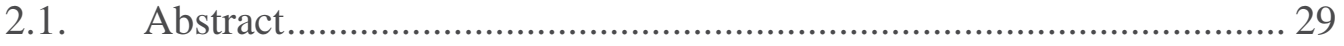

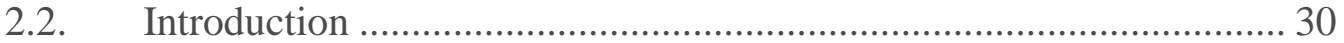


2.3. Material and methods 34

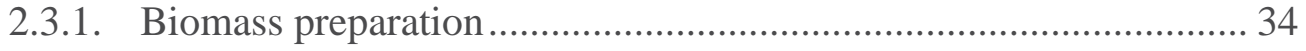

2.3.2. Torrefaction-GC/MS experiment ................................................... 34

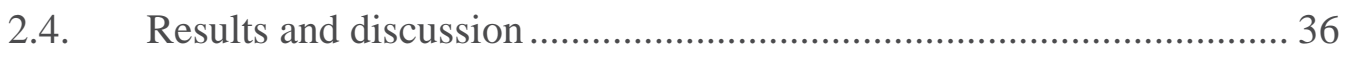

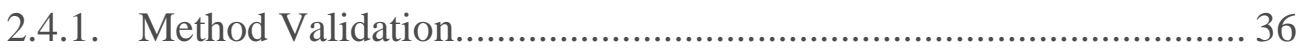

2.4.2. Model development................................................................ 38

2.4.3. Kinetic model and interpretation............................................... 42

2.5. Conclusions and Recommendations .............................................. 48

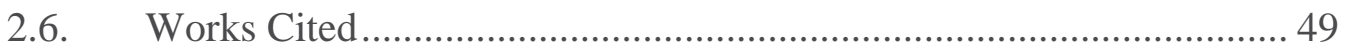

3. Temperature Dependence of Thermal Degradation Model .................................... 55

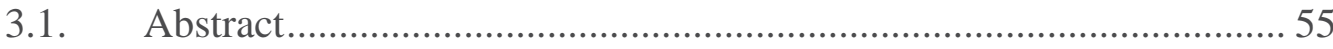

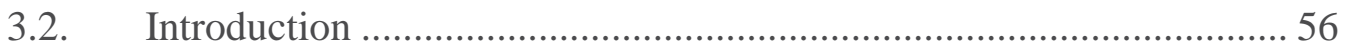

3.3. Material and Methods .............................................................. 61

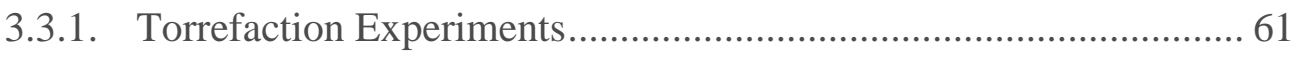

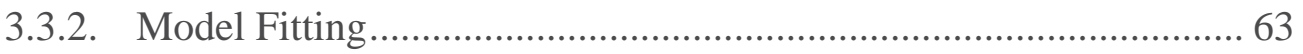

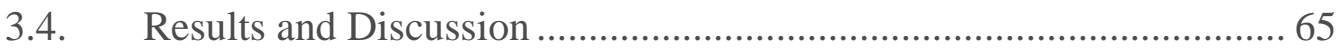

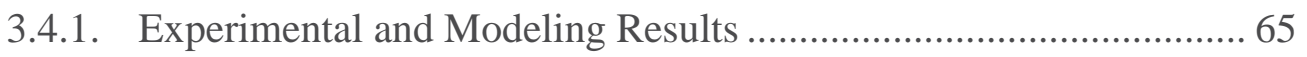

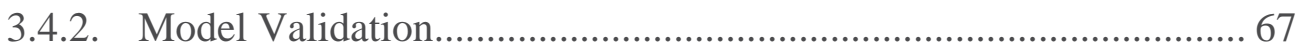

3.4.3. Arrhenius Parameters .............................................................. 71 


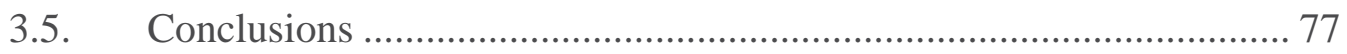

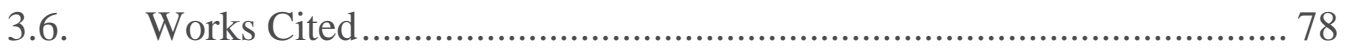

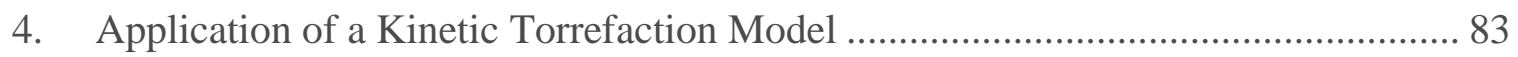

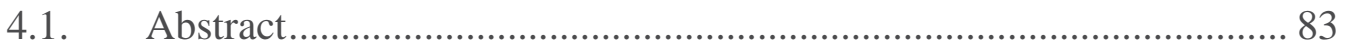

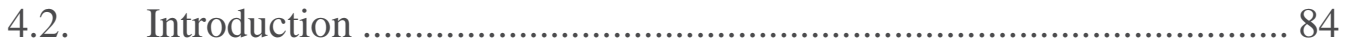

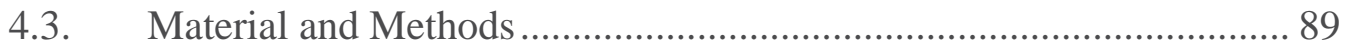

4.3.1. Product Distribution and Mass Loss .......................................... 89

4.3.2. Elemental Composition and Heating Value ................................ 92

4.4. Results and Discussion .......................................................... 94

4.4.1. Modeling Torrefied Biomass Properties ........................................ 94

4.4.2. Future Model Extension ............................................................... 98

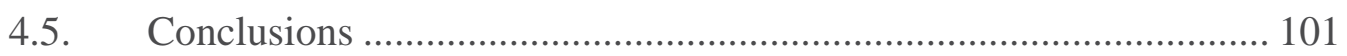

4.6. Works Cited ........................................................................ 102

5. Development of a Unified Torrefaction-Pyrolysis Kinetic Model ........................ 109

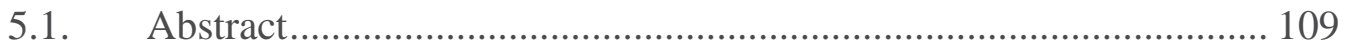

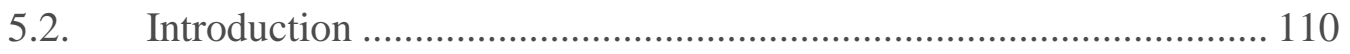

5.3. Materials and Methods ........................................................ 114

5.3.1. Pyrolysis Experiments ........................................................ 114 
5.3.2. Product Distribution and Molecular Fragmentation.

5.3.3. Modeling Approach.

5.4. Results and Discussion ............................................................. 120

5.4.1. Kinetic Model............................................................................. 122

5.4.2. Component-based Model Fitting............................................. 124

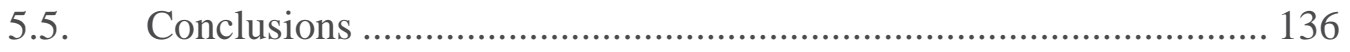

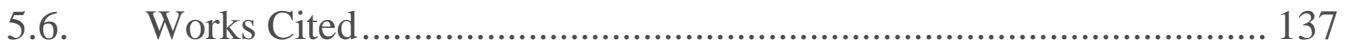

6. Application of a Kinetic Pyrolysis Model ....................................................... 142

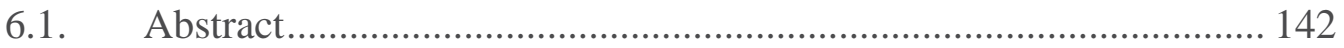

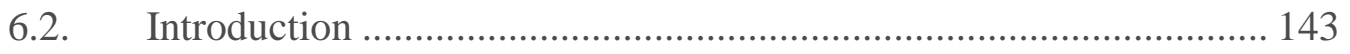

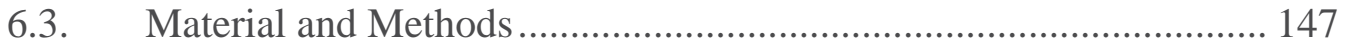

6.3.1. Micropyrolysis Experiments ................................................ 148

6.3.2. Modeling Approach................................................................ 148

6.3.3. Feedstock/Solid Product Characterization ................................. 150

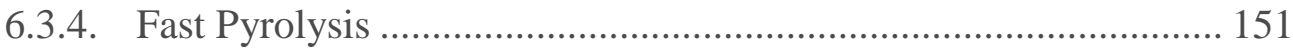

6.3.5. Pyrolysis Product Characterization ........................................... 153

6.4. Results and Discussion .......................................................... 153

6.4.1. Model Calibration ................................................................. 153

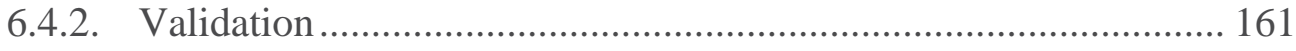


6.4.3. Model Summary

6.5. Conclusions …............................................................................ 168

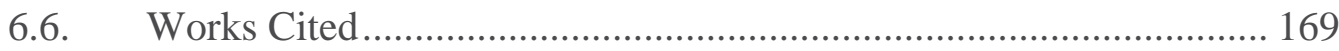

7. Conclusions and Recommendations for Future Work ........................................ 176 


\section{List of Figures}

Figure 1.1: Single component reaction models. ....................................................... 10

Figure 1.2: Two-stage consecutive reaction model. .................................................... 12

Figure 1.3: Three-stage consecutive reaction model. ..................................................... 14

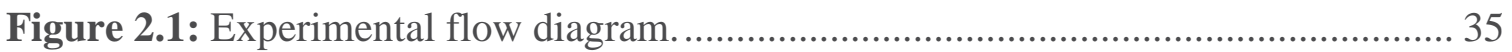

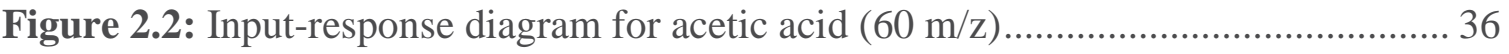

Figure 2.3: (Top) Production rate of major compound ions over the full 90 minute torrefaction experiment. (Bottom) The ion traces over the first thirty minutes of torrefaction. (Bottom Insert) Production rates over the first two minutes............ 39

Figure 2.4: Log-plot of compound production rates....................................................... 40

Figure 2.5: Experimental rate data with model predictions ............................................. 44

Figure 3.1: Experimental transient trends for $18 \mathrm{~m} / \mathrm{z}(\mathrm{H} 2 \mathrm{O}), 28 \mathrm{~m} / \mathrm{z}(\mathrm{CO}), 29 \mathrm{~m} / \mathrm{z}$ (HCOOH), $44 \mathrm{~m} / \mathrm{z}(\mathrm{CO} 2)$, and $60 \mathrm{~m} / \mathrm{z}(\mathrm{CH} 3 \mathrm{COOH})$, and $95 \mathrm{~m} / \mathrm{z}(\mathrm{OC} 4 \mathrm{H} 3 \mathrm{CHO})$ at

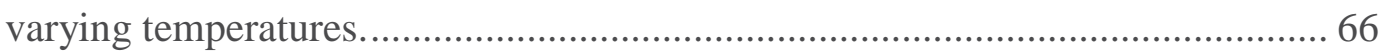

Figure 3.2: Model fitting for all compounds at different torrefaction temperatures. The experimental data are shown as solid lines. The model at each temperature is shown as dashed lines. 68

Figure 3.3: Values of alpha for each component over $260-300^{\circ} \mathrm{C}$................................. 69

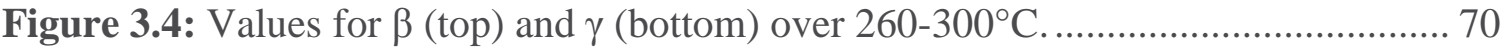

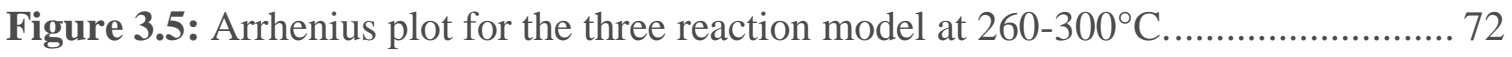

Figure 3.6: Total product profiles for water, acetic acid and carbon dioxide with a product distribution. 76 
Figure 4.1: Production rate profiles and total product profiles for torrefaction products.91

Figure 4.2: Model calibration of volatile product yield. Solid linear trends are paired with series with square markers and dash linear trends are paired with diamond series. Experimental data from (Prins et al., 2006a,b). 93

Figure 4.3: Model predictions (solid lines) of absolute elemental mass loss(top), and changes in relative elemental composition with comparison to literature data(bottom). Experimental data are represent by data points from (Pach et al. 2002; Bridgeman et al. 2008; Phanphanich and Mani 2011; Wannapeera et al. 2011; Broström et al. 2012; Sarvaramini et al. 2013; Sarvaramini and Larachi 2014). . 95

Figure 4.4: Model prediction (solid lines) of energy density, and energy retention in the torrefied biomass. Experimental data are represent by data points from (Pach et al. 2002; Bridgeman et al. 2008; Phanphanich and Mani 2011; Wannapeera et al. 2011; Broström et al. 2012; Sarvaramini et al. 2013; Sarvaramini and Larachi 2014). . 97

Figure 4.5: Literature data for carbon and oxygen (top) and hydrogen (bottom) composition over the entire mass loss regime in an inert atmosphere. Data from (Pach et al. 2002; Mohan et al., 2006; Bridgeman et al. 2008; Phanphanich and Mani 2011; Wannapeera et al. 2011; Broström et al. 2012; Sarvaramini et al. 2013; Sarvaramini and Larachi 2014). Dashed lines are arbitrary trends simply to illustrate data connection. 99

Figure 4.6: Literature data for energy density (top) and yield (bottom) over the entire mass loss regime in an inert atmosphere. Data from (Pach et al. 2002; Mohan et al., 2006; Bridgeman et al. 2008; Phanphanich and Mani 2011; Wannapeera et al. 2011; 
Broström et al. 2012; Sarvaramini et al. 2013; Sarvaramini and Larachi 2014).

Dashed lines are arbitrary trends simply to illustrate data connection. 100

Figure 5.1: Experimental traces of the total chromatogram for a range of temperatures.

Figure 5.2: Typical model fits for TIC traces

Figure 5.3: Arrhenius plot for kinetic modeling of TIC signal. Solid symbols represent modeling results. Empty symbols represent values used in modeling as predicted by straight line trends (dashed lines).

Figure 5.4: Typical experimental traces for 32 mass fragment traces and model fits. Data shown were taken at $350^{\circ} \mathrm{C}$. 127

Figure 5.5: Average stoichiometry factor ratios for unique structural component fragments 130

Figure 5.6: Summary of fit rate constants (data points) for molecular fragments at $315^{\circ} \mathrm{C}$ (Top, Left), $330^{\circ} \mathrm{C}$ (Top, Right), $350^{\circ} \mathrm{C}$ (Middle Top, Left), $375^{\circ} \mathrm{C}$ (Middle Top, Right), $400^{\circ} \mathrm{C}$ (Middle Bottom, Left), $425^{\circ} \mathrm{C}$ (Middle Bottom, Right), Arrhenius Plot for the 32 fragments for pyrolysis (Bottom, Left), and Torrefaction (Bottom, Right). Dashed lines show the respective average value obtained from the TIC chromatogram 134

Figure 6.1: Experimental and literature data for relative composition of wood char through pyrolysis. Literature data from (Arias et al. 2008; Salehi et al. 2011; Wannapeera et al. 2011; Broström et al. 2012; Howe et al. 2015; RW Nachenius et al. 2015a). Mass Loss is on a moisture and ash free basis. 155 
Figure 6.2: Comparison of experimental data and model prediction for normalized composition of wood char through pyrolysis. Volatile Loss* is on a moisture, ash, and fixed carbon free basis. Literature data from (Arias et al. 2008; Manuel GarciaPerez et al. 2008; Salehi et al. 2011; Wannapeera et al. 2011; Broström et al. 2012; Howe et al. 2015; RW Nachenius et al. 2015a) 158

Figure 6.3: Comparison of carbon monoxide, carbon dioxide, and water yield to model predictions for mass calibration of reaction stoichiometry. Volatile Loss* is on a moisture, ash, and fixed carbon free basis. Literature data from (Manuel GarciaPerez et al. 2008; Sınă̆ et al. 2011; Wannapeera et al. 2011; Westover et al. 2013; Howe et al. 2015; RW Nachenius et al. 2015a) 160

Figure 6.4: Higher heating value predictions and data for pyrolytic chars formed at varying process severity. Volatile Loss* is on a moisture, ash, and fixed carbon free basis. Literature data from (Arias et al. 2008; Salehi et al. 2011; Wannapeera et al. 2011; Broström et al. 2012; Howe et al. 2015; RW Nachenius et al. 2015a). 162

Figure 6.5: Model predictions and data for yield of total gas, total liquid, and oil products. Volatile Loss* is on a moisture, ash, and fixed carbon free basis. Literature data from (Manuel Garcia-Perez et al. 2008; Salehi et al. 2011; Sinağ et al. 2011; Wannapeera et al. 2011; Westover et al. 2013; Howe et al. 2015; RW Nachenius et al. 2015a) 164

Figure 6.6: Model phase and elemental distribution predictions. Volatile Loss* is on a moisture, ash, and fixed carbon free basis. 167 


\section{List of Tables}

Table 2.1: Ultimate and proximate analysis of coal, biocoal, and various raw biomass species (Ahn et al. 2001; Demirbaş 2001; Parikh et al. 2005; Bridgeman et al. 2010;

Tumuluru et al. 2011). 33

Table 2.2: Stoicheometeric factors for each modeled compound 45

Table 2.3: Torrefaction kinetic models, adapted from (Di Blasi and Lanzetta 1997; Repellin et al. 2010; Chew and Doshi 2011; Bates and Ghoniem 2012; Broström et al. 2012).

Table 3.1: Kinetic parameters for various feedstocks in a two-stage degradation scheme.

Table 3.2: Relative stoichiometric coefficients produced from reaction one $(\alpha)$, two $(\beta)$, and three $(\gamma) \pm$ one standard deviation. 74

Table 4.1: Stoichiometric coefficients used in the kinetic model(Klinger et al., 2014). . 92

Table 5.1: Major products formed from pyrolysis of pure component species. 117

Table 5.2: Experimental matrix showing the temperature range for each reaction during model fitting 120

Table 5.3: Top ten most abundant ions formed during pyrolysis at $350^{\circ} \mathrm{C}$. 125

Table 5.4: Stoichiometry parameters for the 32 modeled molecular fragments. 132 


\section{Preface}

This doctoral dissertation contains material previously reviewed and published in scientific journals. Full citation details for these works are as follows:

Chapter 2:

Reprinted with permission from KLINGER J, BAR-ZIV E, SHONNARD D. 2013. KINETIC STUDY OF ASPEN DURING TORREFACTION. JOURNAL OF ANALYTICAL AND APPLIED PYROLYSIS 104(0):146-152. Copyright 2013 Elsivier B.V.

DOI Link: http://dx.doi.org/10.1016/j.jaap.2013.08.010

Author contributions:

Klinger - Experimental planning, collection of data, numerical modeling, analysis and interpretation of data, writing of the paper

Bar-Ziv - Experimental planning, analysis and interpretation of data, paper review and editing

Shonnard - Experimental planning, analysis and interpretation of data, paper review and editing 
Chapter 3:

Reprinted with permission from KLINGER J, KLEMETSRUD B, BAR-ZIV E, SHONNARD D. 2014. TEMPERATURE DEPENDENCE OF ASPEN TORREFACTION KINETICS. JOURNAL OF ANALYTICAL AND APPLIED PYROLYSIS 110(0):424429. Copyright 2014 Elsivier B.V.

DOI Link: http://dx.doi.org/ 10.1016/j.jaap.2014.10.008

Author contributions:

\author{
Klinger - Experimental planning, collection of data, numerical modeling, \\ analysis and interpretation of data, writing of the paper \\ Klemetsrud - Collection of data, writing of the paper \\ Bar-Ziv - Experimental planning, analysis and interpretation of data, paper \\ review and editing \\ Shonnard - Experimental planning, analysis and interpretation of data, paper \\ review and editing
}

Chapter 4: 
Reprinted with permission from KLINGER J, BAR-ZIV E, SHONNARD D. 2014. PREDICTING PROPERTIES OF TORREFIED BIOMASS BY INTRINSIC KINETICS. ENERGY \& FUELS 29(1):171-176. Copyright 2014 American Chemical Society.

DOI Link: http://dx.doi.org/10.1021/ef501456p

Author contributions:

Klinger - $\quad$ Planning, numerical modeling, analysis and interpretation, writing of the paper

Bar-Ziv - $\quad$ Planning, analysis and interpretation, paper review and editing Shonnard - Planning, analysis and interpretation, paper review and editing 
Chapter 5:

Reprinted with permission from KLINGER J, BAR-ZIV E, SHONNARD D. 2015.

UNIFIED KINETIC MODEL FOR TORREFACTION-PYROLYSIS. FUEL PROCESSING TECHNOLOGY 138(0):175-183. Copyright 2015 Elsivier B.V.

DOI Link: http://dx.doi.org/ 10.1016/j.fuproc.2015.05.010

Author contributions:

Klinger - $\quad$ Experimental planning, collection of data, numerical modeling, analysis and interpretation of data, writing of the paper

Bar-Ziv - Experimental planning, analysis and interpretation of data, paper review and editing

Shonnard - Experimental planning, analysis and interpretation of data, paper review and editing 


\title{
Chapter 6:
}

Reprinted with permission from ENERGY \& FUELS, submitted for publication. Unpublished work Copyright 2015 American Chemical Society.

Author contributions:

\author{
Klinger - Experimental planning, numerical modeling, analysis and \\ interpretation of data, writing of the paper \\ Bar-Ziv - Experimental planning, analysis and interpretation of data, paper \\ review and editing
}
Shonnard - Experimental planning, analysis and interpretation of data, paper review and editing
Westover - Experimental planning, collection of data, analysis and interpretation of data, paper review and editing
Emerson - Experimental planning, collection of data, analysis and interpretation of data, paper review and editing




\section{Acknowledgements}

I would like to acknowledge the financial support I received from the National Science Foundation through a Sustainable Energy Pathways (MPS/CHE - ENG/ECCS 1230803) and Innovation-Corps grants, the Richard and Bonnie Robbins Foundation, and Dr Ezra Bar-Ziv's research startup fund.

I would like to acknowledge the guidance and mentoring of my co-advisors Dr. Ezra Bar-Ziv and Dr. David Shonnard. Without your support (and careful patience) I could not have developed these published works or focused research expertise. I sincerely appreciate the many thoughtful discussions and advice about research interpretations and approach. Through these past years my education and growth as a researcher remained the top priority - and I thank you.

I would like to acknowledge Dr. Jeffrey Naber and Dr. Michael Mullins for serving on my advisory committee, and for their careful review and support of my work. Your critical comments and discussions always kept my thoughts and research interpretations grounded, realistic, and focused.

I would like to acknowledge the many thoughtful discussions, contributions, and antics of my undergraduate research assistants (Amanda Taylor, Nick Wimmer, Leanne Bregni, Adrien Steinhurst, and Tyler Ezinga) and fellow/past graduate students (Felix Adom, Jifei Liu, Michael Brodeur-Campbell, Olumide Winjobi, Howard Haselhuhn III, Jacob McDonald) - particularly Bethany Klemetsrud, Suchada Ukaew, and Yashwanth Donepudi,. 
I would like to conclude by acknowledging the support of my loving wife Jennifer, my sons Joshua, Gabriel, and Matthew, and my daughter Charlie. Thank you for keeping me focused these year, and keeping my efforts in perspective. Without your compassion and understanding, I would not be able to pursuit my dreams and ambitions. The late nights, early mornings, and seemingly endless work hours in between are for you 


\section{Abstract}

Utilizing biomass provides a possible near-term alternative solution for fossil energy dependence in both electricity generation and transportation. Though thermochemical conversion can produce solid/liquid fuels that are compatible in existing infrastructure, detailed scientific chemical and mechanistic understanding are still being developed. In contribution to these efforts, this work is focused on development of a semiempirical, lumped parameter, chemical kinetic model to describe the degradation of woody biomass.

The initial kinetic model was developed in the torrefaction region to describe the gas-phase evolution of products (water, organic acids, permanent gases, and furfural) through a three consecutive reaction model. In this model, the initial biomass degrades through several solid intermediates that represent of partially degraded polymers to produce the observed gas-phase species through product detachment. The model was able to well describe the measured species transients, and revealed important considerations between processing severity (time, temperature) and enhancement of solid fuel properties. After the model was calibrated to predict the weight distribution between products, it was able to describe the elemental composition of the solid material up to removal of approximately thirty percent of the initial dry sample mass. Engineering considerations such as process efficiency based on the intrinsic reaction (mass and energy yield) were explored. 
The model was then extended into a more traditional pyrolysis range (up to $425^{\circ} \mathrm{C}$ ), while avoiding any significant secondary thermal reactions. Here the model was extended in similar fashion to six consecutive reactions to describe to observed product evolution. It was found that the model not only describes the gas-phase species from cellulose, hemicellulose, and lignin, but also the entirety of torrefaction and pyrolysis within a single unified mechanism, implying that they are similar processes that occur at kinetically different rates due to process temperature. The presented kinetic parameters, process chemistry, and dynamic product removal traces offer unique insight into the thermal degradation mechanism. The unified model predictions were then explored to present product distribution/composition over the complete processing range, and obtain model validation. Also of great importance, the presented model is able to account for differences in solid degradation due to variation in woody feedstock. 


\section{Introduction}

Anthropogenic activity has led to an increase in average radiative forcing on Earth's surface, leading to global temperature by nearly $1.5^{\circ} \mathrm{F}$ (U.S.EPA 2014b). Most of this can be attributed to emissions of carbon dioxide (82\%), methane (9\%), nitrous oxide (6\%), and fluorinated gases (3\%) (IPCC 2013; U.S.EPA 2014a) In 2012, these harmful emissions equated to 6,526 million metric tons of equivalent carbon dioxide produced in the United States. Of these emissions $32 \%$ was from electricity production, which is mainly coal and natural gas, $28 \%$ from transportation (primarily gasoline and diesel), 20\% from industry (primarily integrated process energy/electricity generation from fossil fuels, as well as process emissions), $10 \%$ from the commercial and residential sector (again mainly from combustion of fossil fuels for heating), an $10 \%$ from agriculture as a result of heavy crop/animal production, and applications of fertilizers (Kahn et al. 2007; USEIA ; U.S.EPA 2014b). A common theme emerges from all sectors above - the burning of fossil fuels is main cause for global warming emissions. The resulting changes (and projected changes) in temperature can have devastating effects on the climate, and the environment. If worldwide emissions of greenhouse gases are not challenged and reduced to a level that can be incorporated into the Earth's natural carbon cycles, the average temperature could rise from 2 to $11.5^{\circ} \mathrm{F}$ over the next century (USGCRP 2009).

For this reason and others (e.g. energy independence, utilization of national resources, job creation, etc.), the United States Environmental Protection Agency created the Renewable Fuel Standard (RFS) program in 2005 under the Energy Policy Act (transportation fuels), and proposed implementation of strict Mercury and Air Toxics 
Standards (MATS) based on Maximum Achievable Control Technology (MACT) (electric utilities). The RFS was further developed in 2007 under the Energy Independence and Security Act of 2007 to shift the focus of renewable fuels to more advanced fuel generations such as hydrocarbon transportation fuel produced through thermochemical conversion (U.S.DOE 2014). In addition, many US states have enrolled in Renewable Portfolio Standards (RPS) programs to shift the utility generation of electricity away from the most potent fossil fuels (coal and oil). These US mandates have provided motivation for much research into alternative fuels to alleviate the burdens from the two most potent emission sectors discussed above - renewable gasoline and diesel for the transportation sector and alternative solids fuels/technologies for the energy sector.

In order to address these fuel replacement issues in a compelling way, a drop-in replacement needs to be developed that requires little-to-no-change in existing infrastructure and supply systems. For the power industry, this means a replacement for pulverized coals in solid fuel boilers - and these in-turn are almost exclusively designed to operate on pulverized coals (Broström et al. 2012). The only near-term viable solution for a solid fuel replacement is biomass or an upgraded solid fuel through thermochemical conversion (torrefaction) (Medic et al. 2012). For transportation fuels, this mean the replacement of gasoline and diesel (Kahn). Here again, thermochemical conversion of biomass (pyrolysis) provides the most promise to a drop-in replacement (Mohan et al. 2006).

Torrefaction $\left(200-300^{\circ} \mathrm{C}\right)$ and pyrolysis $\left(350-600^{\circ} \mathrm{C}\right)$ represent the process of thermal degradation in an oxygen free environment. Recent well cited review articles 
discuss the wide collection of empirical data and data modeling, but there are many competing ideas about the complex chemical pathways with no clear solution (Bridgwater et al. 1999; Mohan et al. 2006; Chew and Doshi 2011; van der Stelt et al. 2011; Bridgwater 2012). To help address these energy issues, and make informed process decisions of design and scale-up, detailed kinetic models are needed. Such models can yield valuable insight and considerations necessary to begin production of renewable fuels on an industrial level, such as processing conditions (reactor residence time, temperature, variability, sensitivity, etc.) and can be coupled with heat and mass transport phenomena to be integrated into process reactor models. As discussed in detail below existing kinetic modeling of these processes present torrefaction and pyrolysis as based largely on only solid weight loss data or discrete product profiles, and are limited to the specific reactor system and feedstock. A comprehensive review of these two processes, torrefaction and pyrolysis, are detailed below in addition to specific literature reviews provided in subsequent chapters. Due to the research objectives of this work (see section 1.5), the review is focused around kinetic modeling of torrefaction and pyrolysis.

\subsection{Torrefaction}

Torrefaction is the thermal depolymerization of material in the absence of oxygen in the range of $200-300^{\circ} \mathrm{C}$ (Boardman et al. 2011; Chew and Doshi 2011; Ciolkosz and Wallace 2011). The primary product from this process is a more carbonaceous solid char (60-90\% yield) with smaller production of water, organic acids, aldehydes, and permanent

gases $\left(\mathrm{CO}, \mathrm{CO}_{2}\right)$ (Prins et al. 2006b; Boardman et al. 2011; Medic et al. 2012; Nocquet et 
al. 2014). The carbon content of the original biomass is enhanced (5-20\% increase) through removal of relatively more oxygen (and small amounts of hydrogen), effectively enhancing the heating value of the solid material at a lower mass yield (Lipinsky et al. 2002; Demirbas 2004; Bridgeman et al. 2008; Boardman et al. 2011; Ibrahim et al. 2013). Another important effect of torrefaction is the reduction in energy required during comminution for use in fuel boilers compared to raw biomass. Torrefaction has been shown to reduce this energy up to an order of magnitude(Mani et al. 2004; Bergman 2005; Esteban and Carrasco 2006).

Recently, Ibrahim et al. carried out a parametric study on the torrefaction of woody biomass (willow, eucalyptus, oak, birch, pine, larch, and spruce) to investigate the changes in physicochemical properties (Ibrahim et al. 2013). Samples were processed in a batch reactor $\left(100 \mathrm{~g}\right.$ samples, $\left.10^{\circ} \mathrm{C} / \mathrm{min}\right)$ under a flow of nitrogen. Samples were processed at $270^{\circ} \mathrm{C}$ for 30 minutes (A), $270^{\circ} \mathrm{C}$ for 60 minutes (B), and $290^{\circ} \mathrm{C}$ for 30 minutes (C). These conditions are ordered from least sever to most severe processing. As severity increased, the mass yield decreased. For example the yield of willow ranged from approximately $69 \%$ to $56 \%$, and softwood from $80 \%$ to $67 \%$. The non-volatile mass (fixed carbon and ash) are relatively enhanced: 15.2 to 36.8 and 0.5 to 1.1 respectively for willow; 17.0 to 28.2 and 0.1 to 0.4 respectively for softwood. During ultimate analysis, the relative elemental composition changes from 49.5/6.1/0.2/44.4 (C/H/N/O) to 60.1/5.8/0.0/34.2 for willow, and from 46.7/5.9/0.0/47.4 to 58.7/6.0/0.0/35.3 for softwood. The heating value of the material also increased from 19.4 to $24.2 \mathrm{MJ} / \mathrm{kg}$ for willow and from 18.4 to 23.7 for softwood. The grindability of material also improved. On the Hardgrove Grindability 
Index (HGI) where a score of $<32$ represents poor gridability, and 100 represents complete grindability, willow increased from <32 (raw) to 69.2 (conduction C), and is near typical energies required for size reduction of fossil coals. These improved fuel properties are attributed to the partial degradation of the biomass structure. Variations due to feedstock(also demonstrated in other works referenced above) are reported to be inherent to the specific feedstock, and require separate studies.

It may be possible to account for these variation between feedstock through the variation in initial carbohydrate/fiber structure and distribution. As demonstrated in other works, the structural carbohydrates and fibers degrade at different rates during torrefaction and pyrolysis (Yang et al. 2007; Sarvaramini et al. 2013). Because of this, variations in initial chemical and structural composition may account for the majority of empirical variation. This hypothesis that properties vary according to their composition is tested and addressed later in Chapters 4 and 6.

\subsection{Pyrolysis}

At higher degradation temperatures $\left(350-600^{\circ}\right.$, thermal depolymerziation in an inert environment is referred to as pyrolysis (Bridgwater et al. 1999; Mohan et al. 2006). At these temperatures, the structure of biomass is able to full degrade much faster. Primarily a liquid product is formed (50-75\%) with smaller amounts of permanent gases and solid chars (Mohan et al. 2006). The pyrolysis oil is of great interest due to the ability to catalytically upgrade (much like crude petroleum refining) the material, in the presence 
of hydrogen, to a liquid hydrocarbon fuel that can be blended into the existing fuel distribution system (Bridgwater 2012). Although pyrolysis oil has great potential application, it is important to note that issues of oil $\mathrm{pH}$, stability, corrosively, density, and water solubility create many challenges for its utilization(Mohan et al. 2006). Due to the complex nature of whole biomass pyrolysis, pyrolysis of cellulose, hemicellulose, and lignin are often studied in parallel.

In 2009, Patwardhan et al., investigated the pyrolysis of cellulose and other glucoses-based carbohydrates (Patwardhan et al. 2009). In summary it was found that there is very little char formed from cellulose pyrolysis $(\sim 5 \%)$, while most of the initial mass is partitioned into the condensable oil $(\sim 87 \%)$. The major condensable species formed are levoglucosan $(\sim 63 \%)$, formic acid (6.5\%), and other anhydrosugars (4.5\%). From the observation that levoglucosan is the main product, it was concluded that the mechanism likely product detachment like is a scheme such as: polysaccharides > oligosaccharides > disaccharides $>$ monosaccharides in product detachment. These observations are also see through other works investigating the pyrolysis and pyrolysis mechanism of cellulose/glucose-based carbohydrates (Huang et al. 2010; DK Shen et al. 2010; Collard and Blin 2014)

In 2011, this same group investigate the pyrolysis of hemicellulose and lignin(Patwardhan et al. 2011b; 2011a). The hemicellulose results show that water (15\%), carbon dioxide (19\%), organic acids (11\%), and di-anhydroxylopyranose sugars are the main products with an approximate $15 \%$ yield of char. These yields agree with major findings observed by others (Aho et al. 2008). The major products from fast pyrolysis of 
lignin include char (37\%), carbon dioxide (15.2\%), organic acids (11.5\%), with the remaining identified species being almost entirely phenol, methylated phenols, vinyl phenols, allyl phenols, etc. The compounds formed from the lignin fraction therefore have the greatest molecular weight on average, and have the most favorable carbon and hydrogen to oxygen ratio of the three biomass constituents. These observations and chemical class products from lignin are also noted in other literature (Jackson et al. 2009; Patwardhan et al. 2011a; Zhang et al. 2014).

These general product profiles also apply to the distribution within virgin biomass. Zhang, Mohan, and Pittman et al., found through thermodynamic calculation and empirical work that different wood species, even with varying cellulose, hemicellulose, and lignin distributions produce very similar qualitative product profiles (Zhang et al. 2007). They found that even comparing softwoods such as pine, which are rich in guaiacyl lignin, and hardwoods such as oak, which contain guaiacyl and syringyl lignin units, repeatedly produce similar liquid products in the absence of secondary thermal reactions. Importantly, they noted that secondary thermal reactions (cracking) that convert primary liquid products to gaseous products are almost entirely as a result of long gas-phase residence times and less dependent of inter/intra-particle heat or mass transport effects. Further, they note that the yield of gaseous hydrocarbons (methane, ethane, etc.) are positively linked to such secondary thermal reactions.

As another example of feedstock variability on product distribution, Kelkar et al. investigated product distributions from several North American grass species(Kelkar et al. 2014). They report that Miscanthus and big bluestem have the highest weight percent 
cellulose, sandreed and sideoats have the highest hemicellulose, and big bluestem and miscanthus have the highest weight percent lignin. From their results, it is clear that these generally agree with the profiles discussed above. Specifically, aceltol (another primarily cellulose product) is generated in some of the highest quantities in miscanthus, while acetic acid from hemicellulose is highest in both sideoats and sandreed. The lignin-originating compounds (methyl glyoxal, 4-vinylphenol) do not vary significantly, however 4vinylphenol is most abundant in miscanthus. Variations, as they describe, are due to complex interaction of alkali earth metal ions that catalyze secondary reactions. These side reactions make interpretations difficult, as they are not yet fully understood. These metal ion effects are well known, and documented by other researchers as well (Philpot 1970; Raveendran et al. 1995; Nik-Azar et al. 1997; Mullen et al. 2010; Patwardhan et al. 2010).

\subsection{Kinetic Models for Torrefaction and Pyrolysis}

Due to the complex nature of thermal degradation, many competing ideas exist on the thermal degradation pathway for biomass. Because a formal mechanism is not yet known, many semi-empirical models have been developed to describe laboratory observations over a range of feedstock and conditions. This sections is dedicated to review of models that are prominent in current torrefaction and pyrolysis literature.

\subsubsection{Single Component Models}

Shafizadeh and Chin first proposed the single component pyrolysis model in 1977 (Shafizadeh and Chin Peter P 1977). In this model, wood decomposed to the main products 
(gas, tar, and char) through a set of three first order primary parallel reactions. At higher temperatures, if heat and mass transport phenomena are not controlled, they proposed that secondary reactions occur through two additional lumped reactions where the normally condensable oil (tar) further degrades to production of gas and char. This model, in the absence of secondary reactions, is shown below in Figure 1.1 where the wood (A) degrades to gas $(\mathrm{G})$ through rate constant $\mathrm{kG}$, liquid tar $(\mathrm{L})$ through $\mathrm{kL}$, and char $(\mathrm{C})$ through $\mathrm{kC}$. The mechanism shown in the subplot to the right is discussed later. These classes are lumped pseudo components, but allows for analysis in the absence of dynamic traces of all pyrolytic species, which can easily numerate to over 300 (Evans and Milne 1987). This model types was applied and verified to varying degrees in several other experimental works (Thurner and Mann 1981; Samolada and Vasalos 1991; Felfli et al. 2004; Repellin et al. 2010; Ciolkosz and Wallace 2011; Ratte et al. 2011).

In 1981 Thurner and Mann investigated application of this model to pyrolysis of oak sawdust over the range of $300-400^{\circ} \mathrm{C}$ (Thurner and Mann 1981). Secondary reactions were neglected due to flow of nitrogen through their reaction system that was assumed to carry the tars out of the reaction zone. Through discrete reaction residence time experiments, they were able to satisfactorily extract rate parameters from their Arrhenius plots $\left(\mathrm{R}^{2}\right.$ value between 0.95 and 0.96$)$. When compared to the experimental weightloss measurements, the tar predictions were overestimated $(+5-10 \%)$ at later reaction times (>20 minutes) with the tradeoff of slightly underpredicted (3-5\%) gas production at late times, and elevated temperatures ( 369 and $392^{\circ} \mathrm{C}$ trials). They summarized their kinetic 
parameters as 88.6, 112.7, and $106.5 \mathrm{~kJ} / \mathrm{mol}$, and 8.61E5, 2.47E8, and 4.43E7 min-1 for the activation energies and frequency factors for the three respective reactions.

In a more recent work, Repellin et al., investigated a simplification to the Shafizadeh-Chin Model (Repellin et al. 2010). They investigated TGA analysis of beech and spruce wood in the temperature range of $180-280^{\circ} \mathrm{C}$. In part of their investigation, they combined the gas $(\mathrm{G})$ and liquid (L) yields into a single lumped reaction for volatiles (V). This mechanism is displayed in the right subplot of Figure 1.1. This simple model was an investigation to the prediction of solid mass yield at varying processing conditions. Although this modeling attempt was not the focus of the work, it was found that the model is applicable at low temperature, and was able to predict char yields from spruce and beech wood $\left(\mathrm{R}^{2}=0.99\right.$, and 0.96 respectively) up to $30 \%$ experimental weight loss.
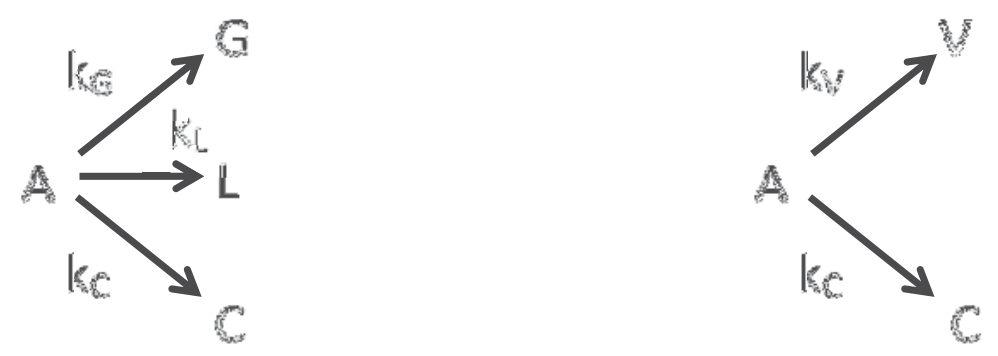

Figure 1.1: Single component reaction models. 
Brostrom et al. also investigated a modified version of the three parallel reaction model with spruce wood in inert/oxidative atmosphere Thermo Gravimetric Analysis TGA (Broström et al. 2012). They incorporated the three parallel reactions, one each for cellulose, hemicellulose, and lignin, in addition to two other parallel reactions to describe the oxidation of species in air. The total mechanism consists, then, of five parallel reactions. This development allows for the interpretation of combustion characteristics from the massloss profiles. Based on their results, they found similar kinetics for the three parallel reactions discussed above. When profiles were resolved of their heating rates, it was also concluded that the rate parameters are independent of processing rate/severity. Interestingly, they also concluded that the combustion rates/profiles were nearly independent of process severity, or that is that the combustion of slightly torrefied wood occurs at approximately the same rate as severely torrefied wood. This is a key finding, due to the application of torrefied biomass in solid fuel boilers. From this, torrefaction does not impose a rate-limiting stage in combustion for electricity generation.

\subsubsection{Multicomponent Models}

Perhaps the most widely used torrefaction/pyrolysis model in current literature was developed by Colomba Di Blasi and Mario Lanzetta in 1997 (Di Blasi and Lanzetta 1997). The model was originally developed to describe the degradation of xylans, but has been subsequently adapted as a mechanism to describe other components/whole biomass. Through their radiative heater pyrolysis system coupled with (TGA), they recorded massloss curves over a range of 473-613K. They proposed that the reaction simultaneously 
produces volatile species (V1) through rate constant $\mathrm{kV} 1$ and a solid pseudo-intermediate (B) through $\mathrm{kb}$, which represents some partially degraded solid structure. B then undergoes a consecutive degradation to form additional volatile species (V2) through $\mathrm{kV} 2$ and the final solid char through kc. These reactions are shown in Figure 1.2.

Through detailed mass balance equations to describe the product evolution, they conclude that the kinetic data for the two stages are A1=3.62E5 s-1, E1=18.3kcal $/ \mathrm{mol}$ and $\mathrm{A} 2=3.83 \mathrm{E} 2 \mathrm{~s}-1, \mathrm{E} 2=13.1 \mathrm{kcal} / \mathrm{mol}$, where the reaction stages are lumped observed changes: $\mathrm{k} 1=\mathrm{kb}+\mathrm{kv} 1$ and $\mathrm{k} 2=\mathrm{kv} 2+\mathrm{kc}$. The first stage releases more volatile components and occurs at much faster rates. The second stage is observed at temperatures above $523 \mathrm{~K}$, and occurs slower than reaction 1. Above previous models, this was the first attempt to predict volatile release independently of the char formation (equal formations was previous state-of-the-art).

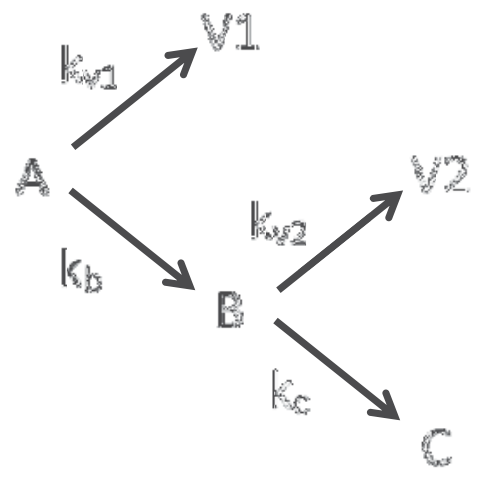

Figure 1.2: Two-stage consecutive reaction model. 
This model was later used for the degradation of biomass sources from 400-648K: wheat and corn straw (Lanzetta and Di Blasi 1998). Here they found parameters of $\mathrm{A} 1=2.43 \mathrm{E} 4 \mathrm{~s}-1, \mathrm{E} 1=15.44 \mathrm{kcal} / \mathrm{mol}$ and $\mathrm{A} 2=5.43 \mathrm{E} 1 \mathrm{~s}-1, \mathrm{E} 2=11.3 \mathrm{kcal} / \mathrm{mol}$ for straw, and $\mathrm{A} 1=6.3 \mathrm{E} 6 \mathrm{~s}-1, \mathrm{E} 1=21.86 \mathrm{kcal} / \mathrm{mol}$ and A2=2.7E3 s-1, E2=15.58 $\mathrm{kcal} / \mathrm{mol}($ Lanzetta and Di Blasi 1998). Though the activation energies are similar between feedstock, the frequency factors drastically change between feedstock. Other researchers have used this model infull or part to describe their experimental observations. For examples see:(Varhegyi et al. 1997; Antal et al. 1998; Lanzetta and Di Blasi 1998; Di Blasi et al. 1999; Svenson et al. 2004; Bergman 2005; Claudia J Gomez et al. 2005; Prins et al. 2006a; Bellais 2007; CJ Gomez et al. 2007; Mui et al. 2008; Barneto et al. 2010; Peng and Wu 2010; Repellin et al. 2010; DK Shen et al. 2010; Chew and Doshi 2011; Liu et al. 2011; van der Stelt et al. 2011; Bates and Ghoniem 2012; Melkior et al. 2012; Bates and Ghoniem 2013). Examples are also further detailed within Chapter 2.

This model was later expanded by Branca and Di Blasi in 2003 (Branca and Di Blasi 2003). This work aimed to describe the thermal degradation of beech wood in the temperature range of 528-708K. To accommodate the higher temperature production, a third reaction was added in similar fashion to the mechanism presented in Figure 1.2. A modified reaction pathway is show as Figure 1.3. As before, biomass (A) simultaneously form volatile species (V1) and a solid intermediate (B) through rate constants kv1 and $\mathrm{kb}$. (B) then degrades to more volatile species (V2) and a second intermediate (D) through rate constants kv2 and $\mathrm{kD}$. In the final reaction, (D) degrades to produce more volatile species (V3) and the final char product $(\mathrm{C})$ through $\mathrm{kv} 3$ and $\mathrm{kC}$. The reaction stages were again 


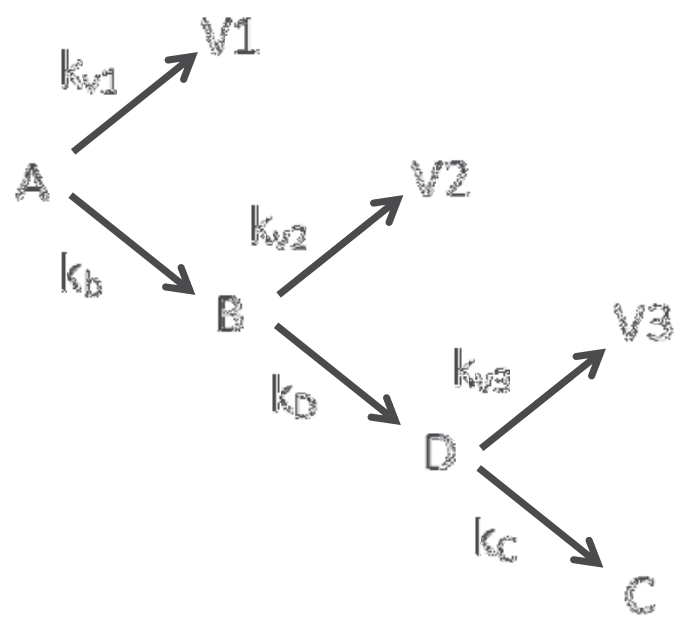

Figure 1.3: Three-stage consecutive reaction model.

summarized as $\mathrm{k} 1=\mathrm{kb}+\mathrm{kv} 1, \mathrm{k} 2=\mathrm{kv} 2+\mathrm{kD}$, and $\mathrm{k} 3=\mathrm{kv} 3+\mathrm{kC}$. The kinetic parameters found were $\ln \mathrm{A} 1=10.2 \mathrm{~s}-1, \mathrm{E} 1=76.2 \mathrm{~kJ} / \mathrm{mol}, \ln \mathrm{A} 2=22.5 \mathrm{~s}-1, \mathrm{E} 2=142.8 \mathrm{~kJ} / \mathrm{mol}$, and $\ln \mathrm{A} 3=2.3$ $\mathrm{s}-1, \mathrm{E} 3=43.8 \mathrm{~kJ} / \mathrm{mol}$ respectively.

Kinetic models have also been developed that are based on a superposition of models for cellulose, hemicellulose, and lignin. In 2006 Rousset et al. performed a literature survey to generate such a model (Rousset et al. 2006). This model is a hybrid of such models presented in section 1.4.1, and the Di Blasi-Lanzetta model discussed above. Results from the work closely match the experimental data, but add complexity to the and uncertainty during interpretations and parameter fitting. 


\subsubsection{Distributed Activation Energy Models (DAEM)}

The complex process of pyrolysis has also been modeled with distributed activation energy models. This assumes that the process is comprised of an infinite number of parallel irreversible first order reactions, and can capture lumped reaction sets that typically occur near the same activation energy. Such models were developed by Sonobe and Worasuwannarak in 2006 and more recently by Sarvaramini et al. in 2013 (Sonobe and Worasuwannarak 2008; Sarvaramini et al. 2013). In the former, cellulose was studied in addition to rice straw, rice husk, and corn cob. The energy density functions for the feedstock have very narrow distributions, and have apex at $170 \mathrm{~kJ} / \mathrm{mol}$ for rice straw, 174 $\mathrm{kJ}$.mol for rice husks, $183 \mathrm{~kJ} / \mathrm{mol}$ for corn cob, and $185 \mathrm{~kJ} / \mathrm{mol}$ for cellulose. While comparable, these values are generally higher than those reported above for the multicomponent models.

This limitation is likely the reason why the later reference uses a DAEM model to represent the degradation of cellulose, hemicellulose, and lignin (Sarvaramini et al. 2013). These predictions were then combined in a composite representation of biomass degradation. This study investigates xylan, lignin, and cellulose, as well as aspen and birch woods over a range of $240-290^{\circ} \mathrm{C}$ and long residence times (up to 180 minutes). Their findings for the energy density functions of xylan $(132 \mathrm{~kJ} / \mathrm{mol}$, narrow), lignin $(196 \mathrm{~kJ} / \mathrm{mol}$, broad), and cellulose (apex at $207 \mathrm{~kJ} / \mathrm{mol}$, narrow distribution) agree with their empirical TGA measurements (R2 from 0.94-0.99) and observations by others (Yang et al. 2007; Sonobe and Worasuwannarak 2008; Gašparovič et al. 2012; Cai et al. 2013; Wu et al. 
2013). Overall there was fair agreement between the predicted composite degradation curve and the measured TGA data ( 0.97 for birch, and 0.92 for aspen).

\subsubsection{Modeling Summary and Knowledge Gaps}

In 2010 Repellin et al. investigated several reaction models for degradation of spruce and beech wood at 180-280C, and 5-60 minute residence time (Repellin et al. 2010). In addition to the single stage model discussed above, they applied the Di Blasi-Lanzetta two-stage model, and the Rousset model. When comparing the predictions and measured mass loss data, the Di Blasi-Lanzetta model performed arguably the best for their simple kiln reactor system. In their conclusion, although all models perform adequately there is a tradeoff between simple models and more complex models. As models become more complex they are often more flexible, robust and accurate, but become more difficult to interpret and accurately fit reaction parameters. Simple models, on the other hand, do not have the ability to predict the detailed behavior that is often observed.

Although the many kinetic works discussed here can very accurately reproduce the experimental data used for validation, there is perhaps a common theme and broad gap in current literature - the basis of these studies is overall weight partitioning between solid, liquid, and gaseous products. Such measurements can be useful in developments of reactor size/geometry, they offer little insight into the process chemistry beyond yields. If an industry was developed around utilizing biomass as an energy source in earnest, it would need to be flexible enough to operate across many varied biomass sources. Such an industry, not unlike fossil hydrocarbon refineries, must have process models to adapt processing conditions to the inhomogeneous feedstock, and would thus require models that 
a sensitive to feedstock composition and can predict process/product chemistry. Some work has shown development of cellulose pyrolysis mechanisms (D. K. Shen and Gu 2009; Collard and Blin 2014), but literature on linking such mechanisms to process conditions are scarce. From the works discussed above and others (Sánchez-Jiménez et al. 2011; Pérez-Maqueda et al. 2014), it is likely that pyrolysis and torrefaction degrade in a sequential manner through a series of intermediates, but product quantification and quality is only discussed (partially) at discrete endpoints without understanding of the fundamental conversion. These observations are also reinforced through conclusions of a state-of-theart review of pyrolysis kinetics literature (Di Blasi 2008).

\subsection{Research Objectives and Proposal Structure}

The works presented within this document are in effort to present a unified degradation model for torrefaction and pyrolysis that uniquely modeled through gas-phase product detachment, applies over a wide temperature region, predicts process chemistry to provide mechanistic insight, is flexible enough to be used in a predictive manner over a variety of feedstock and process conditions, and can yield important engineering information for process scale-up and industrialization. To address the issues discussed above, research objectives were identified within the context of producing renewable fuels from biomass through pyrolysis and torrefaction, and represent the chapter structure of the current document:

1. Survey literature for knowledge gaps in torrefaction/pyrolysis kinetic modeling 
2. Propose an initial kinetic model for torrefaction (low-temperature pyrolysis) through monitoring gas-phase product formation

3. Evaluate the temperature impacts on the process kinetics and implications of different gas/vapor product formation rates/quantities

4. Explore the applications of the model for predicting product formation and solid fuel quality from torrefaction (low-temperature pyrolysis)

5. Extend the kinetic model to higher (traditional) pyrolysis-range temperature and present a unified model for torrefaction and pyrolysis

6. Explore the applications of the unified pyrolysis model

7. Conclude with guidance for future work

Within this document, each objective listed above is discussed in detail in a separate chapter of the same number. Chapters 2 through 5 have been published in peer reviewed journals for dissemination and exposure. Chapter 6 is currently in the peer-review process. 


\subsection{Works Cited}

Aho A, Kumar N, Eränen K, Holmbom B, Hupa M, Salmi T, Murzin DY. 2008. Pyrolysis of softwood carbohydrates in a fluidized bed reactor. International journal of molecular sciences 9(9):1665-1675.

Antal MJ, Varhegyi G, Jakab E. 1998. Cellulose pyrolysis kinetics: revisited. Industrial \& Engineering Chemistry Research 37(4):1267-1275.

Barneto AG, Carmona JA, Alfonso JEM, Serrano RS. 2010. Simulation of the thermogravimetry analysis of three non-wood pulps. Bioresource Technology 101(9):3220-3229.

Bates RB, Ghoniem AF. 2012. Biomass torrefaction: Modeling of volatile and solid product evolution kinetics. Bioresource Technology 124(0):460-469.

Bates RB, Ghoniem AF. 2013. Biomass torrefaction: Modeling of reaction thermochemistry. Bioresource Technology 134(0):331-340.

Bellais M. 2007. Modelling of the pyrolysis of large wood particles.

Bergman PCA. 2005. Combined torrefaction and pelletisation, the TOP process. ECN Biomass, DEN programme of SenterNovem, Dutch Ministry of Economic Affairs, Report ECN-C-05-073.

Boardman RD, Hess JR, Sokhansanj S, Tumuluru JS, Wright CT. 2011. A review on biomass torrefaction process and product properties for energy applications. Industrial Biotechnology 7(5):384+. 
Branca C, Di Blasi C. 2003. Kinetics of the isothermal degradation of wood in the temperature range 528-708 K. Journal of Analytical and Applied Pyrolysis 67(2):207-219.

Bridgeman TG, Jones JM, Shield I, Williams PT. 2008. Torrefaction of reed canary grass, wheat straw and willow to enhance solid fuel qualities and combustion properties. Fuel 87(6):844-856.

Bridgwater AV, Meier D, Radlein D. 1999. An overview of fast pyrolysis of biomass. Organic Geochemistry 30(12):1479-1493.

Bridgwater AV. 2012. Review of fast pyrolysis of biomass and product upgrading. Biomass and Bioenergy 38(0):68-94.

Broström M, Nordin A, Pommer L, Branca C, Di Blasi C. 2012. Influence of torrefaction on the devolatilization and oxidation kinetics of wood. Journal of Analytical and Applied Pyrolysis 96(0):100-109.

Cai J, Wu W, Liu R, Huber GW. 2013. A distributed activation energy model for the pyrolysis of lignocellulosic biomass. Green Chemistry 15(5):1331-1340.

Chew JJ, Doshi V. 2011. Recent advances in biomass pretreatment - Torrefaction fundamentals and technology. Renewable and Sustainable Energy Reviews 15(8):4212-4222.

Ciolkosz D, Wallace R. 2011. A review of torrefaction for bioenergy feedstock production. Biofuels, Bioproducts and Biorefining 5(3):317-329. 
Collard F-X, Blin J. 2014. A review on pyrolysis of biomass constituents: Mechanisms and composition of the products obtained from the conversion of cellulose, hemicelluloses and lignin. Renewable and Sustainable Energy Reviews 38(0):594608.

Demirbas A. 2004. Effects of temperature and particle size on bio-char yield from pyrolysis of agricultural residues. Journal of Analytical and Applied Pyrolysis 72(2):243248.

Di Blasi C, Lanzetta M. 1997. Intrinsic kinetics of isothermal xylan degradation in inert atmosphere. Journal of Analytical and Applied Pyrolysis 40-41(0):287-303.

Di Blasi C, Buonanno F, Branca C. 1999. Reactivities of some biomass chars in air. Carbon 37(8):1227-1238.

Di Blasi C. 2008. Modeling chemical and physical processes of wood and biomass pyrolysis. Progress in Energy and Combustion Science 34(1):47-90.

Esteban LS, Carrasco JE. 2006. Evaluation of different strategies for pulverization of forest biomasses. Powder Technology 166(3):139-151.

Evans RJ, Milne TA. 1987. Molecular characterization of the pyrolysis of biomass. Energy \& Fuels 1(2):123-137.

Felfli FF, Luengo CA, Soler PB. 2004. Mathematical modelling of wood and briquettes torrefaction. Procedings of the 5th Encontro de Energia no Meio Rural. 
Gašparovič L, Labovský J, Markoš J, Jelemenský L. 2012. Calculation of kinetic parameters of the thermal decomposition of wood by distributed activation energy model (DAEM). Chemical and Biochemical Engineering Quarterly 26(1):45-53.

Gomez C, Meszaros E, Jakab E, Velo E, Puigjaner L. 2007. Thermogravimetry/mass spectrometry study of woody residues and an herbaceous biomass crop using PCA techniques. Journal of Analytical and Applied Pyrolysis 80(2):416-426.

Gomez CJ, Varhegyi G, Puigjaner L. 2005. Slow pyrolysis of woody residues and an herbaceous biomass crop: a kinetic study. Industrial \& Engineering Chemistry Research 44(17):6650-6660.

Huang J, Liu C, Wei S, Huang X, Li H. 2010. Density functional theory studies on pyrolysis mechanism of $\beta$-d-glucopyranose. Journal of Molecular Structure: THEOCHEM 958(1-3):64-70.

Ibrahim RHH, Darvell LI, Jones JM, Williams A. 2013. Physicochemical characterisation of torrefied biomass. Journal of Analytical and Applied Pyrolysis 103(0):21-30.

IPCC (Intergovernmental Panel on Climate Change). 2013. Climate change 2013: The physical science basis. Working Group I contribution to the IPCC Fifth Assessment Report. Cambridge, United Kingdom: Cambridge University Press. www.ipcc.ch/report/ar5/wg1. 
Kahn Ribeiro, S., S. Kobayashi, M. Beuthe, J. Gasca, D. Greene, D. S. Lee, Y. Muromachi, P. J. Newton, S. Plotkin, D. Sperling, R. Wit, P. J. Zhou (2007). Transport and its infrastructure. In Climate Change 2007: Mitigation.

Kelkar S, Li Z, Bovee J, Thelen KD, Kriegel RM, Saffron CM. 2014. Pyrolysis of NorthAmerican grass species: Effect of feedstock composition and taxonomy on pyrolysis products. Biomass and Bioenergy 64(0):152-161.

Lanzetta M, Di Blasi C. 1998. Pyrolysis kinetics of wheat and corn straw. Journal of Analytical and Applied Pyrolysis 44(2):181-192.

Lipinsky E, Arcate J, Reed T. 2002. Enhanced wood fuels via torrefaction. Fuel Chemistry Division Preprints 47(1):408-410.

Liu Q, Zhong Z, Wang S, Luo Z. 2011. Interactions of biomass components during pyrolysis: A TG-FTIR study. Journal of Analytical and Applied Pyrolysis 90(2):213-218.

Mani S, Tabil LG, Sokhansanj S. 2004. Grinding performance and physical properties of wheat and barley straws, corn stover and switchgrass. Biomass and Bioenergy 27(4):339-352.

Medic D, Darr M, Shah A, Potter B, Zimmerman J. 2012. Effects of torrefaction process parameters on biomass feedstock upgrading. Fuel 91(1):147-154. 
Melkior T, Jacob S, Gerbaud G, Hediger S, Le Pape L, Bonnefois L, Bardet M. 2012. NMR analysis of the transformation of wood constituents by torrefaction. Fuel 92(1):271280.

Mohan D, Pittman CU, Steele PH. 2006. Pyrolysis of Wood/Biomass for Bio-oil: A Critical Review. Energy \& Fuels 20(3):848-889.

Mui EL, Cheung W, Lee VK, McKay G. 2008. Kinetic study on bamboo pyrolysis. Industrial \& Engineering Chemistry Research 47(15):5710-5722.

Mullen CA, Boateng AA, Goldberg NM, Lima IM, Laird DA, Hicks KB. 2010. Bio-oil and bio-char production from corn cobs and stover by fast pyrolysis. Biomass and Bioenergy 34(1):67-74.

Nik-Azar M, Hajaligol M, Sohrabi M, Dabir B. 1997. Mineral matter effects in rapid pyrolysis of beech wood. Fuel Processing Technology 51(1):7-17.

Nocquet T, Dupont C, Commandre J-M, Grateau M, Thiery S, Salvador S. 2014. Volatile species release during torrefaction of biomass and its macromolecular constituents: Part 2 - Modeling study. Energy 72(0):188-194.

Patwardhan PR, Satrio JA, Brown RC, Shanks BH. 2009. Product distribution from fast pyrolysis of glucose-based carbohydrates. Journal of Analytical and Applied Pyrolysis 86(2):323-330. 
Patwardhan PR, Satrio JA, Brown RC, Shanks BH. 2010. Influence of inorganic salts on the primary pyrolysis products of cellulose. Bioresource Technology 101(12):4646-4655.

Patwardhan PR, Brown RC, Shanks BH. 2011a. Understanding the Fast Pyrolysis of Lignin. ChemSusChem 4(11):1629-1636.

Patwardhan PR, Brown RC, Shanks BH. 2011b. Product Distribution from the Fast Pyrolysis of Hemicellulose. ChemSusChem 4(5):636-643.

Peng Y, Wu S. 2010. The structural and thermal characteristics of wheat straw hemicellulose. Journal of Analytical and Applied Pyrolysis 88(2):134-139.

Pérez-Maqueda LA, Sánchez-Jiménez PE, Perejón A, García-Garrido C, Criado JM, Benítez-Guerrero M. 2014. Scission kinetic model for the prediction of polymer pyrolysis curves from chain structure. Polymer Testing 37(0):1-5.

Philpot C. 1970. Influence of mineral content on the pyrolysis of plant materials. Forest Science 16(4):461-471.

Prins MJ, Ptasinski KJ, Janssen FJJG. 2006a. Torrefaction of wood: Part 1. Weight loss kinetics. Journal of Analytical and Applied Pyrolysis 77(1):28-34.

Prins MJ, Ptasinski KJ, Janssen FJJG. 2006b. Torrefaction of wood: Part 2. Analysis of products. Journal of Analytical and Applied Pyrolysis 77(1):35-40. 
Ratte J, Fardet E, Mateos D, Héry J-S. 2011. Mathematical modelling of a continuous biomass torrefaction reactor: TORSPYD ${ }^{\mathrm{TM}}$ column. Biomass and Bioenergy 35(8):3481-3495.

Raveendran K, Ganesh A, Khilar KC. 1995. Influence of mineral matter on biomass pyrolysis characteristics. Fuel 74(12):1812-1822.

Repellin V, Govin A, Rolland M, Guyonnet R. 2010. Modelling anhydrous weight loss of wood chips during torrefaction in a pilot kiln. Biomass and Bioenergy 34(5):602609.

Rousset P, Turner I, Donnot A, Perré P. 2006. The choice of a low-temperature pyrolysis model at the microscopic level for use in a macroscopic formulation. Annals of Forest Science 63(2):213-229.

Samolada M, Vasalos I. 1991. A kinetic approach to the flash pyrolysis of biomass in a fluidized bed reactor. Fuel 70(7):883-889.

Sánchez-Jiménez P, Pérez-Maqueda L, Perejón A, Pascual-Cosp J, Benítez-Guerrero M, Criado J. 2011. An improved model for the kinetic description of the thermal degradation of cellulose. Cellulose 18(6):1487-1498.

Sarvaramini A, Assima GP, Larachi F. 2013. Dry torrefaction of biomass - Torrefied products and torrefaction kinetics using the distributed activation energy model. Chemical Engineering Journal 229(0):498-507. 
Shafizadeh F, Chin Peter P S. 1977. Thermal Deterioration of Wood. Wood Technology: Chemical Aspects. AMERICAN CHEMICAL SOCIETY. p. 57-81.

Shen D, Gu S, Bridgwater A. 2010. The thermal performance of the polysaccharides extracted from hardwood: cellulose and hemicellulose. Carbohydrate Polymers 82(1):39-45.

Shen DK, Gu S. 2009. The mechanism for thermal decomposition of cellulose and its main products. Bioresource Technology 100(24):6496-6504.

Sonobe T, Worasuwannarak N. 2008. Kinetic analyses of biomass pyrolysis using the distributed activation energy model. Fuel 87(3):414-421.

Svenson J, Pettersson JB, Davidsson KO. 2004. Fast pyrolysis of the main components of birch wood. Combustion science and technology 176(5-6):977-990.

Thurner F, Mann U. 1981. Kinetic investigation of wood pyrolysis. Industrial \& Engineering Chemistry Process Design and Development 20(3):482-488.

US Department of Energy, (2014). Alternative Fuels Data Center: Energy Independence and Security Act of 2007. US DOE. (online) Available at: http://www.afdc.energy.gov/laws/eisa.html.

US Environmental Protection Agency, (2014)a. Climate Change: Basic Information. US EPA. (online) Available at: http://www.epa.gov/climatechange.

US Environmental Protection Agency, (2014)b. Inventory of U.S. Greenhouse Gas Emissions and Sinks: 1990-2012. US EPA. 
U.S. Energy Information Administration (2012). Electricity Explained - Basics. (online) Available at: http://www.eia.gov/energyexplained/.

USGCRP (2009). Global Climate Change Impacts in the United States. Thomas R. Karl, Jerry M. Melillo, and Thomas C. Peterson (eds.). United States Global Change Research Program. Cambridge University Press, New York, NY, USA..

van der Stelt MJC, Gerhauser H, Kiel JHA, Ptasinski KJ. 2011. Biomass upgrading by torrefaction for the production of biofuels: A review. Biomass and Bioenergy 35(9):3748-3762.

Varhegyi G, Antal MJ, Jakab E, Szabó P. 1997. Kinetic modeling of biomass pyrolysis. Journal of Analytical and Applied Pyrolysis 42(1):73-87.

Wu W, Cai J, Liu R. 2013. Isoconversional kinetic analysis of distributed activation energy model processes for pyrolysis of solid fuels. Industrial \& Engineering Chemistry Research 52(40):14376-14383.

Yang H, Yan R, Chen H, Lee DH, Zheng C. 2007. Characteristics of hemicellulose, cellulose and lignin pyrolysis. Fuel 86(12-13):1781-1788.

Zhang J, Toghiani H, Mohan D, Pittman CU, Toghiani RK. 2007. Product analysis and thermodynamic simulations from the pyrolysis of several biomass feedstocks. Energy \& Fuels 21(4):2373-2385. 


\section{Development of Thermal Degradation Model}

Reprinted with permission from KLINGER J, BAR-ZIV E, SHONNARD D. 2013. KINETIC STUDY OF ASPEN DURING TORREFACTION. JOURNAL OF ANALYTICAL AND APPLIED PYROLYSIS 104(0):146-152. Copyright 2013 Elsivier B.V. ${ }^{1}$

\subsection{Abstract}

Using torrefied biomass, or biocoal, as a solid combustion fuel provides opportunity to introduce a sustainable feedstock into the energy market. The decomposition of biomass to biocoal is a very complex chemical process, yet detailed understanding of the mechanistic changes that occur can allow for system control and optimization. Torrefaction of lignocellulosic biomass has been studied extensively, and kinetic models have been developed to attempt to describe the observed behavior during Thermal Gravimetric Analysis (TGA) experiments, using very slow heating rates. The goal of this paper was to develop a baseline semi-empirical model for torrefaction of aspen wood using very fast heating rates $\left(1000^{\circ} \mathrm{C} / \mathrm{s}\right)$ and $\mathrm{GC}-\mathrm{MS}$ analysis. This fast heating rate was adopted in order to uncouple heat transfer and chemical kinetics.

1 The material contained in this chapter was previously published in Journal of analytical and Applied Pyrolysis. 
Having direct information about the specific chemical evolution during torrefaction affords mechanistic insights into torrefaction, along with opportunities for improved process design and control. The proposed kinetics model involves three sequential reactions in which initially the parent hemicellulose material produces gaseous products $\left(\mathrm{CO}\right.$ and $\mathrm{CO}_{2}$ ), water, and organic acids (formic and acetic) and a solid intermediate. The next reaction further degrades the solid intermediate into the stated products. The final reaction further generates the products along with the final bio-coal product. We found the sequential reactions to have characteristic times of $0.99 \mathrm{~min}, 2.14 \mathrm{~min}$ and $39.45 \mathrm{~min}$ respectively at $300^{\circ} \mathrm{C}$. Improvements to the models and routes for future investigation are also discussed.

\subsection{Introduction}

Coal-fired utility boilers are the most prominent electricity generation systems, producing $40-50 \%$ of consumed electricity across the globe (42\% in the U.S.) (EIA 2009; 2010). Coal exists in great abundance around the world, and is a valuable solid fuel because of its high energy density and low cost. Coal does, however, have well-know environmental issues such as the production of $\mathrm{CO}, \mathrm{CO}_{2}, \mathrm{SOx}, \mathrm{NOx}$, particulates, mercury, and poly-aromatic hydrocarbons to name a few(Smith and Gruber 1966; Mastral et al. 2000; Zhao et al. 2008). In the current age of increasing environmental awareness, these issues inherent to coal combustion must be continuously addressed and controlled through the use of additional high-cost process operations. 
A possible solution to environmental concerns is replacement of the coal by a different feedstock that is environment conscious - sustainable biomass. Because the coalpower industry is so prominent, it is important, if not necessary, to use a drop-in replacement in existing infrastructure. Initially, raw regenerative biomass was investigated as a possible solution, and demonstrated for commercial purposes (Ayhan 2008; Reichling and Kulacki 2011). The combustion of biomass inherently has a preferable emissions profile because it produces no net $\mathrm{CO}_{2}$ emission due to a biogenic carbon cycle, and does not contain sulfur and mercury (Wright et al. 2008; Gasol et al. 2009; Fan et al. 2011; Saidur et al. 2011). However, some issues exist with raw biomass processing and combustion, including high bulk volumes, moisture content, low calorific value, material hydrophobicity, production of undesirable tars, and high energy and time requirements for size reduction (Devi et al. 2003; Bergman 2005; Prins et al. 2007). One solution to address these issues and still utilize biomass based fuel, has been the implementation of torrefaction as a pretreatment to produce biocoal.

Biomass torrefaction is a method of mild thermal treatment in the temperature range of $200-300^{\circ} \mathrm{C}$ under inert atmosphere that, through a complex coupled chemical-kineticheat-and-mass-transfer process, converts the biomass into biocoal. In this process mostly the hemicellulose fraction of biomass degrades, with small contributions from the lignin and cellulose fractions (Yang et al. 2007; Boardman et al. 2011; Chew and Doshi 2011). The products of torrefaction are 70-90\% solids (ash and biocoal), 6-35\% liquid (mostly water with some fatty acids, phenols, acids, alcohols, furans, ketones) and 1-10\% gas (CO, $\mathrm{CO}_{2}, \mathrm{H}_{2}$ ) (Boardman et al. 2011; Ciolkosz and Wallace 2011). 
There are major advantages to biocoal when compared to raw biomass, one of the most prominent being reduction in energy and time requirements for particle size reduction. The energy required to pulverize biocoal is approximately one tenth that of biomass (Bergman 2005). This is due to the decomposition of hemicellulose which changes the viscoelastic properties of the feedstock (Panshin and deZeeuw 1980). In addition to this feedstock improvement, torrefaction also increases the calorific value of biomass up to $40 \%$ by removing bound feedstock moisture and reducing the mass by up to $30-50 \%$ (Chen et al. 2011; van der Stelt et al. 2011). Finally, the oxygen to carbon ratio is improved by significantly reducing the oxygen content, while the carbon fraction is increased accordingly (van der Stelt et al. 2011). Mostly importantly, torrefied biomass (biocoal) has similar physico-chemical properties to traditional coal and can be considered a premium drop-in replacement, requiring no addition upgrades to existing utility boilers. Table 2.1 compares the properties of coal, biocoal, and various raw biomass species.

Regardless of the feedstock or energy production method, however, a key aspect of electricity-generation systems is their high feedstock throughput (Spath et al. 1999; Reichling and Kulacki 2011). As demands for energy are projected to increase consistently by approximately 50 quadrillion BTUs every 5 years starting from a measurement of 505 quadrillion BTUs in 2008 (DOE/EIA 2011), a detailed understanding of the entire energy generation process is required for process optimization and design. Because of similarities between the properties of biocoal and traditional coal, most processing steps are similar to those already in practice with exception of feedstock production. For this reason among others, some emphasis has been placed into developing models and detailed understanding 
of the production of biocoal, or more specifically on torrefaction technology. Recent review articles have summarized several existing proposed wood torrefaction models based on Thermo Gravimetric Analysis (TGA) including a single step global model (Repellin et al. 2010), a three parallel reaction Shafizadeh and Chin model(Shafizadeh and Chin 1977), a two step consecutive Di Blasi-Lanzetta model (Di Blasi and Lanzetta 1997; Prins et al. 2006; Repellin et al. 2010), and a two parallel Broido-Shafizadeh model (Repellin et al. 2010). Despite these efforts there are many competing ideas about the complex chemical pathways, with no definite solution (Chew and Doshi 2011).

The present work focuses on proposing a mechanistic reaction scheme with a semiempirical model, using different techniques than traditionally employed. The proposed models were developed with very high sample heating rates $\left(1000^{\circ} \mathrm{C} / \mathrm{sec}\right)$, and direct Gas Chromatography/Mass Spectroscopy (GC/MS) analysis. Very high heating rates during model development are critical in order to uncouple heat transfer from chemical reaction and thus study the true intrinsic reactions present during torrefaction.

Table 2.1: Ultimate and proximate analysis of coal, biocoal, and various raw biomass species (Ahn et al. 2001; Demirbaş 2001; Parikh et al. 2005; Bridgeman et al. 2010; Tumuluru et al. 2011).

\begin{tabular}{lccccccccc}
\hline Biomass & \multicolumn{4}{c}{ Ultimate Analysis } & \multicolumn{4}{c}{ Proximate Analysis } \\
& $\mathrm{C}$ & $\mathrm{H}$ & $\mathrm{O}$ & $\mathrm{N}$ & $\mathrm{S}$ & $\mathrm{FC}$ & $\mathrm{VM}$ & Ash & $\mathrm{HHV}$ \\
& $(\%)$ & $(\%)$ & $(\%)$ & $(\%)$ & $(\%)$ & $(\%)$ & $(\%)$ & $(\%)$ & $(\mathrm{MJ} / \mathrm{kg})$ \\
\hline Corn Stover & 42.6 & 5.1 & 36.5 & 0.8 & 0.1 & 15.4 & 69.7 & 6.9 & 16.3 \\
Softwood & 52.1 & 6.1 & 41.0 & 0.2 & 0.0 & 28.1 & 70.0 & 1.7 & 20.1 \\
Hardwood & 47.8 & 5.8 & 45.8 & 0.1 & 0.0 & 11.3 & 88.2 & 0.5 & 18.8 \\
Switchgrass & 42.0 & 5.2 & 34.0 & 0.7 & 0.2 & 12.9 & 69.1 & 8.1 & 16.3 \\
Lignite & 63.9 & 5.0 & 24.5 & 0.6 & 0.5 & 46.0 & 49.5 & 4.5 & 17.6 \\
Sub-Bit. Coal & 70.0 & 5.2 & 23.6 & 1.0 & 0.2 & 48.0 & 48.0 & 1.5 & 25.9 \\
Biocoal & 70.7 & 5.6 & 20.1 & 0.6 & - & 32.3 & 63.5 & 1.9 & 28.5 \\
\hline
\end{tabular}

FC: Fixed Carbon, VM: Volatile Mater, HHV: Higher Heating Value 


\subsection{Material and methods}

\subsubsection{Biomass preparation}

Debarked aspen samples were obtained from Dr. Christopher Webster in the School of Forest Resources and Environmental Science at Michigan Tech. Samples were debarked and then dried from their original moisture content at $105^{\circ} \mathrm{C}$ in a drying oven until a difference in mass was no longer detectable. In addition, samples were milled to smaller particles using a small scale Thomas Wiley® knife mill (NR. 3557524 359264). Following size reduction, a W.S. Tyler Rotap (model RX-29, serial 9774) equipped with a range of sieve trays was used to obtain samples with known dimensions. Sizes larger than 32 Tyler Mesh (500 microns) but smaller than 28 Tyler Mesh (599 microns) were considered for this study. The fibers were observed to have approximate shapes of cylinders. The wood fibers had diameter of approximately $0.5 \mathrm{~mm}$ and lengths ranging from $1.0-3.0 \mathrm{~mm}$.

\subsubsection{Torrefaction-GC/MS experiment}

Torrefaction of aspen samples in this work was performed at $300^{\circ} \mathrm{C}$ for 90 min with a micropyrolysis reactor (model 5200HPPyroprobe) manufactured by CDS Analytical. A microbalance (Citizen Scales Inc., Model CM5) with a readability of $1 \mu \mathrm{g}$ was used to record the sample masses. Figure 2.1 shows the experimental apparatus.

During the experiment, approximately $0.5 \mathrm{mg}$ biomass samples were contained within a quartz reaction vial with an inert ultra high pure $(99.999 \%)$ helium atmosphere. Sample heating $\left(1000^{\circ} \mathrm{C} / \mathrm{s}\right)$ is achieved via radiative, convective, and conductive heat transport from a platinum filament surrounding the transparent reaction vial. Once sample 


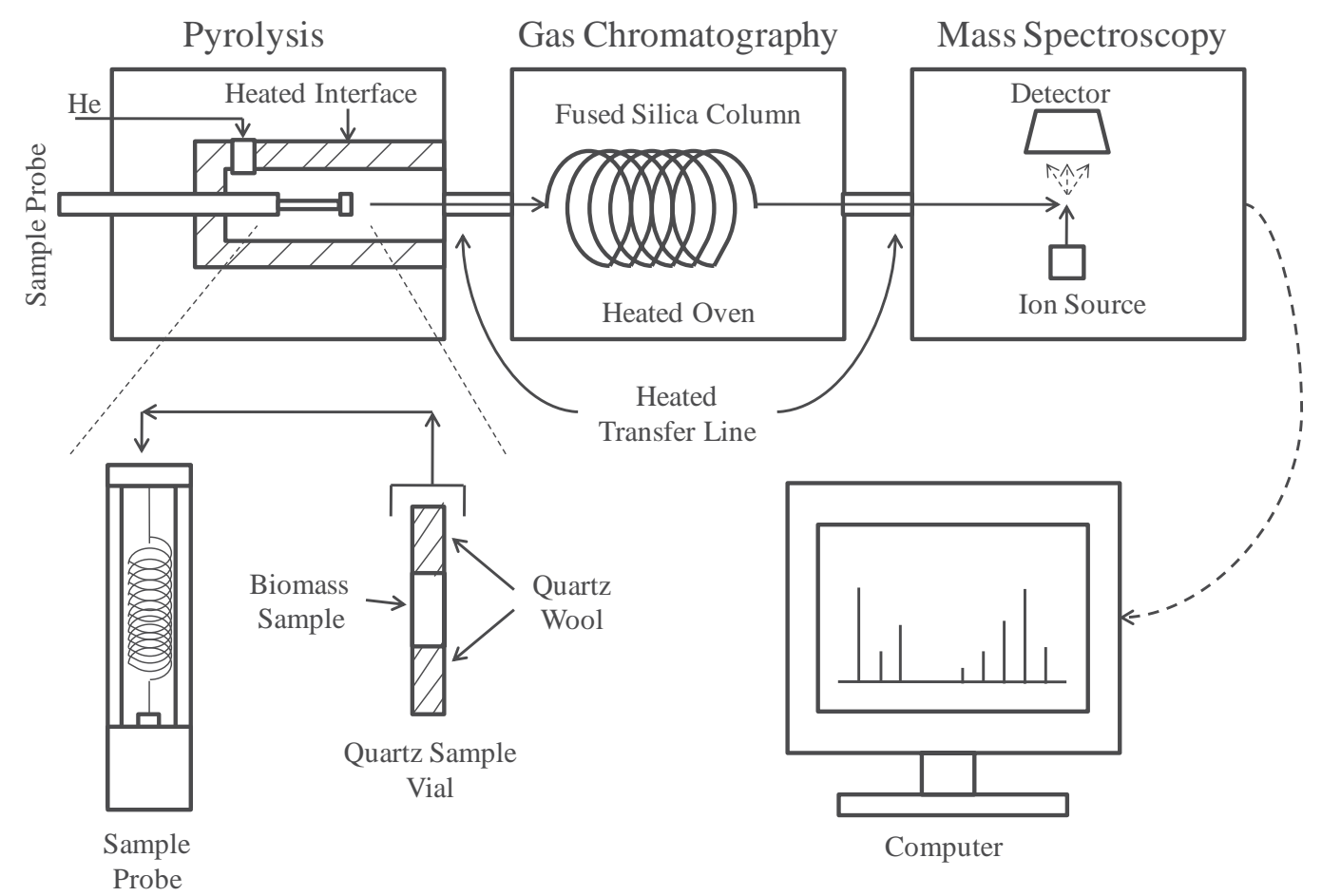

Figure 2.1: Experimental flow diagram.

heating begins, the flow of helium gas over the sample is diverted to the inlet port on a Trace GC Ultra (ModelK8880181) gas chromatograph by Thermo-Finnigan (now ThemoFisher) equipped with a $30 \mathrm{~m}$ RXI-5MS fused silica (low polarity phase, Crossbond ${ }^{\circledR} 5 \%$ diphenyl/95\% dimethyl polysiloxane) capillary column by Restek. The GC column was maintained at $300{ }^{\circ}$ Cduring experimental trials, and had a constant 1.5 $\mathrm{ml} / \mathrm{min}$ (superficial velocity of $50.9 \mathrm{~cm} / \mathrm{s}$ ) gas throughout. The $\mathrm{GC}$ was connected to a quadrupole mass spectrometer (Trace DSQII, Thermo-Finnigan), which recorded the ion fragment intensities over time. The MS was set to monitor a range of molecular mass from 1-350 $\mathrm{m} / \mathrm{z}$. The experimental conditions mentioned above provided an environment that minimizes interactions of compounds with system components (GC column, etc.). 


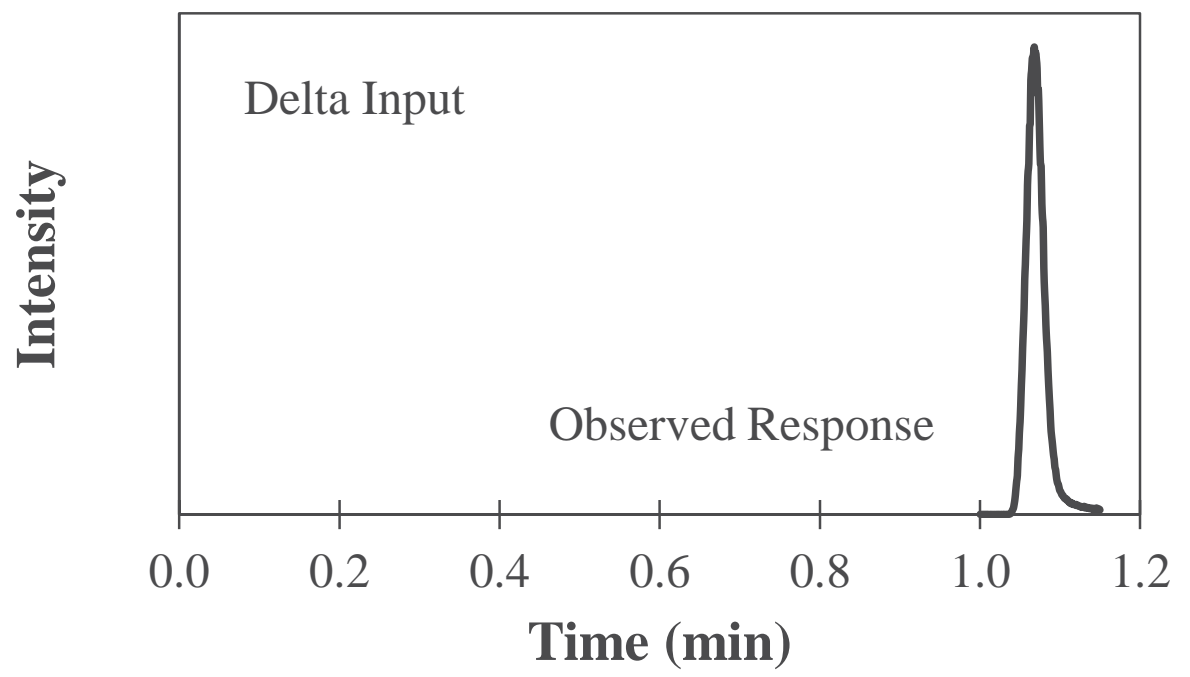

Figure 2.2: Input-response diagram for acetic acid $(60 \mathrm{~m} / \mathrm{z})$

In addition to the experimental procedures above, great care was taken to evaluate complicating factors due to heat and mass transfer with the sample, column interaction effects, and flow dispersion. These evaluations combined both theoretical calculation and using pulse-inputs into the GC under conditions identical to the experiments. Input response results are shown in Figure 2.2, and directly show how the instrument system interacts to create the observed signal. These results are discussed in the following sections.

\subsection{Results and discussion}

\subsubsection{Method Validation}

The measurement of torrefaction products is affected by several factors. A complicating factor of great importance is limitations associated with heat transport. Using solutions for unsteady-state heat transfer in solids tabulated in work by Carslaw and 
Jaeger(Carslaw and Jaeger 1959), it was found that approximately $90 \%$ of the surface temperature (boundary value) is observed by the center of a finite cylinder (with radius of the wood chips) after only 0.24 seconds. For these calculations the maximum effective radius (300 microns) allowable through the sieving step was considered for the characteristic length, along with a thermal diffusivity of $1.79 \mathrm{~mm}^{2} / \mathrm{sec}$ for biomass (Babu and Chaurasia 2004). Detailed results and temperature profiles are shown in the supplemental material. Given that the time scale for conducting energy transport $(0.24 \mathrm{sec})$ is much less than the duration of the experiment (90 min), heat transfer limitations are considered to be very minor. The radiative heat transport from the heated filament to the biomass particle surface was not considered due to the effectiveness demonstrated in the slower of the two major heat transport steps, conduction.

Similar to the analysis addressing heat transport limitations, mass transport was investigated assuming a porous media model for the torrefied biomass. Using methods similar to heat transfer study, the transport is represented by an effective diffusion coefficient, and a value of $1.50 \mathrm{~mm}^{2} / \mathrm{s}$ was assumed (Di Blasi 1996; He and Behrendt 2011). The mass transport becomes analogous to the heat transport, and in the case of torrefaction for the stated particle size mass transport limitations from diffusion is insignificant.

Finally, interactions of the products of torrefaction with the GC/MS instrumentation (GC column resin) were considered. An example of signal convolution due to the GC/MS is shown in Figure 2.2. As indicated above in these tests, a GC autosampler injects a sample $(1 \mu \mathrm{l})$ of acetic acid at time zero; and this is represented by a delta function input. It is important to note that the amount of acetic acid injected was 
much greater than that observed over the time of torrefaction (90 min) - meaning that any observed interaction effects due to the system are accounted for liberally by this method. After approximately 62 seconds, the detector begins to observe a significant amount of the acetic acid ion fragment. Based on the superficial velocity, the time the gases/vapors take approximately 59 seconds to flow through the column. The output, or measured product signal, is dispersed in an almost Gaussian fashion, with a Full Width at Half Maximum (FWHM) of approximately 1.4 seconds. These results, when compared to the experiment duration of 90 minutes, indicate that there is negligible interaction with the chromatography system and the modeled compounds beyond the initial production rate $(<0.5 \mathrm{~min})$. We conclude from these validation analyses that the measured response at the mass selective detector is indicating the actual rates of production of the species in the torrefaction chamber of the micropyrolysis instrument.

\subsubsection{Model development}

Although there are many identifiable compounds from torrefaction, the model in this work was targeted around major compounds produced during torrefaction, namely: CO, CO2, water, and organic acids (van der Stelt et al. 2011). Figure 2.3 shows a comparison between the MS relative intensities obtained for these compounds, represented by a characteristic ion fragment. The different plots represent the same data at varying time scales to highlight their similarities and differences- namely that their initial production are very similar, but several compounds exhibit a major secondary production peak. The characteristic fragments used were chosen based on their abundance in the species' 

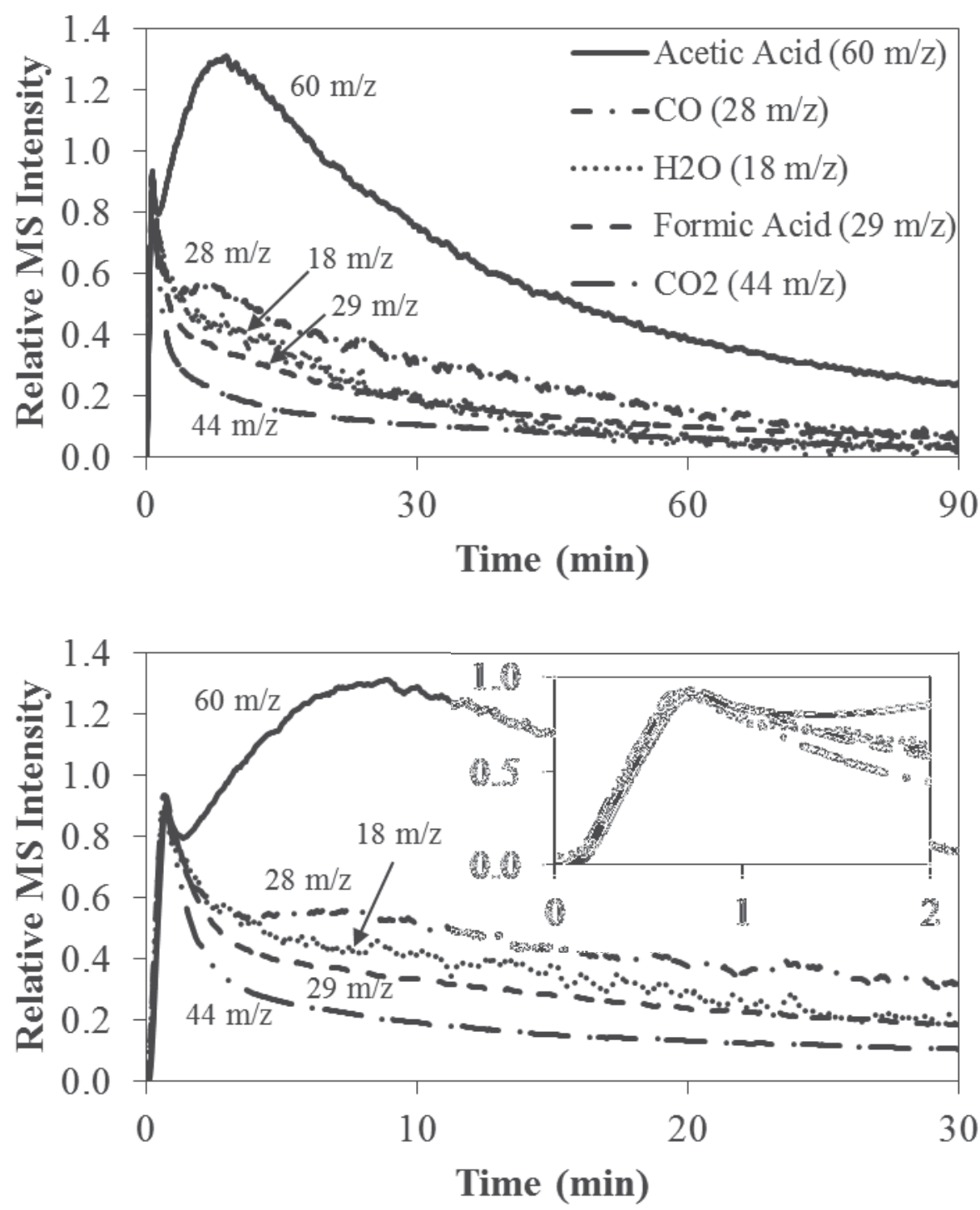

Figure 2.3: (Top) Production rate of major compound ions over the full 90 minute torrefaction experiment. (Bottom) The ion traces over the first thirty minutes of torrefaction. (Bottom Insert) Production rates over the first two minutes.

fragmentation pattern: $\mathrm{CO}(28 \mathrm{~m} / \mathrm{z}), \mathrm{CO} 2(44 \mathrm{~m} / \mathrm{z})$, water $(18 \mathrm{~m} / \mathrm{z})$, acetic acid $(60 \mathrm{~m} / \mathrm{z})$, and formic acid $(29 \mathrm{~m} / \mathrm{z})$. Other species commonly associated with the $60 \mathrm{~m} / \mathrm{z}$ fragment (glycolaldehyde and methyl formate) during thermal degradation were not detected, and are thought to originate from the decomposition of cellulose structure, which is not 
degraded significantly during torrefaction (Evans and Milne 1987; Patwardhan et al. 2009). The carbonyl $(29 \mathrm{~m} / \mathrm{z})$ fragment which is associated with a carboxyl group, was found to more readily form carboxylic acids as opposed to other organic compounds (van der Stelt et al. 2011). Finally, because $29 \mathrm{~m} / \mathrm{z}$ was not observed as a characteristic ion fragment of acetic acid, this carbonyl fragment was associated directly to the other carboxylic acid detected, formic acid.

All compounds shown were normalized by the height of their first production peak for comparison (MS relative intensities), as some compounds exhibit more than one peak during torrefaction. The first production of all the compounds appears to be identical(characteristically) for all compounds at early times, though different as torrefaction advances. Examining these traces on a log-linear plot (Figure 2.4) at early times (0.5-2.0 min) can aid in understanding the kinetics of production at early times. If

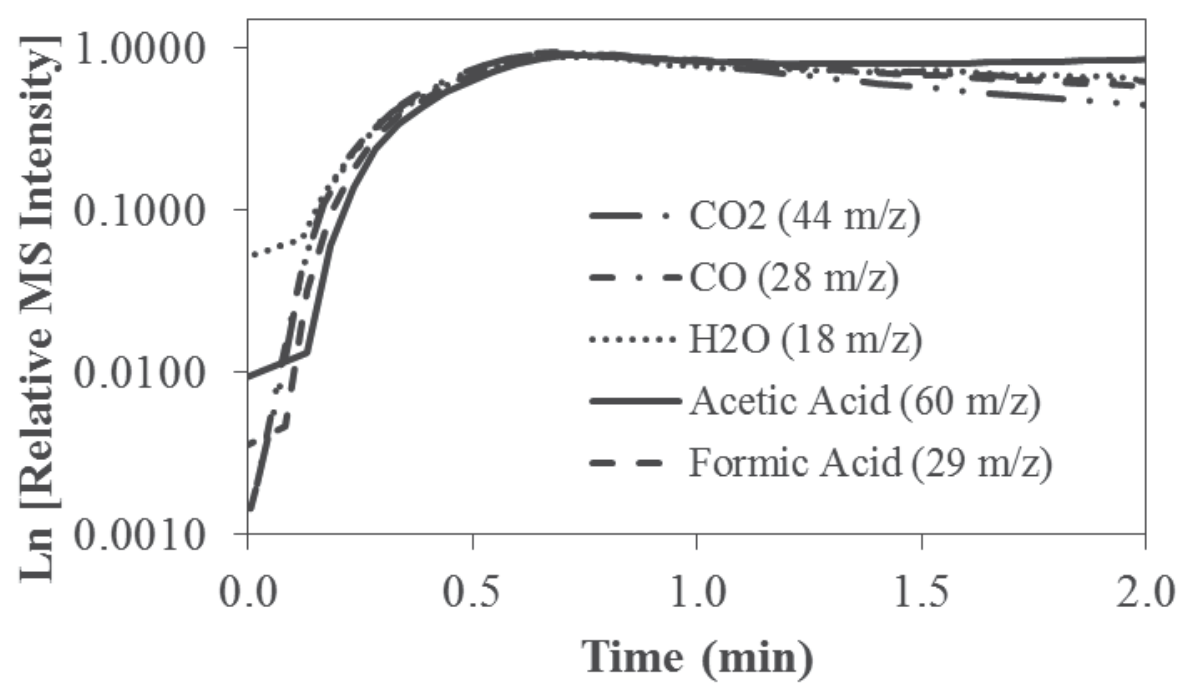

Figure 2.4: Log-plot of compound production rates 
relative intensity changes in a linear fashion when plotted as in Figure 2.4, then the initial production is described by an exponential (first-order irreversible) decay process. From Figure 2.4 if we exclude the first $0.5 \mathrm{~min}$ and focus on the behavior afterwards it is clear that these compounds are produced with similar characteristics (overlapping lines indicate the similar production) and with first order kinetics - i.e. they are produced simultaneously in the same first order reaction. From this, it is proposed that the first reaction in the torrefaction mechanism is the decomposition of the biomass hemicellulose to directly produce the various products. If this is true, the production rates must be at their maximum at time zero. This discrepancy with what is observed is caused by the small convolution imparted to the signal by heat-mass transfer as well as chromatographic influences previously discussed. It is proposed, then, that the first order exponential function that describes times $0.5-2.0$ min should be extrapolated to describe the first reaction from time zero. However, upon examining the production beyond these early times, it is noted that all compounds are continually produced yet with something other than a first order decay. Namely, the majority of acetic acid is produced beyond this first mechanism. The only way for this to occur is through the use of solid intermediates between the parent biomass and the final bio-coal. These intermediates would then further degrade to produce the observed species in subsequent irreversible first-order reactions. It is proposed that there are two additional reactions beyond the first, where solid intermediates produced from the previous reaction further degrade to produce the observed species. 


\subsubsection{Kinetic model and interpretation}

The proposed set of reactions begins with the degradation of the parent hemicellulose material $(H)$ into a solid reaction intermediate $\left(R_{1}\right)$ and products from reaction $1\left(P_{i, 1}\right)$ with reaction rate constant $k_{1}$. The second reaction consists of the solid reaction intermediate further degrading through a second reaction rate constant $\left(k_{2}\right)$ to further produce products $\left(P_{i, 2}\right)$ and intermediate $\left(R_{2}\right)$. The third and final reaction produces products $\left(P_{i, 3}\right)$ and the final bio-coal product $(C)$ from the second intermediate with rate constant $\left(k_{3}\right)$. These reactions are summarized in Equations 1-3.

$$
\begin{gathered}
H \stackrel{k_{1}}{\rightarrow} R_{1}+\sum_{i} \alpha_{i} P_{i} \\
R_{1} \stackrel{k_{2}}{\rightarrow} R_{2}+\sum_{i} \beta_{i} P_{i} \\
R_{2} \stackrel{k_{3}}{\rightarrow} C+\sum_{i} \gamma_{i} P_{i}
\end{gathered}
$$

where $\alpha_{i}, \beta_{i}, \gamma_{i}$ are stoichiometric coefficients for production of species $i$ in reactions (1)-(3), and $k_{1}>k_{2}>k_{3}$. Assuming first order reactions, the time dependent solution for the rate of production of product $P_{i}$ is shown in Equations (4)-(6), and the details of this solution are shown in the supporting materials.

$$
\frac{d P_{i}}{d t}=\alpha_{i} k_{1} H+\beta_{i} k_{2} R_{1}+\gamma_{i} k_{3} R_{2}
$$

\section{Contribution From}

$$
\frac{d P_{i}}{d t}=\alpha_{i} \theta\left[\exp \left(-k_{1} t\right)\right]
$$




$$
\begin{array}{ll}
+\beta_{1} \theta \varphi\left[\exp \left(-k_{1} t\right)-\exp \left(-k_{2} t\right)\right] & \text { (reaction 2) } \\
+\gamma_{i} \theta \varphi \omega\left[\left(k_{2}-k_{3}\right) \exp \left(-k_{1} t\right)\right] & \\
+\left(k_{3}-k_{1}\right) \exp \left(-k_{2} t\right) & \text { (reaction 3) } \\
-\left(k_{2}-k_{1}\right) \exp \left(-k_{3} t\right) & \\
\theta=k_{1} H_{0}, \quad \varphi=\frac{k_{2}}{k_{2}-k_{1}}, \quad \omega=\frac{k_{3}}{\left(k_{3}-k_{1}\right)\left(k_{2}-k_{3}\right)}
\end{array}
$$

The reaction variables $k_{1}, k_{2}, k_{3}, \beta_{i}, \gamma_{i}$ and $(H)_{o}$ were fit simultaneously to all data by minimizing the squared error between the measured experimental data and the model predictions. The objective function to fit the variables is shown in Equation 8.

$$
\begin{gathered}
\min \sum_{j} \sum_{i=0}\left(p_{i, j}-P_{i, j}\right)^{2} \\
P_{i, j}=P\left(t_{i},\left\{k_{1}, k_{2}, k_{3}, \beta_{j}, \gamma_{j},(H)_{o}\right\}\right)
\end{gathered}
$$

where $p_{i, j}$ is the measured data for species $j$ at time $i, P_{i, j}$ is the calculated model value for species $j$ at time $i$. The reaction rate coefficients were found to be $k_{1}=$ $1.0079 \mathrm{~min}^{-1}, k_{2}=0.4664 \mathrm{~min}^{-1}$, and $k_{3}=0.0253 \mathrm{~min}^{-1}$. The characteristic times, or inverse reaction rates, were $0.99 \mathrm{~min}, 2.14 \mathrm{~min}$ and $39.45 \mathrm{~min}$ respectively. The experimental data with the reaction scheme are shown in Figure 2.5. This figure shows very close agreement between the proposed model (labeled "Model" in the figure) and the experimental data (labeled $44 \mathrm{~m} / \mathrm{z}, 60 \mathrm{~m} / \mathrm{z}$, etc.), as well as the contributions from the three reactions (labeled "Rxn 1", "Rxn 2", “Rxn 3"). 

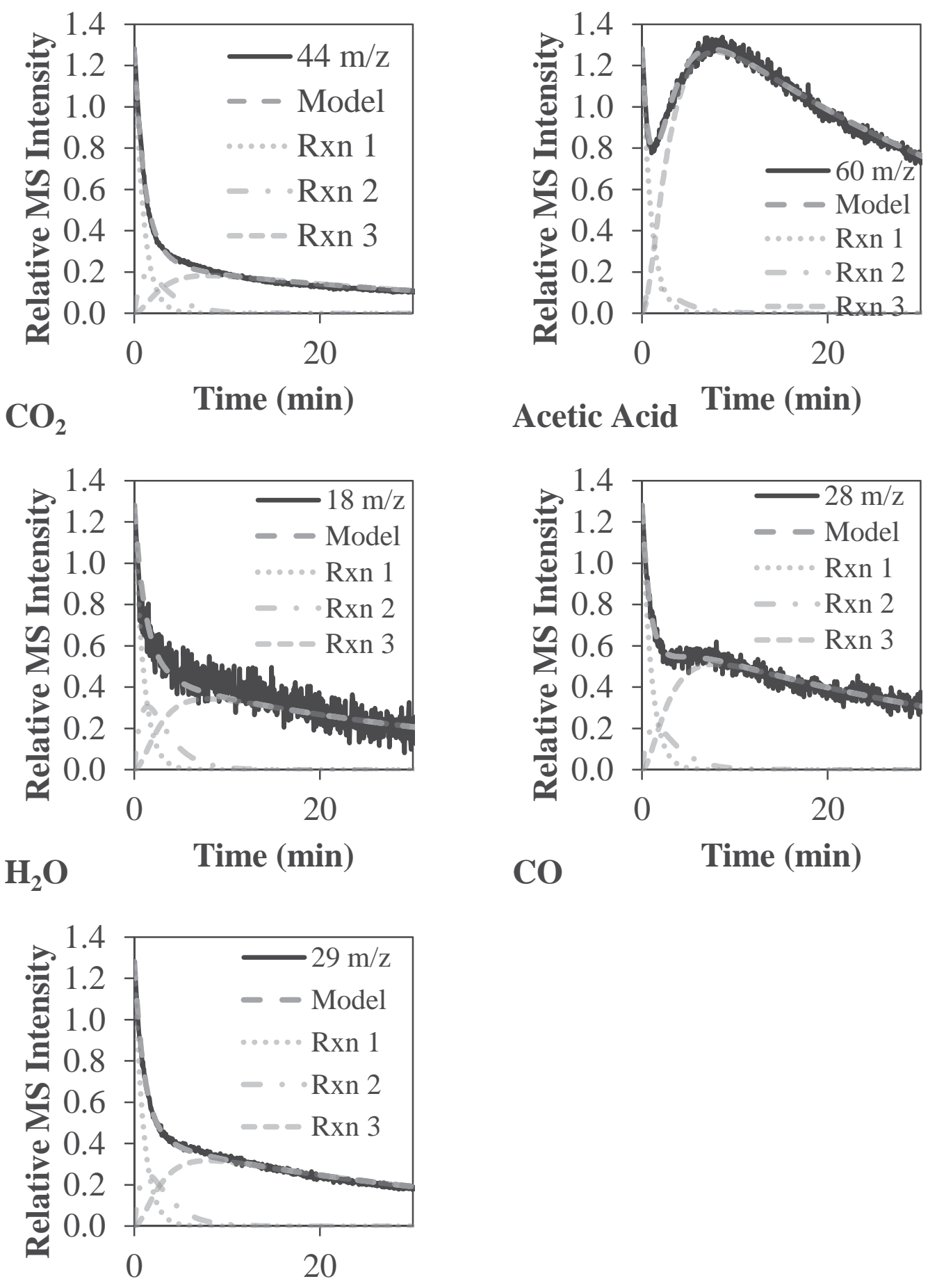

Formic Acid Time (min)

Figure 2.5: Experimental rate data with model predictions 
Table 2.2: Stoicheometeric factors for each modeled compound

\begin{tabular}{cccc}
\hline & $\alpha_{i}$ & $\beta_{i}$ & $\gamma_{i}$ \\
\hline $\mathrm{CO}_{2}$ & 1.28 & 0.88 & 24.2 \\
$\mathrm{H}_{2} \boldsymbol{O}$ & 1.28 & 0.78 & 8.65 \\
$\mathrm{CH}_{3} \mathbf{C O O H}$ & 1.28 & 1.29 & 16.2 \\
$\mathbf{H C O O H}$ & 1.28 & 0.54 & 60.0 \\
\hline
\end{tabular}

Each compound shares an identical production according to the first degradation reaction, which arises from the normalization of the data. During this method, $\alpha_{i}$ is forced to a value found with the extrapolation mention previously, while the other stoicheometeric factors were calculated as relative values. The values of these coefficients are shown in Table 2.2. The model predicts that the maximum amount of hemicellulose occurs at time zero, while the first intermediate peaks around $1.5 \mathrm{~min}$, and the second intermediate is maximized after approximately $8 \mathrm{~min}$. It is clearly shown that the second reaction has some contributing effects, but the majority of sustained chemical production occurs during reaction 3. Perhaps the solid hemicellulose intermediate at this stage is unstable, or readily fragments to a more suitable derivative. For all species studied here, the model predictions are in good agreement with the laboratory data. This lends evidence to our proposed model, suggesting that the products are produced simultaneously is a series of sequential reactions. 
This idea is shared by other works which attempt to describe torrefaction. Table 2.3 displays a summary of some established torrefaction models (Chew and Doshi 2011).

When compared to existing models, the work here has several novel aspects and insights: (1) moves beyond lumped models, to the identification of specific chemical species transients' during torrefaction, (2) the model was developed around observed species, and thus direct changes to the biomass instead of weight loss curves, (3) very fast heating rates, which decoupled transport and kinetic effects arising from temperature ramping. When comparing to existing models, perhaps the closest match is the two-step consecutive Di Blasi-Lanzetta model. This model has been used extensively in other studies in attempt to explain trends obtained from TGA studies (Di Blasi and Lanzetta 1997; Bates and Ghoniem 2012; Pétrissans et al. 2012). In this model, the parent biomass $(A)$ forms volatile product group $1\left(V_{1}\right)$ and a reaction intermediate $(B)$ through reaction rates $k_{v 1}$ and $k_{1}$ respectively. After this first reaction, the intermediate is further broken into a second group of volatile products $\left(V_{2}\right)$ and a solid product $(C)$. These reactions are summarized in Equations 10-11 (Di Blasi and Lanzetta 1997).

$$
\begin{aligned}
& A \stackrel{k_{v 1}}{\rightarrow} V_{1}, A \stackrel{k_{1}}{\rightarrow} B \\
& B \stackrel{k_{v 2}}{\rightarrow} V_{2}, B \stackrel{k_{2}}{\rightarrow} C
\end{aligned}
$$


Table 2.3: Torrefaction kinetic models, adapted from (Di Blasi and Lanzetta 1997; Repellin et al. 2010; Chew and Doshi 2011; Bates and Ghoniem 2012; Broström et al. 2012).

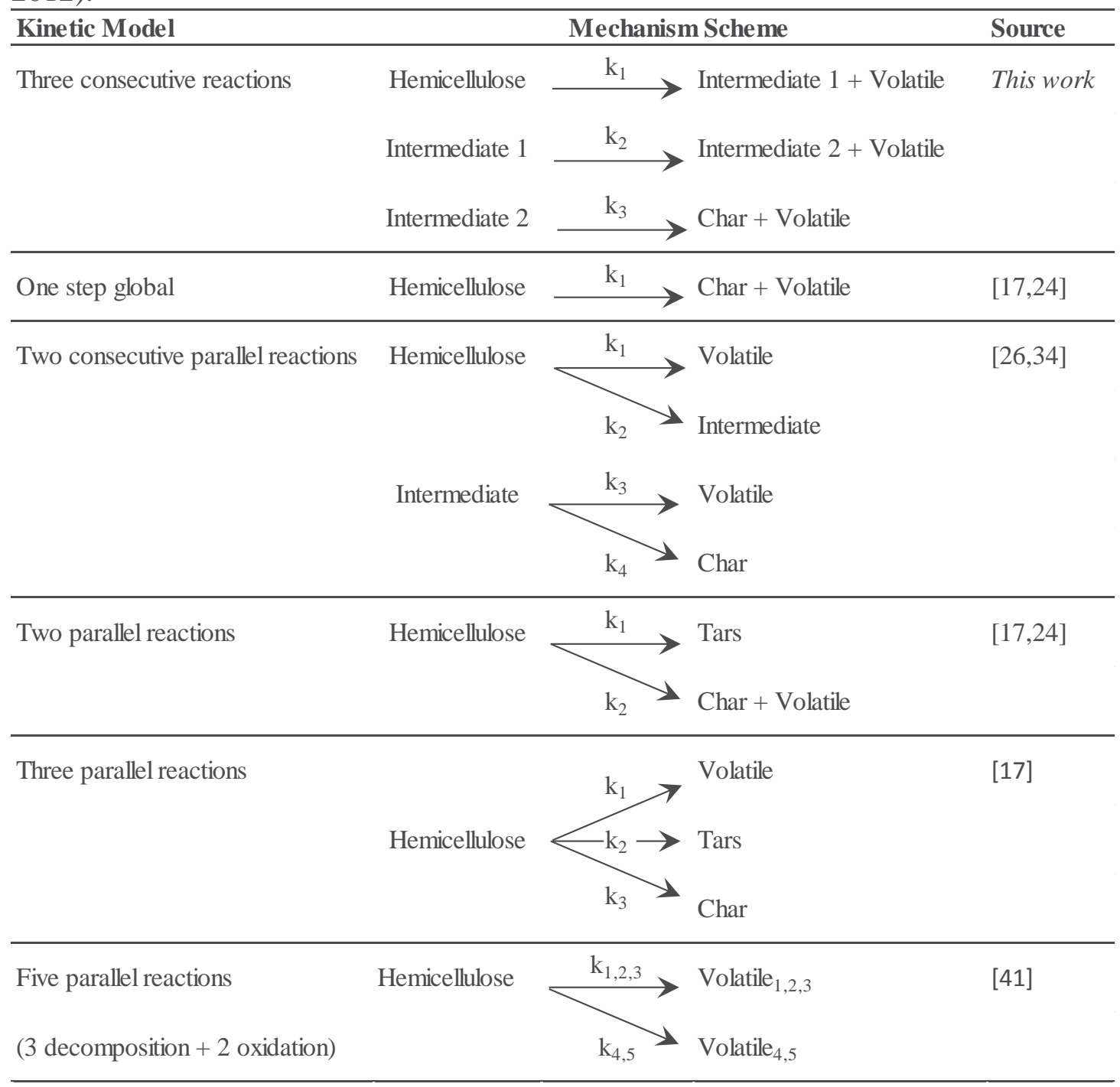




\subsection{Conclusions and Recommendations}

The new model presented in this work describes the evolution of gases ( $\mathrm{CO}$ and $\mathrm{CO} 2$ ), water, and organic acids (formic and acetic) from the torrefaction of aspen. The proposed models were formed around the observations of fast product evolution followed by varying amounts of sustained production at later times. The model consists of three sequential reactions with characteristic times of $0.99 \mathrm{~min}, 2.14 \mathrm{~min}$ and $39.45 \mathrm{~min}$ respectively. The data for the species measured were well fit by the model. Transient characterization of the remaining biomass solids could provide a well-defined path for model improvements. Techniques such as Fourier transform infrared spectroscopy (FTIR) could be employed to develop a key understanding of change in functional groups. In addition, convoluting factors such as heat transfer, flow dispersion, and GC column interaction should be further addressed or incorporated in the model to further refine the key early-time assumptions. 


\subsection{Works Cited}

Ahn DH, Gibbs BM, Ko KH, Kim JJ. 2001. Gasification kinetics of an Indonesian subbituminous coal-char with CO2 at elevated pressure. Fuel 80(11):1651-1658.

Ayhan D. 2008. Importance of biomass energy sources for Turkey. Energy Policy 36(2):834-842.

Babu BV, Chaurasia AS. 2004. Parametric study of thermal and thermodynamic properties on pyrolysis of biomass in thermally thick regime. Energy Conversion and Management 45(1):53-72.

Bates RB, Ghoniem AF. 2012. Biomass torrefaction: Modeling of volatile and solid product evolution kinetics. Bioresource Technology 124(0):460-469.

Bergman PCA. 2005. Combined torrefaction and pelletisation, the TOP process. ECN Biomass, DEN programme of SenterNovem, Dutch Ministry of Economic Affairs, Report ECN-C-05-073.

Boardman RD, Hess JR, Sokhansanj S, Tumuluru JS, Wright CT. 2011. A review on biomass torrefaction process and product properties for energy applications. Industrial Biotechnology 7(5):384+.

Bridgeman TG, Jones JM, Williams A, Waldron DJ. 2010. An investigation of the grindability of two torrefied energy crops. Fuel 89(12):3911-3918. 
Broström M, Nordin A, Pommer L, Branca C, Di Blasi C. 2012. Influence of torrefaction on the devolatilization and oxidation kinetics of wood. Journal of Analytical and Applied Pyrolysis 96(0):100-109.

Carslaw HS, Jaeger JC. 1959. Conduction of heat in Solids, 2nd edition. Oxford: Clarendon Press. p. 101,200.

Chen W-H, Hsu H-C, Lu K-M, Lee W-J, Lin T-C. 2011. Thermal pretreatment of wood (Lauan) block by torrefaction and its influence on the properties of the biomass. Energy 36(5):3012-3021.

Chew JJ, Doshi V. 2011. Recent advances in biomass pretreatment - Torrefaction fundamentals and technology. Renewable and Sustainable Energy Reviews 15(8):4212-4222.

Ciolkosz D, Wallace R. 2011. A review of torrefaction for bioenergy feedstock production. Biofuels, Bioproducts and Biorefining 5(3):317-329.

Demirbaş A. 2001. Carbonization ranking of selected biomass for charcoal, liquid and gaseous products. Energy Conversion and Management 42(10):1229-1238.

Devi L, Ptasinski KJ, Janssen FJJG. 2003. A review of the primary measures for tar elimination in biomass gasification processes. Biomass and Bioenergy 24(2):125140.

Di Blasi C. 1996. Heat, momentum and mass transport through a shrinking biomass particle exposed to thermal radiation. Chemical Engineering Science 51(7):1121-1132. 
Di Blasi C, Lanzetta M. 1997. Intrinsic kinetics of isothermal xylan degradation in inert atmosphere. Journal of Analytical and Applied Pyrolysis 40-41(0):287-303.

DOE/EIA. 2011. Report DOE/EIA-0484(2011). U.S. Energy Information Administration.

EIA. 2009. Report \#:DOE/EIA-0484, International Energy Outlook, 2009. Report \#: DOE/EIA-0484.

EIA. 2010. Annual Energy Projections with Projections to 2035, Report \#: DOE/EIA0383(2010). Report \#: DOE/EIA-0383.

Evans RJ, Milne TA. 1987. Molecular characterization of the pyrolysis of biomass. Energy \& Fuels 1(2):123-137.

Fan J, Kalnes TN, Alward M, Klinger J, Sadehvandi A, Shonnard DR. 2011. Life cycle assessment of electricity generation using fast pyrolysis bio-oil. Renewable Energy 36(2):632-641.

Gasol CM, Gabarrell X, Anton A, Rigola M, Carrasco J, Ciria P, Rieradevall J. 2009. LCA of poplar bioenergy system compared with Brassica carinata energy crop and natural gas in regional scenario. Biomass and Bioenergy 33(1):119-129.

He F, Behrendt F. 2011. A new method for simulating the combustion of a large biomass particle-A combination of a volume reaction model and front reaction approximation. Combustion and Flame 158(12):2500-2511.

Mastral AM, Callén MS, Garcia T. 2000. Toxic organic emissions from coal combustion. Fuel Processing Technology 67(1):1-10. 
Panshin AJ, deZeeuw C. 1980. Textbook of wood technology. New York: McGraw-Hill Book Company.

Parikh J, Channiwala SA, Ghosal GK. 2005. A correlation for calculating HHV from proximate analysis of solid fuels. Fuel 84(5):487-494.

Patwardhan PR, Satrio JA, Brown RC, Shanks BH. 2009. Product distribution from fast pyrolysis of glucose-based carbohydrates. Journal of Analytical and Applied Pyrolysis 86(2):323-330.

Pétrissans A, Younsi R, Chaouch M, Gérardin P, Pétrissans M. 2012. Experimental and numerical analysis of wood thermodegradation. Journal of Thermal Analysis and Calorimetry 109(2):907-914.

Prins MJ, Ptasinski KJ, Janssen FJJG. 2006. Torrefaction of wood: Part 1. Weight loss kinetics. Journal of Analytical and Applied Pyrolysis 77(1):28-34.

Prins MJ, Ptasinski KJ, Janssen FJJG. 2007. From coal to biomass gasification: Comparison of thermodynamic efficiency. Energy 32(7):1248-1259.

Reichling JP, Kulacki FA. 2011. Comparative analysis of Fischer-Tropsch and integrated gasification combined cycle biomass utilization. Energy 36(11):6529-6535.

Repellin V, Govin A, Rolland M, Guyonnet R. 2010. Modelling anhydrous weight loss of wood chips during torrefaction in a pilot kiln. Biomass and Bioenergy 34(5):602609. 
Saidur R, Abdelaziz EA, Demirbas A, Hossain MS, Mekhilef S. 2011. A review on biomass as a fuel for boilers. Renewable and Sustainable Energy Reviews $15(5): 2262-2289$.

Shafizadeh F, Chin PPS. 1977. Thermal Deterioration of Wood. Wood Technology: Chemical Aspects. AMERICAN CHEMICAL SOCIETY. p. 57-81.

Smith WS, Gruber CW. 1966. Atmospheric emissions from coal combustion: an inventory guide. Journal Name: Public Health Service Publication; (United States); Journal Volume: 999-AP-24:Medium: X; Size: Pages: vp.

Spath PL, Mann MK, Kerr DR. 1999. Life Cycle Assessment of Coal-Fired Power Production. NREL/TP-570-25119. Golden, Colorado: National Renewable Energy Laboratory.

Tumuluru JS, Sokhansanj S, Wright CT, Boardman RD, Yancey NA. 2011. A review on issues and pretreatment methods to successfully cofire biomass and coal. 2011 ASABE Annual International Meeting. Louisville, Kentucky.

van der Stelt MJC, Gerhauser H, Kiel JHA, Ptasinski KJ. 2011. Biomass upgrading by torrefaction for the production of biofuels: A review. Biomass and Bioenergy 35(9):3748-3762.

Wright MM, Brown RC, Boateng AA. 2008. Distributed processing of biomass to bio-oil for subsequent production of Fischer-Tropsch liquids. Biofuels, Bioproducts and Biorefining 2(3):229-238. 
Yang H, Yan R, Chen H, Lee DH, Zheng C. 2007. Characteristics of hemicellulose, cellulose and lignin pyrolysis. Fuel 86(12-13):1781-1788.

Zhao Y, Wang S, Duan L, Lei Y, Cao P, Hao J. 2008. Primary air pollutant emissions of coal-fired power plants in China: Current status and future prediction. Atmospheric Environment 42(36):8442-8452. 


\section{Temperature Dependence of Thermal Degradation Model}

Reprinted with permission from KLINGER J, KLEMETSRUD B, BAR-ZIV E, SHONNARD D. 2014. TEMPERATURE DEPENDENCE OF ASPEN TORREFACTION KINETICS. JOURNAL OF ANALYTICAL AND APPLIED PYROLYSIS 110(0):424429. Copyright 2014 Elsivier B.V. ${ }^{2}$

\subsection{Abstract}

Torrefied biomass provides opportunities for an alternative, renewable fuel in the energy market. Much work on torrefaction is based on weight loss transients without much insight into the evolution of volatile species. A previous model from our group has been developed that predicts the degradation of raw biomass into specific chemical species during torrefaction (water, acetic acid, carbon monoxide, carbon dioxide, formic acid and furfural) in three consecutive reaction steps. The goal of this work is to understand how the kinetics of torrefaction change with temperature. Kinetic parameters for aspen wood were obtained for the first 90 minutes of $260-300^{\circ} \mathrm{C}\left(1000^{\circ} \mathrm{C} / \mathrm{s}\right)$ torrefaction. The preexponential factors were 3.32E9, 1.43E11, and 2.08E14min^^-1, and the activation energies $1.05 \mathrm{E} 2,1.27 \mathrm{E} 2$, and $1.72 \mathrm{E} 2 \mathrm{~kJ} / \mathrm{mol}$ for the three reactions. Kinetic parameters found correspond well to similar values from global weight loss studies, and suggest that

\footnotetext{
${ }^{2}$ The material contained in this chapter was previously published in Journal of analytical and Applied Pyrolysis.
} 
increased torrefaction severity leads to progressively more recalcitrant forms of torrefied biomass. These continuous production traces for the volatile organic species yield insight into torrefaction, and require careful consideration of torrefaction time and temperature to design the desired solid fuel product.

\subsection{Introduction}

Currently $42 \%$ of the electricity generated in the United States comes from coal combustion (EIA 2010; DOE/EIA 2011). Coal is known to produce one-third of the CO2 emissions in the United States and releases other harmful pollutants such as CO, SOx, NOx, particulates, and mercury. Because of the growing concern of global warming, the need to find renewable $\mathrm{CO} 2$ neutral feedstock is immediate. Biocoal (or torrefied biomass) (Bergman 2005; Bridgeman et al. 2010; Ciolkosz and Wallace 2011; van der Stelt et al. 2011) can be an immediate solution in coal utility boilers. This renewable fuel can be used as a drop-in replacement for coal firing due to its high energy density, similar properties to coal, low emissions and potential for CO2 neutrality (Chew and Doshi 2011; Ciolkosz and Wallace 2011; van der Stelt et al. 2011).

Biocoal is produced from the torrefaction of biomass, at temperatures from 200$300^{\circ} \mathrm{C}$ in an oxygen free environment. During torrefaction, mostly the hemicellulose portion of the biomass degrades through a complex coupled chemical-kinetic-heat-andmass-transfer process (Yang et al. 2007; Boardman et al. 2011; Chew and Doshi 2011). There are small contributions from cellulose and lignin during this process; with the 
contribution of cellulose increasing significantly at temperatures above $300^{\circ} \mathrm{C}$ (Prins et al. 2006a; Yang et al. 2007). When the biomass is heated up quickly in an inert atmosphere, biomass is dehydrated, the viscoelastic properties are changed, and the calorific value increases (Wei-Hsin Chen and Kuo 2011; van der Stelt et al. 2011). In addition, the energy requirements to reduce the size biocoal is substantially smaller, up to an order of magnitude, when compared to raw biomass (Bergman 2005; Bridgeman et al. 2010; Chew and Doshi 2011; Phanphanich and Mani 2011; Shang et al. 2012). Biocoal is then able to be a drop-in replacement for pulverized coal.

In order to have a better control of the torrefaction process and develop more efficient reactors for biocoal production, the torrefaction of biomass and the kinetics of species evolution, and changes in the residual biomass need to be better understood. Much gravimetric work has been done to model changes during torrefaction such as parallel reaction (Shafizadeh and Chin 1977; Repellin et al. 2010; Chew and Doshi 2011; Broström et al. 2012) and consecutive reactions models (Colomba Di Blasi and Lanzetta 1997; Prins et al. 2006a; Bates and Ghoniem 2012; Klinger et al. 2013; Nocquet et al. 2014a). These models are useful for targeting throughput in equipment design, but provide little insights into the value-added benefits of torrefaction such as the improved fuel and physical properties over raw biomass mentioned above. A detailed understanding of the feedstock degradation during the torrefaction process, or the gas species evolution, is necessary for prediction of product quality changes with reaction conditions.

One specific approach to modeling torrefaction kinetics is to develop equations around weight loss data. One such model that is well accepted in literature is the two stage 
degradation of hemicellulose (xylans) developed by Di Blasi and Lanzetta (Colomba Di Blasi and Lanzetta 1997). This two stage model first degrades to a solid intermediate through rate constant $\mathrm{k}_{1}$, and volatiles through $\mathrm{kv}_{1}$, followed by a sequential step to torrefied biomass through $\mathrm{k}_{2}$ and more volatile products through $\mathrm{kv}_{2}$. This model predicts one stage of degradation at early times, and one stage for degradation over long processing times. The rate constants for each stage are also combined to give a global rate constant for that step $\left(\mathrm{k}_{1}=\mathrm{k}_{\mathrm{b}}+\mathrm{kv}_{1}, \mathrm{k}_{2}=\mathrm{kc}+\mathrm{kv}_{2}\right)$. This was further developed by Di Blasi and Branca in subsequent years to include a similar third degradation stage (constants now $\mathrm{k}_{\mathrm{B}}$ and $\mathrm{kv}_{1}$, $\mathrm{k}_{\mathrm{D}}$ and $\mathrm{kv}_{2}$, and $\mathrm{k}_{\mathrm{C}}$ and $\mathrm{kv}_{3}$ respectively) when whole wood species (beech) were studied instead of xylans (Branca and Di Blasi 2003; C. Di Blasi et al. 2013). Further, these rate constants were combined to predict the pseudo-reactions where $\mathrm{k}_{1}$ is the sum of the constants for volatile production and the production of the solid intermediate $\left(\mathrm{k}_{1}=\mathrm{kv}_{1}+\mathrm{k}_{\mathrm{B}}\right)$ in reaction one. The six rate coefficients were therefore combined and analyzed as three global constants $\left(\mathrm{k}_{1}=\mathrm{kv}_{1}+\mathrm{k}_{\mathrm{B}}, \mathrm{k}_{2}=\mathrm{kv}_{2}+\mathrm{k}_{\mathrm{D}}, \mathrm{k}_{3}=\mathrm{kv}_{3}+\mathrm{k}_{\mathrm{C}}\right)$ from $528 \mathrm{~K}$ to $584 \mathrm{~K}$ (6000 seconds), and $573 \mathrm{~K}$ to $708 \mathrm{~K}$ (up to 2000 seconds). The first reaction $\left(\mathrm{k}_{1}\right)$ was reported to dominate from $528 \mathrm{~K}$ to $593 \mathrm{~K}$, the second $\left(\mathrm{k}_{2}\right)$ from $528 \mathrm{~K}$ to $708 \mathrm{~K}$, and the third $\left(\mathrm{k}_{3}\right)$ from $603 \mathrm{~K}$ to $708 \mathrm{~K}$. While these models may be convenient for estimating material throughput in equipment design, they do not provide any process insight into product quality, or any information on a chemical level.

Several studies have investigated modeling of torrefaction and coupling information about volatile species evolution (Prins et al. 2006a; 2006b; Bates and Ghoniem 2012; Klinger et al. 2013; Nocquet et al. 2014a; 2014b). Prins et al. studied the torrefaction 
of willow over $225-300^{\circ} \mathrm{C}$ using the Di Blasi and Lanzetta model discussed above (Prins et al. 2006a). This was quickly followed by a subsequent study investigating the product distribution that is observed (Prins et al. 2006b). These were later combined to accurately predict the volatile product evolution over a range of temperatures and times (Bates and Ghoniem 2012). More recently, Nocquet et al., took a similar approach using beechwood, cellulose, lignin, and xylan standards (Nocquet et al. 2014b; 2014a). In the kinetic study, the two-stage Di Blasi and Lanzetta model was used to model the decomposition of the cellulose, hemicellulose, and lignin fractions of the biomass, with a stoichiometry parameter for the production of the respective volatile species (Nocquet et al. 2014a). With a correction factor to account for the interaction of the related constituents of virgin wood, they were able to accurately predict the volatile evolution at discrete points, and also match a continuous mass loss signal. In order to move beyond a discrete point understanding of volatile torrefaction species, however, our group previously investigated a model based strictly around gas-phase species kinetics (Klinger et al. 2013).

The previous study predicts the first 90 minutes of torrefaction at $300^{\circ} \mathrm{C}$, and the yield of products in a three-step torrefaction model (Klinger et al. 2013). This model was able to accurately predict the amount of various chemical species evolved during torrefaction and was based on the degradation of the hemicellulose material at $300^{\circ} \mathrm{C}$. The reaction model is shown below. 


$$
\begin{aligned}
& H \stackrel{k_{1}}{\rightarrow} R_{1}+\sum_{i} \alpha_{i} P_{i} \\
& R_{1} \stackrel{k_{2}}{\rightarrow} R_{2}+\sum_{i} \beta_{i} P_{i} \\
& R_{2} \stackrel{k_{3}}{\rightarrow} C+\sum_{i} \gamma_{i} P_{i}
\end{aligned}
$$

In this model the initial hemicellulose $(\mathrm{H})$ is degraded with reaction rate constant $k_{1}$ into a reaction intermediate $R_{1}$ and forms a suite of products $\left\{P_{i, 1}\right\}$. The first reaction intermediate $\mathrm{R}_{1}$ is then degraded with rate constant $\mathrm{k}_{2}$ into a second reaction intermediate $\mathrm{R}_{2}$ and produces more of these products $\left\{\mathrm{P}_{\mathrm{i}, 2}\right\}$. The second reaction intermediate is then degraded with rate constant $\mathrm{k}_{3}$ into the biocoal product $(\mathrm{C})$ along with an additional release of reaction products $\left\{\mathrm{P}_{\mathrm{i}, 3}\right\}$. This model accounts for the production of major torrefaction products through characteristic mass spectrometer (MS) ion fragments of: water $(18 \mathrm{~m} / \mathrm{z})$, carbon monoxide $(28 \mathrm{~m} / \mathrm{z})$, formic acid $(29 \mathrm{~m} / \mathrm{z})$, carbon dioxide $(44 \mathrm{~m} / \mathrm{z})$, acetic acid $(60 \mathrm{~m} / \mathrm{z})$ and furfural $(95 \mathrm{~m} / \mathrm{z})$.

This paper aims to deepen this model by applying this model over a range of torrefaction temperatures, and investigate the kinetics of torrefaction purely on the gasphase reactions. In this work we take a lumped parameter assumption, where that the reaction rate coefficients are the same for each compound evolved, but the intensities of the specific species change with a stoichiometric coefficient $(\alpha, \beta, \gamma)$. These coefficients represent a relative amount of volatile product generated from each consecutive reaction stage, and are unique for each species - each of the six compounds investigated have a stoicheometeric parameter for each reaction. If this model is valid over the temperature 
range, then the stoichiometric coefficients should be independent of temperature for each of Rxns (1-3). This assumption was validated in this research. This approach to predicting torrefaction is novel, but was previously investigated at only at $300^{\circ} \mathrm{C}$ (Klinger et al. 2013). By obtaining gas-phase kinetics, accurate predictions of the volatile yields can be obtained for both isothermal and non-isothermal conditions. The dynamic evolution of these species was investigated, and unique implications of interpreting torrefaction through weight loss data in the absence of these novel results is discussed.

\subsection{Material and Methods}

As in our previous study (Klinger et al. 2013) we used aspen biomass for this current research. Aspen samples were debarked then dried in an oven at $105^{\circ} \mathrm{C}$ until no difference in mass was observed. A Thomas Wiley® knife mill (NR. 3557524359264 ) was used to reduce the size of the wood particles. To obtain particle sizes of $0.5-0.6 \mathrm{~mm}$ a W.S. Tyler Rotap (model RX-29, serial 9774) was used. The aspen samples were roughly cylindrical with diameters of approximately $0.5 \mathrm{~mm}$ and length ranging from $1-3 \mathrm{~mm}$.

\subsubsection{Torrefaction Experiments}

To obtain kinetic data, the dried aspen wood samples were torrefied using a CDS Analytical micro-pyrolysis unit (model 5200HP Pyroprobe). The aspen was torrefied at temperatures of $260^{\circ} \mathrm{C}$ to $300^{\circ} \mathrm{C}$ at $10^{\circ} \mathrm{C}$ intervals for 90 minutes. The volatile species evolved were continuously analyzed using a Trace GC Ultra (Model K8880181) gas chromatograph by ThermoFisher and a quadrupole mass spectrometer (Trace DSQII, 
ThermoFisher). The GC was fit with an inert, non-retentive, $10 \mathrm{~m}$ fused silica column (Restek, Rxi Guard Column). This eliminated any interaction with the compounds in the GC, and acted as a transfer line from the torrefaction reactor to the MS.

Aspen samples of 0.1-0.2mg were weighed to within an accuracy of $1 \mu \mathrm{g}$ using a microbalance (Citizen Scales Inc., Model CM5). The samples were then placed in a quartz reaction tube $(25 \mathrm{~mm} \times 2 \mathrm{~mm}$ OD) and held in place by two small pieces of glass wool on either end of the reaction tube. The samples were loaded into the micro-pyrolysis unit such that the wood chips were within the center of the heating zone and rapidly heated to the desired temperature. Rapid heating $\left(1000^{\circ} \mathrm{C} / \mathrm{sec}\right)$ was accomplished using a platinum heating filament that surrounded the quartz reaction tube. Ultra high purity helium (99.999\%) was used as the carrier gas in order to create an inert atmosphere within the reaction zone and to transport the gaseous and vapor products into the inlet port of the GC through a heated stainless steel transfer line $\left(300^{\circ} \mathrm{C}\right)$. The $\mathrm{GC}$ column was kept at $300^{\circ} \mathrm{C}$ for all experiments and the flow of helium gas kept at $1.5 \mathrm{ml} / \mathrm{min}$ (superficial velocity of $50.9 \mathrm{~cm} / \mathrm{s})$. After the samples passed through the GC, they then entered the quadrupole mass spectrometer where the ion fragments' intensities with respect to time were recorded. The mass spectrometer measured the continuous signal of ions from $15-350 \mathrm{~m} / \mathrm{z}$ for 90 minutes. Data were then exported to a Microsoft Excel sheet for analysis. The measured data were normalized by dividing the MS intensity measured at each time point by the initial mass of aspen. 


\subsubsection{Model Fitting}

As mentioned, the proposed model (Rxns 1-3) is a consecutive 3-step degradation model for the early stages of torrefaction (up to 90 minutes). This model was developed for the main products from torrefaction: $\mathrm{CO}, \mathrm{CO}_{2}, \mathrm{H}_{2} \mathrm{O}$, organic acids (acetic acid and formic acid), and furfural (Prins et al. 2006b; Boardman et al. 2011; Klinger et al. 2013) (although some studies report that methanol, methane, formaldehyde, and hydrogen are also observed (Pach et al. 2002; Prins et al. 2006b; Couhert et al. 2009; Deng et al. 2009; Boardman et al. 2011; Shang et al. 2013; Yingquan Chen et al. 2014; Nocquet et al.), they were excluded here because they were not formed in any detectable level in our studies). Measuring these compounds over the course of torrefaction can yield information about the gas phase formation kinetics. In addition, changes in recalcitrance of the torrefied biomass, and changes in elemental composition can be inferred.

From our previous study (Klinger et al. 2013) it was shown that at early times the production rate from Rxn 1 is dominant, while at later times Rxn 3 is the most important for product formation. An estimate for the parameters in $\operatorname{Rxn} 1\left(H_{0} \alpha_{i}, k_{1}\right)$ during early time (0.5-2.0 minutes) and the parameters for $\operatorname{Rxn} 3\left(H_{0} \gamma_{i}, k_{3}\right)$ at late times (>60 minutes) were obtained by adjusting the parameters to match the production intensity (stoichiometric coefficients) and dynamics (rate constants) over the specified times. The final parameters for $\operatorname{Rxn} 2\left(H_{0} \beta_{i}, k_{2}\right)$ were then fit using a nonlinear, generalized reduced gradient method. The fitting routine was performed in Microsoft Excel around reducing the sum of squared error between the model and all measured data. 
This method assumes that torrefaction is a set of devolatilization reactions that take place over a range of temperatures. Further, this implies that the stoichiometric parameters $(\alpha, \beta, \gamma)$ are independent of temperature. In addition, the model predicts lumped groups of product formation (i.e. all species have the same rate constant for each reaction step). These assumptions in the formation of the model are important and yield constraints about the system, and chemical significance. Because the same reactions are assumed to occur over the temperature range, a constraint is imposed that the stoichiometric parameters should not deviate with temperature. Validation of this is investigated in a following section. Further, the kinetics of torrefaction have been shown to closely follow traditional Arrhenius behavior (Colomba Di Blasi and Lanzetta 1997; Branca and Di Blasi 2003; Prins et al. 2006a; Repellin et al. 2010; Wei-Hsin Chen and Kuo 2011; Broström et al. 2012; Cavagnol et al. 2013; Sarvaramini et al. 2013; Shang et al. 2013) and impart further insight into kinetic aspects of the modeling. Initial estimates for the rate constants described above were used to obtain an initial set of Arrhenius parameters. These values were then used to obtain a new set of rate constants that are strictly linear on a ln $\mathrm{k}$ vs. 1/T basis. These values were then allowed to change along with the stoichiometric parameters $(\alpha, \beta, \gamma)$ in the iterative process of reducing the sum of squared error between the model and the experimental data. This method was followed for all species and temperatures.

All six volatile species were examined over the temperature range of $260-300^{\circ} \mathrm{C}$, however, when the torrefaction temperature decreased to $260^{\circ} \mathrm{C}$, carbon monoxide was not generated in sufficient quantity to produce a clear signal in the detector. A very low signal 
to noise ratio $(\mathrm{S} / \mathrm{N})$ makes it impossible to distinguish from the background noise, and these data were therefore excluded from the set.

\subsection{Results and Discussion}

\subsubsection{Experimental and Modeling Results}

Figure 3.1 shows typical traces of all compounds at $20^{\circ} \mathrm{C}$ intervals (to simplify the presentation) to demonstrate the different behaviors observed in the formation of gaseous and vapor products. Remaining data traces are shown in the supplemental materials. These traces are directly related to the rates at which these components are produced. The figure also shows that as the temperature increases, the characteristic reaction times decrease. At early times, during the initial decay, we can observe the highest intensities for the products

at the highest temperatures. As the temperatures decrease these production rates slow, and the production is prolonged over later times. This behavior flattens out the production curves, and thus demands much longer times to reach the same production amounts. From the figure, the steady decrease in production rate with temperature is intuitive and suggests simple temperature dependence. The production rate data decrease significantly over the $40^{\circ} \mathrm{C}$ investigation range. This suggests that the process is very sensitive to both temperature and time, and any relative decrease in temperature would require a much longer processing time to reach the same feedstock degradation.

Except for very early times, all compounds appear as a monotonic decay that decreases with decreasing temperature, but require several reactions to describe both the 

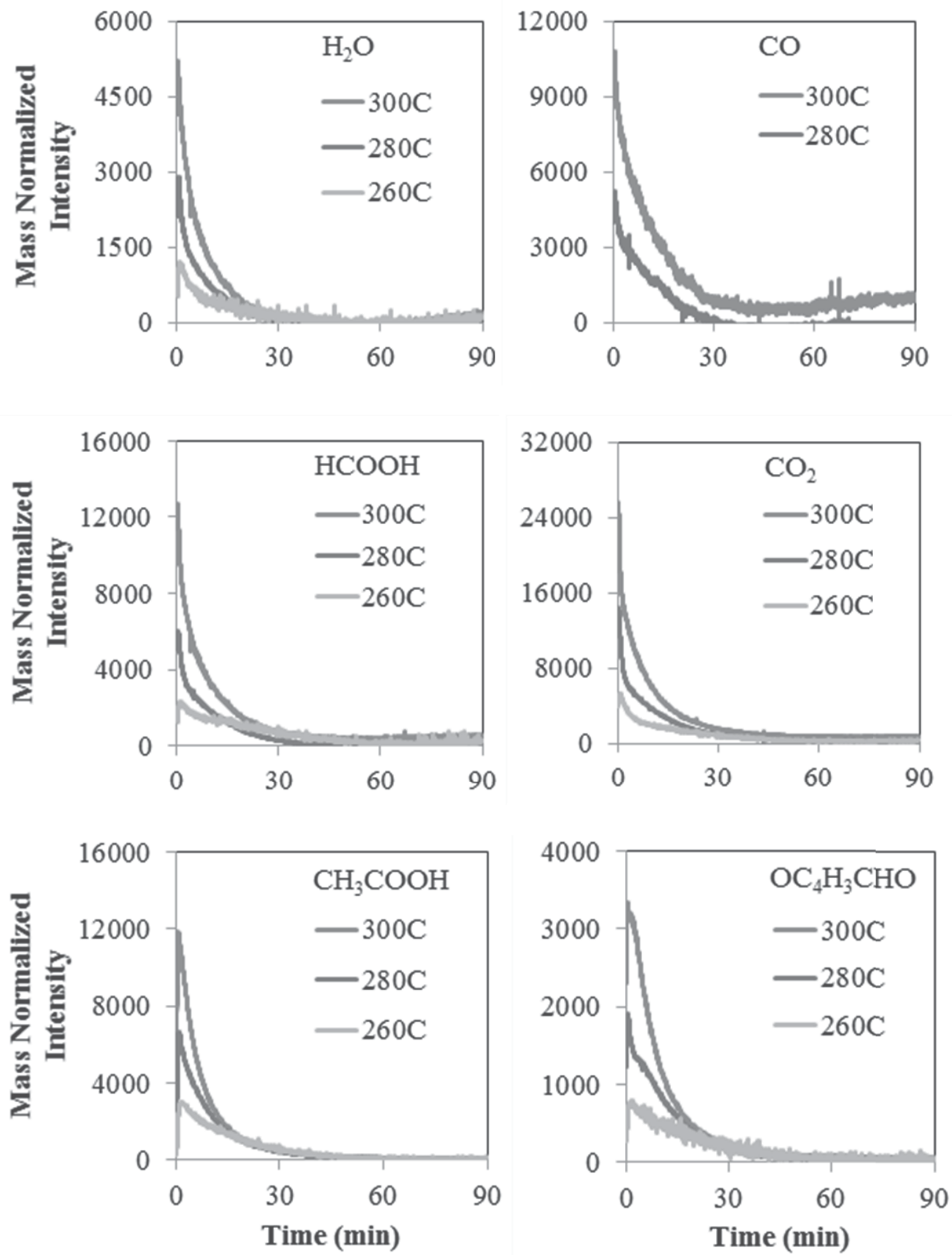

Figure 3.1: Experimental transient trends for $18 \mathrm{~m} / \mathrm{z}$ (H2O), $28 \mathrm{~m} / \mathrm{z}$ (CO), $29 \mathrm{~m} / \mathrm{z}$ $(\mathrm{HCOOH}), 44 \mathrm{~m} / \mathrm{z}(\mathrm{CO} 2)$, and $60 \mathrm{~m} / \mathrm{z}(\mathrm{CH} 3 \mathrm{COOH})$, and $95 \mathrm{~m} / \mathrm{z}(\mathrm{OC} 4 \mathrm{H} 3 \mathrm{CHO})$ at varying temperatures. 
early and late time production rates. The acetic acid and furfural behavior is more complicated, and exhibits a slightly delayed production. These compounds are dominated by a delayed apex production peak shortly after the initial rate. The modeling of these traces, as shown in Figure 3.2, demonstrates that the initial monotonic production (Rxn 1) of acetic acid and furfural is quickly overtaken by a larger production in the subsequent reactions ( $\operatorname{Rxn} 2$ and $\operatorname{Rxn} 3)$. This generates a production apex after the initial time. Like the other traces, this peak decreases in size with decreasing temperature as the production delayed in time enough that it is masked by the slow kinetics. Figure 3.2 shows typical model fits for all six compounds at $20^{\circ} \mathrm{C}$ intervals. Good agreement between the model and the recorded data was observed over the temperature range investigated. Remaining transient sets are displayed in the supplemental section.

\subsubsection{Model Validation}

It is important to note, again, that the model was assumed to apply over the whole temperature range - meaning the stoichiometric coefficients $(\alpha, \beta, \gamma)$ should be independent

of temperature. In addition, the rate coefficients are species independent - meaning the model predicts lumped groups of product formation. The kinetic parameters were fit to the experimental data as explained above and for $\alpha, \beta$, and $\gamma$. To examine the variability in these stoichiometry parameters, the average value of $\alpha$ determined for all species and temperatures, and $\alpha / \alpha_{\text {avg }}$ was plotted as a function of temperature. These results are shown in Figure 3.3. The figure shows the scatter in values for $\alpha$ away from the average. 

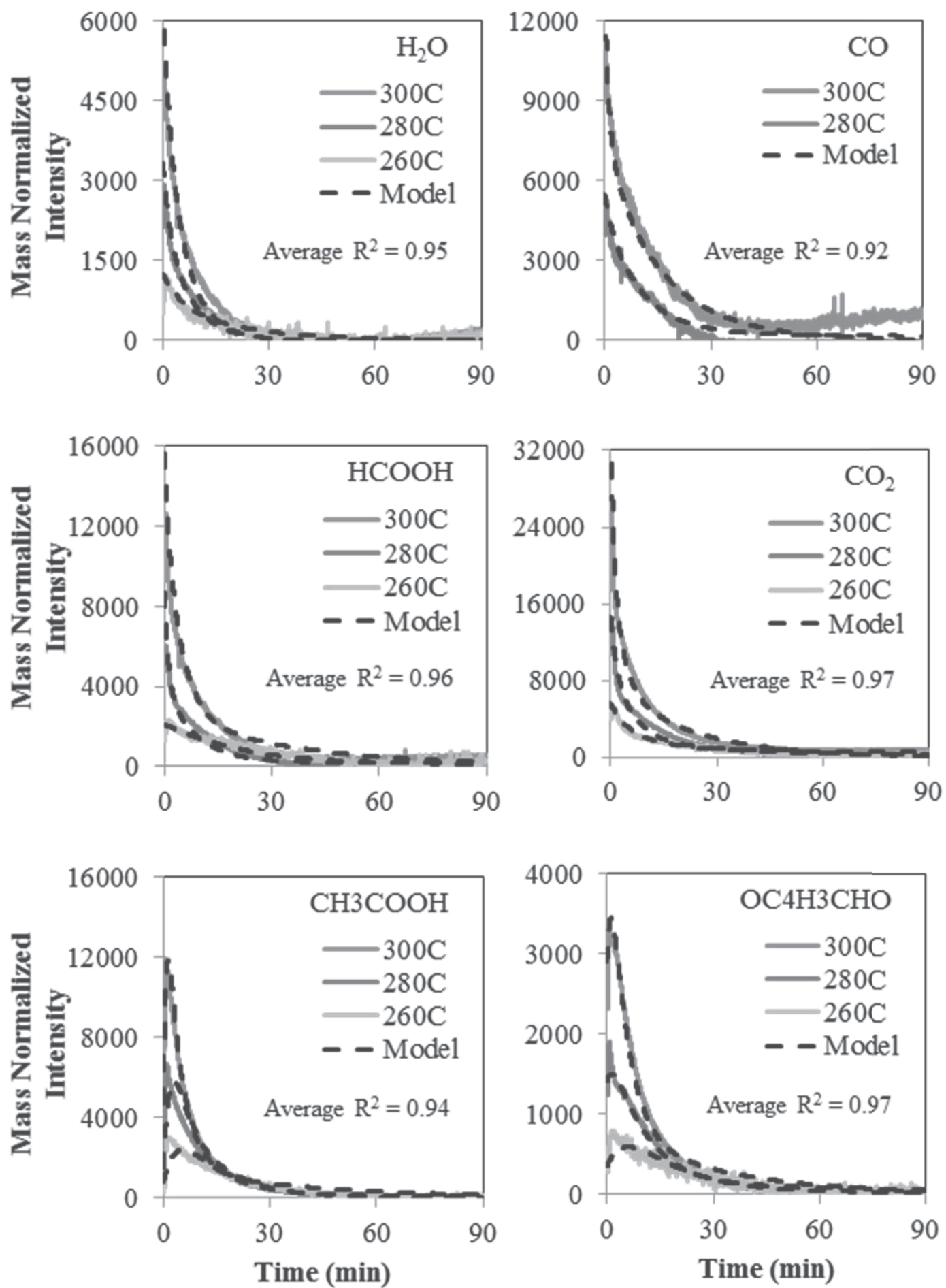

Figure 3.2: Model fitting for all compounds at different torrefaction temperatures. The experimental data are shown as solid lines. The model at each temperature is shown as dashed lines. 


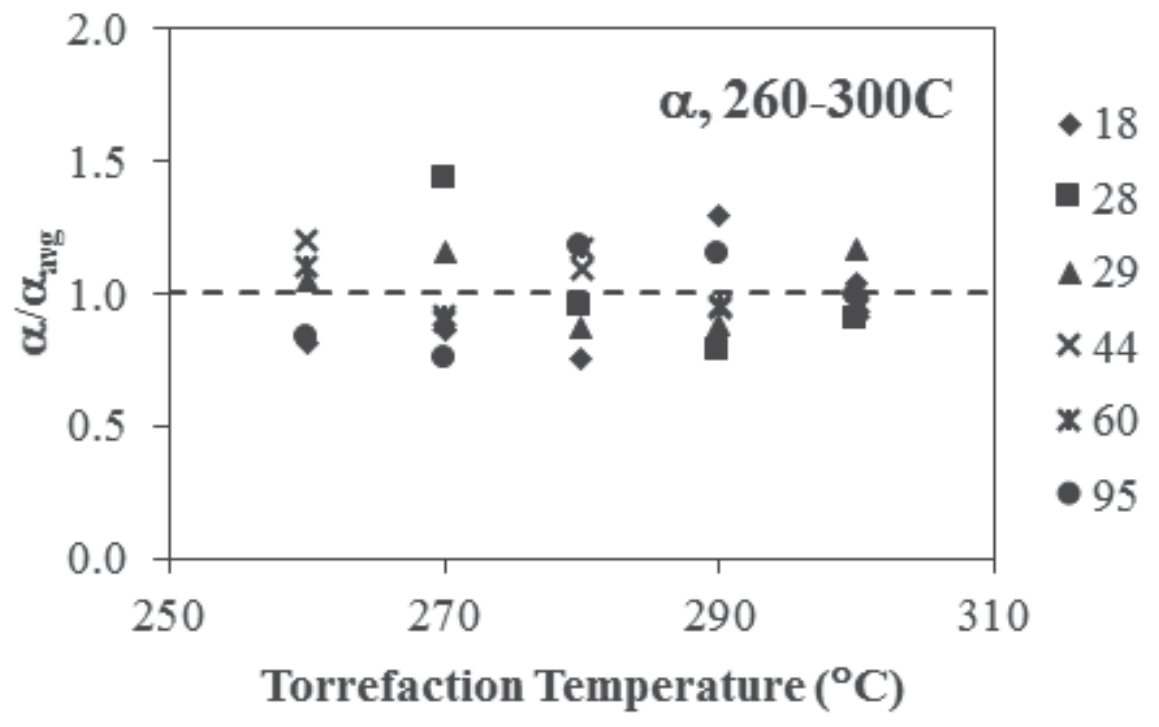

Figure 3.3: Values of alpha for each component over $260-300^{\circ} \mathrm{C}$.

Although there is some variability, the value is approximately constant with temperature. Similarly the contribution from (Rxn 2) and (Rxn 3) were investigated as functions of temperature, and in relation to the production from $(\operatorname{Rxn} 1)$ through $\alpha$. Figure 3.4 shows values for $\beta / \alpha$ and $\gamma / \alpha$ over the experimental temperature range, again supporting that the values are temperature independent. These confirming aspects of this work can lead to further chemical insight and development from a lumped product model to a more detailed reaction degradation mechanism. In conclusion, all values obtained for $\alpha / \alpha_{\text {avg }}, \beta / \alpha$ and $\gamma / \alpha$ validated that the stoichiometric coefficients are temperature independent, because we are dealing with the same reactions. 

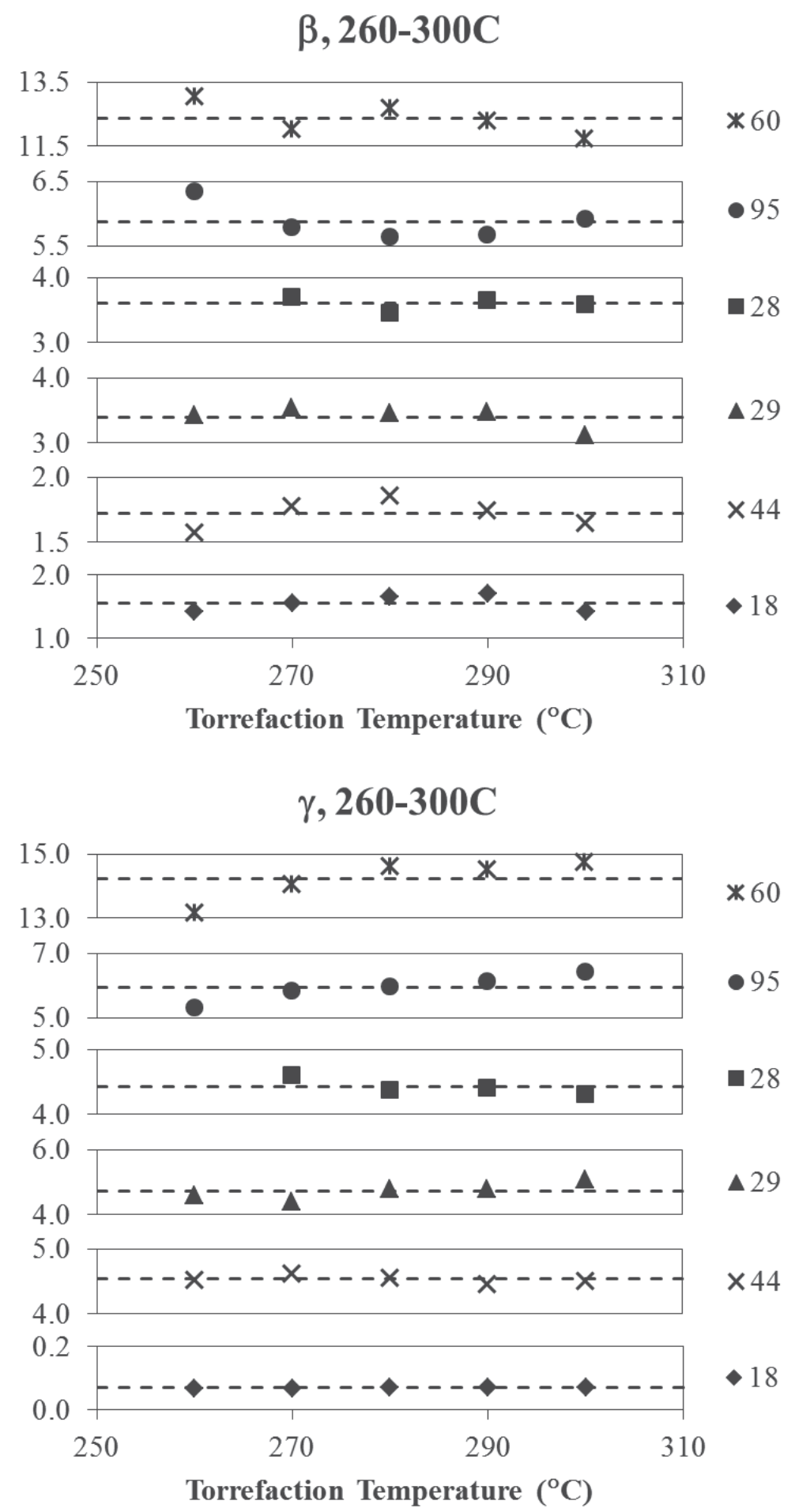

Figure 3.4: Values for $\beta$ (top) and $\gamma$ (bottom) over $260-300^{\circ} \mathrm{C}$. 


\subsubsection{Arrhenius Parameters}

Figure 3.5 shows the relationship between the three reaction rate constants (as

obtained from our fitting procedure) and temperature. The error bars represent the standard deviation between the specific rate constant for all species at the specified temperature, showing very good agreement (with $\mathrm{R}^{2}$ for the three trends 0.99, 0.99, and 0.98, respectively). These data collected from the chemical species model employed in this work show, as others have with only weight loss curves, that the kinetics of torrefaction closely follow Arrhenius behavior (Colomba Di Blasi and Lanzetta 1997; Branca and Di Blasi 2003; Prins et al. 2006a; Repellin et al. 2010; Wei-Hsin Chen and Kuo 2011; Broström et al. 2012; Cavagnol et al. 2013; Sarvaramini et al. 2013; Shang et al. 2013). The preexponential factors are 3.32E9, 1.43E11, and 2.08E14 $\mathrm{min}^{-1}$, respectively. The activation energies are 1.05E2, 1.27E2, and 1.72E2 kJ/mol respectively. This Arrhenius behavior demonstrates that the three reaction model is able to capture the temperature dynamics quite well. These kinetic parameters can be used to predict changes in rates at reaction conditions and hence control the torrefaction process and its product distribution.

The proposed model assumes that each reaction produces a group of products through a lumped kinetic rate constant, or, the unique reaction rate constant is responsible for production of all species in that reaction step. The determined kinetic parameters, then, are related to an equivalent scheme and parameters based on weight loss measurements. The two-stage Di Blasi and Lanzetta model (Colomba Di Blasi and Lanzetta 1997) has been applied to different types of feedstock include xylans (Colomba Di Blasi and Lanzetta 1997; Cavagnol et al. 2013; Nocquet et al. 2014a), woody feedstock (Branca and Di Blasi 


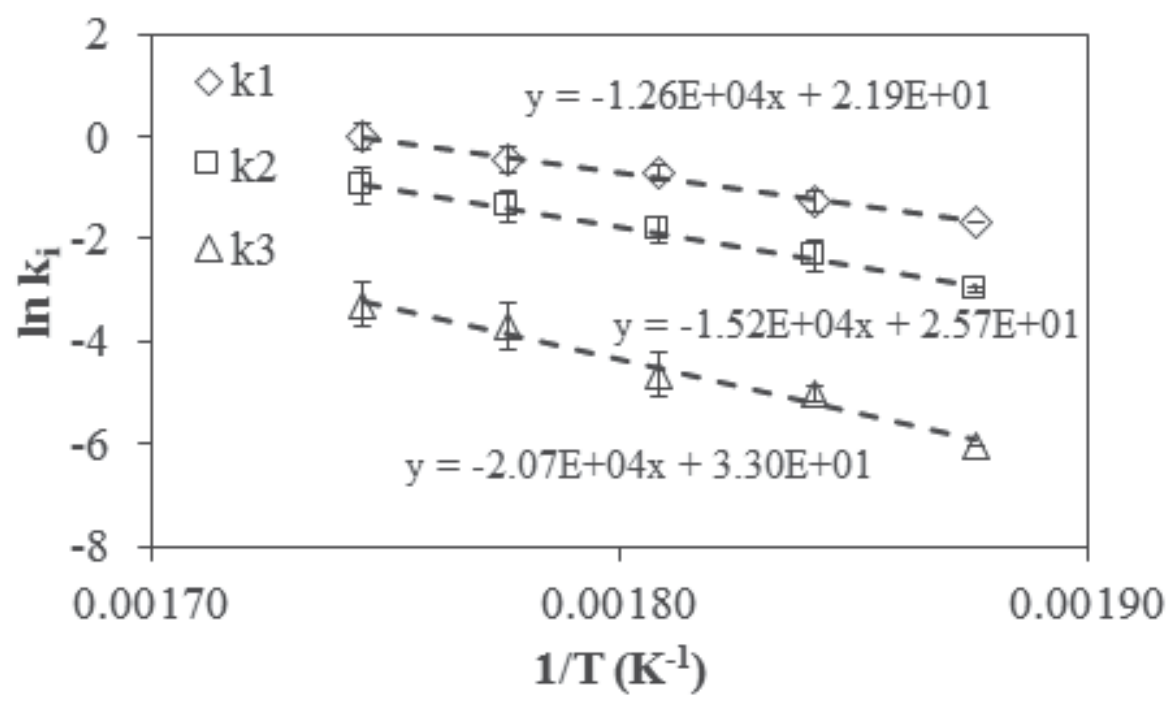

Figure 3.5: Arrhenius plot for the three reaction model at $260-300^{\circ} \mathrm{C}$.

2003; Prins et al. 2006a; Bates and Ghoniem 2012; Cavagnol et al. 2013; Ren et al. 2013; Nocquet et al. 2014a), and straws (Lanzetta and Di Blasi 1998; Shang et al. 2013). Table 3.1 shows a summary of kinetic parameters for the various feedstock. The activation energies for the three stage Branca and Di Blasi model (Branca and Di Blasi 2003; C. Di Blasi et al. 2013) were $76.2,142.8$, and $43.8 \mathrm{~kJ}$ mol-1 respectively, and the pre-exponential factors were 2.69E4, 5.91E9, and $10.0 \mathrm{~s}-1$ (1.6E6, 3.6E11, and 6.0E2 min-1) respectively. While the present study predicts higher activation energies are required for decomposition and a progressively more recalcitrant solid structure as torrefaction progresses, the overall magnitude of the parameters are similar, and should differ with biomass source.

Over the temperatures and duration of torrefaction studied, the present work has reasonably predicted the product formation of the six major gas/vapor products. This accounts for any changes, by difference, in the torrefied biomass. In addition to accurately 
Table 3.1: Kinetic parameters for various feedstocks in a two-stage degradation scheme.

\begin{tabular}{|c|c|c|c|c|c|}
\hline Feedstock & $\begin{array}{c}\text { A1 } \\
\left(\mathrm{min}^{-1}\right)\end{array}$ & $\begin{array}{c}\mathrm{A} 2 \\
\left(\mathrm{~min}^{-1}\right)\end{array}$ & $\begin{array}{c}\text { E1 } \\
(\mathrm{kJ} / \mathrm{mol})\end{array}$ & $\begin{array}{c}\mathrm{E} 2 \\
(\mathrm{~kJ} / \mathrm{mol})\end{array}$ & Source \\
\hline Xylan & $2.17 \mathrm{E} 7$ & $2.30 \mathrm{E} 4$ & 76.6 & 54.8 & $\begin{array}{c}\text { (Di Blasi and } \\
\text { Lanzetta 1997) }\end{array}$ \\
\hline Beech & $1.6 \mathrm{E} 6$ & $3.6 \mathrm{E} 11$ & 76 & 143 & $\begin{array}{c}\text { (Branca and Di } \\
\text { Blasi 2003) }\end{array}$ \\
\hline Straw & $1.46 \mathrm{E} 6$ & $3.26 \mathrm{E} 3$ & 64.6 & 47.3 & $\begin{array}{l}\text { (Lanzetta and Di } \\
\text { Blasi 1998) }\end{array}$ \\
\hline Corn stalks & $3.78 \mathrm{E} 8$ & $1.62 \mathrm{E} 5$ & 91.5 & 65.2 & $\begin{array}{l}\text { (Lanzetta and Di } \\
\text { Blasi 1998) }\end{array}$ \\
\hline Willow & $1.49 \mathrm{E} 6$ & $6.6 \mathrm{E} 11$ & 76.0 & 151.7 & $\begin{array}{c}\text { (Prins et al. 2006; } \\
\text { Bates and } \\
\text { Ghoniem 2012) }\end{array}$ \\
\hline Wheat straw & 2.09E6 & $2.60 \mathrm{E} 5$ & 71.0 & 76.6 & (Shang et al. 2013) \\
\hline
\end{tabular}

predict the observed experimental data, the predicted kinetics are repeatable and closely follow traditional Arrhenius behavior. The observed energies have a similar magnitude to values that others have obtained with similar weight-loss schemes discussed above. The activation energies proposed in this work predict that at early times the biomass structure is relatively easily broken down compared to $\operatorname{Rxn} 2$ and $\operatorname{Rxn} 3$. As torrefaction progresses, however, the subsequent reaction steps require more energy. This increase from Rxn 1 to Rxn 2, and from Rxn 2 to Rxn 3 implies that the solid intermediates are becoming progressively more recalcitrant with torrefaction severity. Heat and mass transfer effects have been shown to be negligible in previous work (Klinger et al. 2013). Therefore, the instantaneous heating rates employed are able to decrease any impacts or complications of heat ramping involved in prior TGA methods. Finally, the modeling of experimental data supports our assertion that the same global reactions are taking place over the range of 
torrefaction temperatures - or that the stoichiometric ratios of product formation are independent of temperature.

\subsubsection{Reaction Contributions in Product Profiles}

The stoichiometric coefficients obtained from our work provide a way to compare the production contributions from each reaction step. Note that the coefficients in the above mechanism are specific to each component, but independent of temperature. To more readily compare these coefficients, they are normalized to the amount of product formed from Rxn 1. These relative contributions are shown in Table 3.2. As can be seen from the table, the majority of water is produced from the first $(\alpha=1)$ and second $(\beta / \alpha=1.6)$ reactions. Very little production $(\gamma / \alpha=0.1)$ from the third reaction takes place at long times. In stark contrast to that, most compounds are only produced in significant quantities at later reaction times; for example acetic acid has small contribution from $\operatorname{Rxn} 1(\alpha=1)$, with a major contribution from $\operatorname{Rxn} 2(\beta / \alpha=12.0)$ and $\operatorname{Rxn} 3(\gamma / \alpha=14.0)$. This suggests that very careful consideration of torrefaction severity and duration is required to match the desired process outcomes with process conditions.

Table 3.2: Relative stoichiometric coefficients produced from reaction one $(\alpha)$, two $(\beta)$, and three $(\gamma) \pm$ one standard deviation.

\begin{tabular}{lrrr}
\hline Compound & $\boldsymbol{\alpha}$, Unity & $\boldsymbol{\beta}$, Norm & $\boldsymbol{\gamma}$, Norm \\
\hline $\mathrm{H}_{2} \mathrm{O}$ & $1.0 \pm 0.2$ & $1.6 \pm 0.1$ & $0.1 \pm 0.0$ \\
$\mathrm{CO}$ & $1.0 \pm 0.3$ & $3.6 \pm 0.1$ & $4.4 \pm 0.1$ \\
$\mathrm{CO}_{2}$ & $1.0 \pm 0.1$ & $1.7 \pm 0.1$ & $4.5 \pm 0.1$ \\
$\mathrm{HCOOH}$ & $1.0 \pm 0.1$ & $3.4 \pm 0.2$ & $4.7 \pm 0.3$ \\
$\mathrm{CH}_{3} \mathrm{COOH}$ & $1.0 \pm 0.1$ & $12.0 \pm 0.5$ & $14.0 \pm 0.7$ \\
$\mathrm{OC}_{4} \mathrm{H}_{3} \mathrm{CHO}$ & $1.0 \pm 0.2$ & $5.9 \pm 0.3$ & $6.0 \pm 0.4$ \\
\hline
\end{tabular}


If these results are examined through the lens of an anticipated product distribution, the relationship between weight loss, product evolution, and product characteristics can be realized. It is known that the gas phase products are comprised mostly of water, acetic acid, and $\mathrm{CO}_{2}$ (for example Ref (Boardman et al. 2011) indicated for willow the products are $89.3 \%$ water, $4.8 \%$ acetic acid, and $3.3 \% \mathrm{CO}_{2}$; other literature values are in the same magnitude but differ slightly with biomass source). Using our stoichiometric parameters and the product distribution of Ref (Boardman et al. 2011), the product evolution profiles were found and are shown in Figure 3.6. If total weight loss is examined alone, it would appear that only a few minutes are required to complete the majority of the torrefaction process. However, an examination of the chemical species evolution reveals that long processing times are required to evolve carboxylic and other group compounds. Removal of these groups from the raw biomass is required for the biocoal to resemble the characteristics of fossil coal (Panshin and deZeeuw 1980; Bergman 2005; Bridgeman et al. 2010; Chew and Doshi 2011; Ciolkosz and Wallace 2011; van der Stelt et al. 2011). Similar delayed feedstock decomposition and gaseous/vapor evolution profiles have been previously observed, but not modeled or extensively characterized (Branca and Di Blasi 2003; Prins et al. 2006a; Bridgeman et al. 2008; Bates and Ghoniem 2012). It is our 


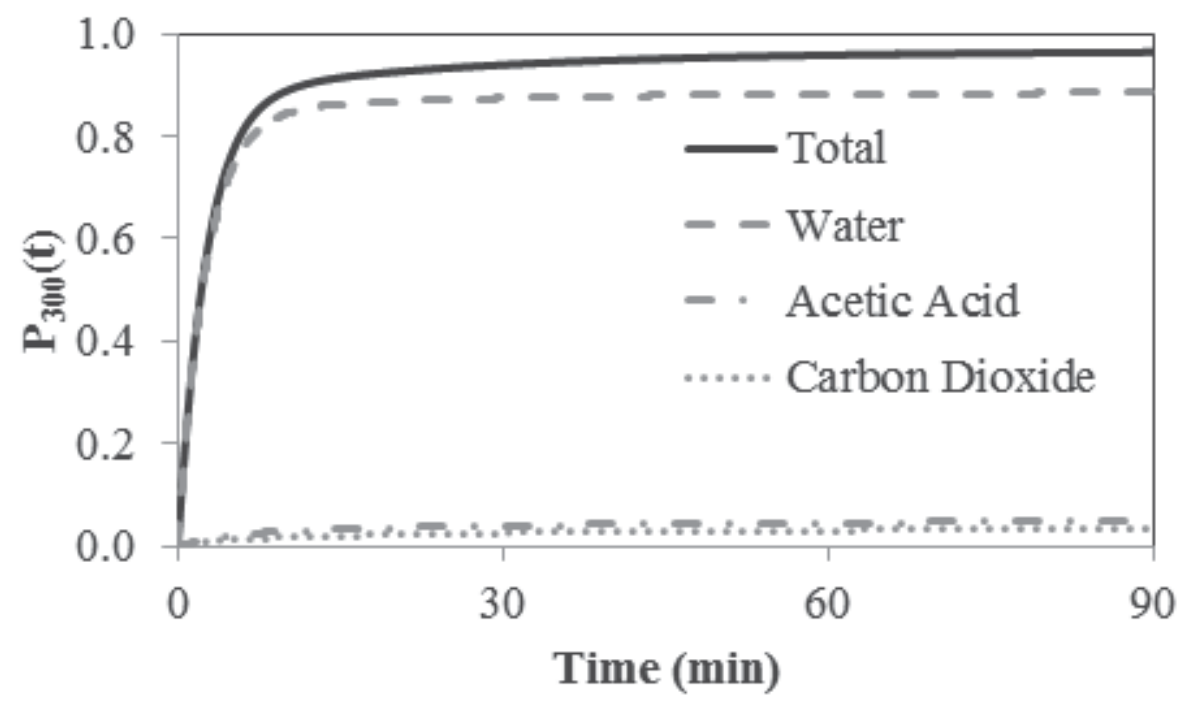

Figure 3.6: Total product profiles for water, acetic acid and carbon dioxide with a product distribution.

assertion here, and from our previous study (Klinger et al. 2013), that while these late-time degradation steps may appear negligible from a weight loss viewpoint, they are an important consideration consisting of removing primary organics. These longer reaction times lead to preferable changes in torrefied biomass properties. 


\subsection{Conclusions}

This study demonstrates that the three step model can accurately predict gas-phase product kinetics over the initial stages of torrefaction (up to 30\% mass loss) from 260$300^{\circ} \mathrm{C}$. The pre-exponential factors obtained were 3.32E9, 1.43E11, and 2.08E14min ${ }^{-1}$, and the activation energies were $1.05 \mathrm{E} 2,1.27 \mathrm{E} 2$, and $1.72 \mathrm{E} 2 \mathrm{~kJ} / \mathrm{mol}$ for the three reactions, respectively. At early times, the evolution of chemically formed water dominates, while later times are required to remove the organic compounds such as acetic acid. Understanding torrefaction product evolution may lead to better prediction of product quality from varying or non-isothermal processing conditions, a topic to be investigated in future work. 


\subsection{Works Cited}

Bates RB, Ghoniem AF. 2012. Biomass torrefaction: Modeling of volatile and solid product evolution kinetics. Bioresource Technology 124(0):460-469.

Bergman PCA. 2005. Combined torrefaction and pelletisation, the TOP process. ECN Biomass, DEN programme of SenterNovem, Dutch Ministry of Economic Affairs, Report ECN-C-05-073.

Boardman RD, Hess JR, Sokhansanj S, Tumuluru JS, Wright CT. 2011. A review on biomass torrefaction process and product properties for energy applications. Industrial Biotechnology 7(5):384+.

Branca C, Di Blasi C. 2003. Kinetics of the isothermal degradation of wood in the temperature range 528-708 K. Journal of Analytical and Applied Pyrolysis 67(2):207-219.

Bridgeman TG, Jones JM, Shield I, Williams PT. 2008. Torrefaction of reed canary grass, wheat straw and willow to enhance solid fuel qualities and combustion properties. Fuel 87(6):844-856.

Bridgeman TG, Jones JM, Williams A, Waldron DJ. 2010. An investigation of the grindability of two torrefied energy crops. Fuel 89(12):3911-3918.

Broström M, Nordin A, Pommer L, Branca C, Di Blasi C. 2012. Influence of torrefaction on the devolatilization and oxidation kinetics of wood. Journal of Analytical and Applied Pyrolysis 96(0):100-109. 
Cavagnol S, Sanz E, Nastoll W, Roesler JF, Zymla V, Perré P. 2013. Inverse analysis of wood pyrolysis with long residence times in the temperature range 210290\&\#xa0; ${ }^{\circ} \mathrm{C}$ : Selection of multi-step kinetic models based on mass loss residues. Thermochimica Acta 574(0):1-9.

Chen W-H, Kuo P-C. 2011. Isothermal torrefaction kinetics of hemicellulose, cellulose, lignin and xylan using thermogravimetric analysis. Energy 36(11):6451-6460.

Chen Y, Yang H, Yang Q, Hao H, Zhu B, Chen H. 2014. Torrefaction of agriculture straws and its application on biomass pyrolysis poly-generation. Bioresource Technology $156(0): 70-77$.

Chew JJ, Doshi V. 2011. Recent advances in biomass pretreatment - Torrefaction fundamentals and technology. Renewable and Sustainable Energy Reviews 15(8):4212-4222.

Ciolkosz D, Wallace R. 2011. A review of torrefaction for bioenergy feedstock production. Biofuels, Bioproducts and Biorefining 5(3):317-329.

Couhert C, Salvador S, Commandré JM. 2009. Impact of torrefaction on syngas production from wood. Fuel 88(11):2286-2290.

Deng J, Wang G-j, Kuang J-h, Zhang Y-1, Luo Y-h. 2009. Pretreatment of agricultural residues for co-gasification via torrefaction. Journal of Analytical and Applied Pyrolysis 86(2):331-337. 
Di Blasi C, Lanzetta M. 1997. Intrinsic kinetics of isothermal xylan degradation in inert atmosphere. Journal of Analytical and Applied Pyrolysis 40-41(0):287-303.

Di Blasi C, Branca C, Masotta F, De Biase E. 2013. Experimental Analysis of Reaction Heat Effects during Beech Wood Pyrolysis. Energy \& Fuels 27(5):2665-2674.

DOE/EIA. 2011. Report DOE/EIA-0484(2011). U.S. Energy Information Administration.

EIA. 2010. Annual Energy Projections with Projections to 2035, Report \#: DOE/EIA0383(2010). Report \#: DOE/EIA-0383.

Klinger J, Bar-Ziv E, Shonnard D. 2013. Kinetic study of aspen during torrefaction. Journal of Analytical and Applied Pyrolysis 104(0):146-152.

Lanzetta M, Di Blasi C. 1998. Pyrolysis kinetics of wheat and corn straw. Journal of Analytical and Applied Pyrolysis 44(2):181-192.

Nocquet T, Dupont C, Commandre J-M, Grateau M, Thiery S, Salvador S. 2014a. Volatile species release during torrefaction of biomass and its macromolecular constituents: Part 2 - Modeling study. Energy 72(0):188-194.

Nocquet T, Dupont C, Commandre J-M, Grateau M, Thiery S, Salvador S. 2014b. Volatile species release during torrefaction of wood and its macromolecular constituents: Part 1 - Experimental study. Energy 72(0):180-187.

Pach M, Zanziand R, Björnbom E. 2002. Torrefied Biomass a Substitute for Wood and Charcoal. 6th Asia-Pacific International Symposium on Combustion and Energy Utilization. Kuala Lumpur, Malaysia. 
Panshin AJ, deZeeuw C. 1980. Textbook of wood technology. New York: McGraw-Hill Book Company.

Phanphanich M, Mani S. 2011. Impact of torrefaction on the grindability and fuel characteristics of forest biomass. Bioresource Technology 102(2):1246-1253.

Prins MJ, Ptasinski KJ, Janssen FJJG. 2006a. Torrefaction of wood: Part 1. Weight loss kinetics. Journal of Analytical and Applied Pyrolysis 77(1):28-34.

Prins MJ, Ptasinski KJ, Janssen FJJG. 2006b. Torrefaction of wood: Part 2. Analysis of products. Journal of Analytical and Applied Pyrolysis 77(1):35-40.

Ren S, Lei H, Wang L, Bu Q, Chen S, Wu J. 2013. Thermal behaviour and kinetic study for woody biomass torrefaction and torrefied biomass pyrolysis by TGA. Biosystems Engineering 116(4):420-426.

Repellin V, Govin A, Rolland M, Guyonnet R. 2010. Modelling anhydrous weight loss of wood chips during torrefaction in a pilot kiln. Biomass and Bioenergy 34(5):602609.

Sarvaramini A, Assima GP, Larachi F. 2013. Dry torrefaction of biomass - Torrefied products and torrefaction kinetics using the distributed activation energy model. Chemical Engineering Journal 229(0):498-507.

Shafizadeh F, Chin PPS. 1977. Thermal Deterioration of Wood. Wood Technology: Chemical Aspects. AMERICAN CHEMICAL SOCIETY. p. 57-81. 
Shang L, Ahrenfeldt J, Holm JK, Sanadi AR, Barsberg S, Thomsen T, Stelte W, Henriksen UB. 2012. Changes of chemical and mechanical behavior of torrefied wheat straw. Biomass and Bioenergy 40(0):63-70.

Shang L, Ahrenfeldt J, Holm JK, Barsberg S, Zhang R-z, Luo Y-h, Egsgaard H, Henriksen UB. 2013. Intrinsic kinetics and devolatilization of wheat straw during torrefaction. Journal of Analytical and Applied Pyrolysis 100(0):145-152.

van der Stelt MJC, Gerhauser H, Kiel JHA, Ptasinski KJ. 2011. Biomass upgrading by torrefaction for the production of biofuels: A review. Biomass and Bioenergy 35(9):3748-3762.

Yang H, Yan R, Chen H, Lee DH, Zheng C. 2007. Characteristics of hemicellulose, cellulose and lignin pyrolysis. Fuel 86(12-13):1781-1788. 


\section{Application of a Kinetic Torrefaction Model}

Reprinted with permission from KLINGER J, BAR-ZIV E, SHONNARD D. 2014. PREDICTING PROPERTIES OF TORREFIED BIOMASS BY INTRINSIC KINETICS. ENERGY \& FUELS 29(1):171-176. Copyright 2014 American Chemical Society. ${ }^{3}$

\subsection{Abstract}

Power generation facilities are under constant pressure to comply with increasingly stringent environmental regulations - namely coal utilities. One possibility to aid in compliance is through the use of torrefied biomass as a replacement or supplement for traditional fossil coal. To get continuous understanding of the changes to biomass as it is torrefied, a three stage chemical reaction model with intrinsic rate coefficients was used. This gas/vapor phase model predicts the evolution of primary torrefaction products, and was further used to predict changes in elemental composition and energy content of torrefied biomass. From the model, over the typical torrefaction region (up to $\sim 25-30 \%$ mass loss) the relative amount of carbon in increased by approximately $9 \%$, the oxygen decreased approximately $10 \%$, and the hydrogen content was relatively unchanged. The material retained $90 \%$ of the original available energy, and the higher heating value

\footnotetext{
${ }^{3}$ The material contained in this chapter was previously published in Energy \& Fuels.
} 
increased by $22.5 \%$ from 19.1 to $23.4 \mathrm{MJ} / \mathrm{kg}$. These properties were modeled as a function of mass loss and correspond well to values measured by others for woody feedstock (mean error of $1.7 \%$ for carbon, $0.28 \%$ for hydrogen, and $2.4 \%$ for oxygen).

\subsection{Introduction}

Electric utilities in the United States are experiencing many changes in fuel sources and generation methods due to changes in the economic climate and fuel costs, and the recent legislation and regulatory mandates(Conti et al. 2014). Major impacts include lower natural gas prices from increase shale gas utilization, implementation in 2015 of strict Mercury and Air Toxics Standards (MATS) based on Maximum Achievable Control Technology (MACT) for units larger than $25 \mathrm{MW}$, and ongoing Renewable Fuel Standards (RFS) and state specific Renewable Portfolio Standards (RPS), to name a few(Conti et al. 2014). Yet, a significant portion of the power industry is currently dependent on solid fuel boilers - and these in-turn are almost exclusively designed to operate on pulverized coals(Broström et al. 2012). In order to retain this massive infrastructure, a fuel needs to be directly substituted for coal, providing an uninterrupted stable baseload power supply. Biomass is the only choice for a renewable, baseload substitute for coal(D. Medic et al. 2012a). Biomass was investigated in co-firing situations in utility boilers, and as feedstock for other energy methods such as gasification(Ayhan 2008; Dai et al. 2008; Couhert et al. 2009; Bar-Ziv and Chudnovsky 2011; Phanphanich and Mani 2011; Reichling and Kulacki 2011; Yin et al. 2012). However, biomass has poor fuel properties when compared to coal such as decreased bulk density, energy density, grindability, hydrophobicity, an increased 
moisture content, and is subject to microbial degradation(Devi et al. 2003; Bergman 2005; Prins et al. 2007; Bridgeman et al. 2008; Phanphanich and Mani 2011; Broström et al. 2012; Sarvaramini et al. 2013; Sarvaramini and Larachi 2014). These properties lead to issues all along the logistics and operation chain, and at best lead to de-rating of the boilers.

To directly address these issues, torrefaction of biomass is under heavy investigation as a pretreatment stage. Torrefaction typically occurs around $200-300^{\circ} \mathrm{C}$, and initially degrades the hemicellulose fraction of biomass in an oxygen-free atmosphere(Yang et al. 2007; Chew and Doshi 2011; Ciolkosz and Wallace 2011; Stelte et al. 2011; Dorde Medic et al. 2012b)). Some work has shown through fiber analysis that at high torrefaction temperatures $\left(>280^{\circ} \mathrm{C}\right)$, larger portions of the cellulose and lignin begin to degrade(Zheng et al. 2012; Khazraie Shoulaifar et al. 2014) while others show very little relative change(Chang et al. 2012). With increasing torrefaction severity, energy density, hydrophobicity are also greatly increased while stopping microbial activity and reducing moisture content and size reduction requirements significantly(Bergman 2005; Arias et al. 2008; Bridgeman et al. 2008; Bridgeman et al. 2010; Boardman et al. 2011; Wei-Hsin Chen et al. 2011b; Phanphanich and Mani 2011; van der Stelt et al. 2011; D. Medic et al. 2012a; Dorde Medic et al. 2012b). Further, the volatile gases and organics formed during torrefaction can be combusted for energy during the process, making it self-sustaining on an energy basis beyond the initial start-up(Bates and Ghoniem 2013; Ohliger et al. 2013; Sarvaramini and Larachi 2014). Because of these direct improvements to fuel properties, torrefied biomass is a promising drop-in fuel substitute and many groups have detailed proximate/ultimate property improvements for various feedstocks and torrefaction 
severities(Arias et al. 2008; Bridgeman et al. 2008; Couhert et al. 2009; Qing Chen et al. 2011a; Wei-Hsin Chen et al. 2011b; Phanphanich and Mani 2011; Wannapeera et al. 2011; Bates and Ghoniem 2012; Broström et al. 2012; Carrasco et al. 2013; Sarvaramini et al. 2013; Sarvaramini and Larachi 2014). The collection of empirical data can give indications of optimum torrefaction conditions, but because the process is specific to the raw feedstock, temperature, and residence time among others, a comprehensive understanding or engineering model of torrefaction is required to make informed process decisions(Bridgeman et al. 2008; Wannapeera et al. 2011; Bates and Ghoniem 2012; 2013).

Several attempts have been made to correlate torrefaction properties with process conditions to gain insight into the process. Medic et al., correlated temperature and feedstock moisture as independent variables to predict mass loss and energy yield with a quadratic surface methodology for corn stover(D. Medic et al. 2012a). Almeida et al., used mass loss in linear regressions to predict changes in fixed carbon (and thereby volatile matter), and gross calorific value (and thereby energy yield) for three species of eucalyptus wood and bark(Almeida et al. 2010). Lee et al., also used a response surface methodology to correlate torrefaction severity (time and temperature) to weight loss, energy value, and energy yield for mixed softwoods(Lee et al. 2012). These empirical data correlations performed well for their respective feedstock, but were not used or extended as predictive for additional feedstock. Because the work is purely empirical and not based from a fundamental understanding as discussed above, it is likely that new empirical data would have to be collected to adjust the correlations for additional feedstock. 
Bates and Ghoniem combined a weight-loss kinetic model with expected product distributions from torrefaction to understand and predict changes in volatile yield (gas and vapor), and changes in elemental composition as a function of mass loss(Bates and Ghoniem 2012). They established reasonable agreement when compared to separate mixed feedstock literature data. This was further developed to include thermochemistry predictions for torrefaction, and modeled heating value, solid energy yield, and heat of reaction as functions of weight loss(Bates and Ghoniem 2013). The kinetic model and product distribution used in their work, however, were generated from discrete product measurements (up to approximately $33 \%$ mass loss) and were derived from thermogravimetric analysis (TGA) using slow heating rates.

Previously, our group proposed a chemical kinetics model that examined the gasphase kinetics of torrefaction(Klinger et al. 2013). This model consists of three consecutive reactions, and is based on the transient evolution of six major torrefaction products: water, carbon monoxide, carbon dioxide, acetic acid, formic acid, and furfural. The model is summarized in stages below (Rxn $1-$ Rxn 3). Close agreement between the model and experimental data was found over the first 90 minutes of $300^{\circ} \mathrm{C}$ torrefaction. In later work, the kinetics were examined over a range of torrefaction temperatures from $260-300^{\circ} \mathrm{C}$ and the model parameters were further refined(Klinger et al. 2014). 


$$
\begin{aligned}
& H \stackrel{k_{1}}{\rightarrow} R_{1}+\sum_{i} \alpha_{i} P_{i} \\
& R_{1} \stackrel{k_{2}}{\rightarrow} R_{2}+\sum_{i} \beta_{i} P_{i} \\
& R_{2} \stackrel{k_{3}}{\rightarrow} C+\sum_{i} \gamma_{i} P_{i}
\end{aligned}
$$

In the model, the parent material $\left(H\right.$, hemicellulose) degrades (with constant $\left.k_{l}\right)$ to form a solid intermediate $\left(R_{1}\right)$ and a group of $\operatorname{products}\left(P_{i, 1}\right)$ with a reaction stoichiometry factor $\left(\alpha_{i}\right)$. This solid intermediate then degrades to form a secondary solid intermediate $\left(R_{2}\right)$ and more volatile $\operatorname{products}\left(P_{i, 2}\right)$ with rate constant $\left(k_{2}\right)$. This intermediate then degrades in-turn to form the final torrefied biomass and volatile products $\left(P_{i, 3}\right)$ with reaction constant $\left(k_{3}\right)$. The water $(18 \mathrm{~m} / \mathrm{z})$, carbon monoxide $(28 \mathrm{~m} / \mathrm{z})$, carbon $\operatorname{dioxide}(44 \mathrm{~m} / \mathrm{z})$, acetic $\operatorname{acid}(60 \mathrm{~m} / \mathrm{z})$, formic $\operatorname{acid}(29 \mathrm{~m} / \mathrm{z})$, and furfural $(95 \mathrm{~m} / \mathrm{z})$ transients were recorded from a mass spectrum signal. The kinetic parameter for the three reactions were 3.32E9, 1.43E11, and 2.08E14min-1 for the pre-exponential factors, and 1.05E2, 1.27E2, and $1.72 \mathrm{E} 2 \mathrm{~kJ} / \mathrm{mol}$ for the activation energies respectively(Klinger et al. 2014). It is important to note that this model assumes that the same intrinsic reactions are responsible for mass-loss from product detachment at all temperatures, and changes in temperature only affect the rates of reaction.

This paper examines the use of the intrinsic kinetics model to predict the resulting properties of the torrefied biomass fuel, and was further validated by accurate prediction of properties across a wide range of woody biomass materials. The product detachment model is a fundamental approach that is decoupled from heat and mass transfer 
effects. These intrinsic and fundamental results can then be used to predict non-isothermal conditions and, with inclusion of heat and mass transfer effects, to industrial scale processes. Future extensions of this approach are also examined.

\subsection{Material and Methods}

The previous development of the three-stage torrefaction model was based on dry, debarked aspen wood(Klinger et al. 2013; Klinger et al. 2014). The material was dried at $105^{\circ} \mathrm{C}$ to remove any moisture, and sized to approximately $0.5-0.6 \mathrm{~mm}$. The wood particles ranged from $0.5-3.0 \mathrm{~mm}$ in length. The total sample mass was on the order of $100 \mu \mathrm{g}$. Torrefaction experiments (5200HP Pyroprobe, CDS Analytical) were carried out with high heating rates $\left(1000^{\circ} \mathrm{C} / \mathrm{s}\right)$ for the first 90 minutes of torrefaction. Gas and vapor products were measured and recorded with an in-line GC/MS system (Trace GC Ultra, DSQII mass spectrometer, ThermoFisher). Full description on the modeling process is available in the previous work(Klinger et al. 2013; Klinger et al. 2014).

\subsubsection{Product Distribution and Mass Loss}

From the chemical transients obtained from the MS signals, the production rate dynamics of torrefaction products are known. These signals can then be integrated to obtain the total production of the various compounds with respect to torrefaction time. Production rate profiles (at $300^{\circ} \mathrm{C}$ ) normalized to unity and their respective product evolution profiles and normalized to their total production values are shown in Figure 4.1. These profiles were constructed from kinetic/modeling parameters fit from measurements 
in our earlier studies(Klinger et al. 2013; Klinger et al. 2014). Beyond initial times, the production rates of the volatile species appear to be decreasing monotonically. Most compounds studied originated from the hemicellulose fraction of the biomass, and their rates of production approach zero near the 90 minute torrefaction time. The most notable differences occur in water and acetic acid. Water produced much quicker than the other compounds, and subsequently account for the majority of mass loss at early times. Conversely, acetic acid has a relatively low production rate at early times and has a longer sustained production at later times. Like acetic acid, the remaining compounds (formic acid, carbon dioxide, carbon monoxide, and furfural) also have delayed production when compared to water.

These delayed profile observations are also supported in the tabulated data for the stoichiometric coefficients in Table 4.1(Klinger et al. 2014). Note that the values presented here are normalized to the value of $\alpha$, or the production amount attributed to the first reaction. In addition, these parameters were not calibrated and therefore cannot be directly compared between species. These parameters are indicative, though, of the relative distribution of product formation between the three reaction steps. Using this intra-species comparative approach, a distribution between early and late time production can be observed.

In order for the model to yield quantitative results, the volatile production values need to be calibrated. Prins et al. detailed volatile product weight fractions during torrefaction of willow at several times and temperatures, and spanning approximately 9367\% mass yields(Prins et al. 2006a; 2006b). Using these empirical volatile weight fractions 

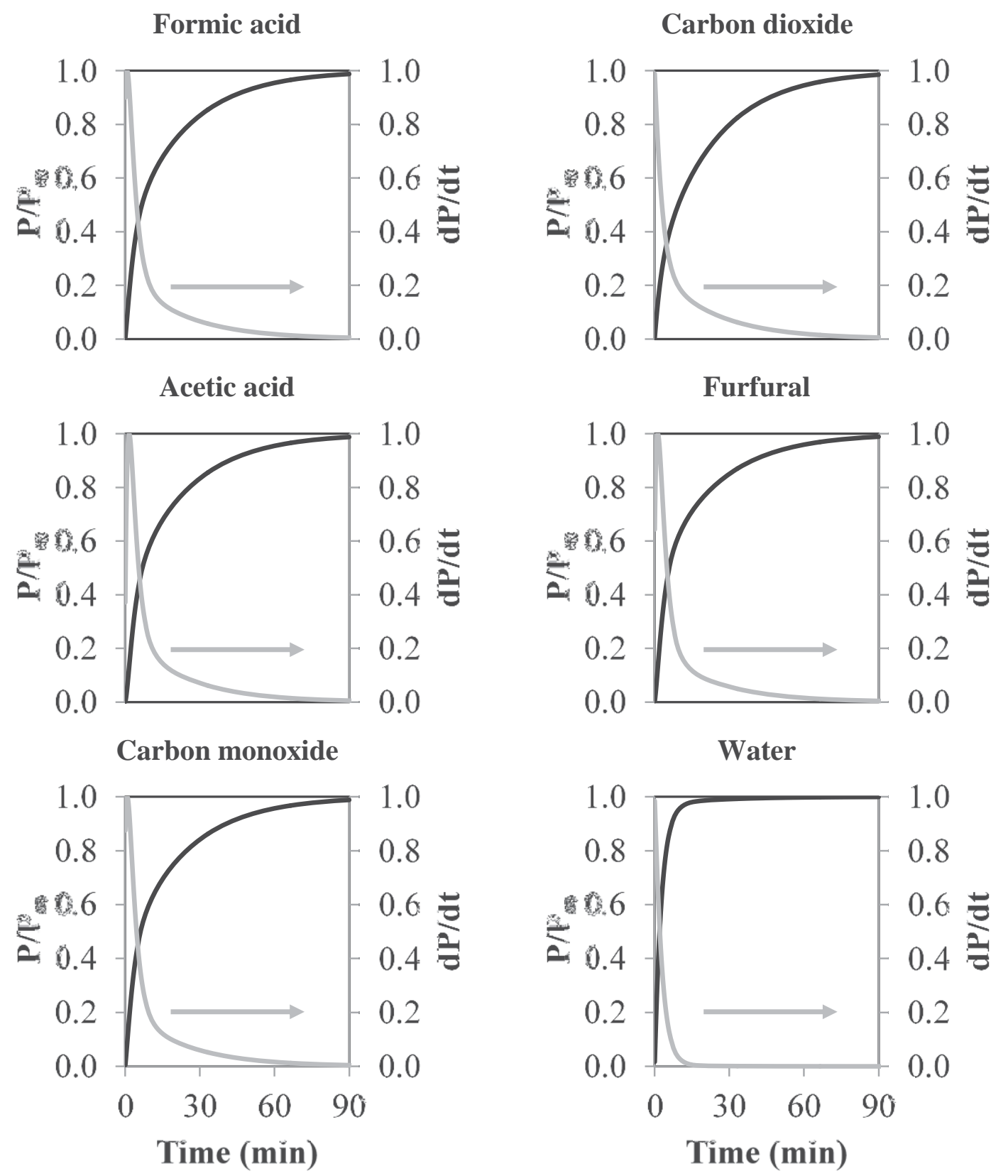

Figure 4.1: Production rate profiles and total product profiles for torrefaction products. 
Table 4.1: Stoichiometric coefficients used in the kinetic model(Klinger et al., 2014).

\begin{tabular}{lccc}
\hline Compound & $\boldsymbol{\alpha}$ & $\boldsymbol{\beta}$ & $\boldsymbol{\gamma}$ \\
\hline Water & 1.0 & 1.6 & 0.1 \\
Carbon monoxide & 1.0 & 3.6 & 4.4 \\
Carbon dioxide & 1.0 & 1.7 & 4.5 \\
Formic acid & 1.0 & 3.4 & 4.7 \\
Acetic acid & 1.0 & 12.0 & 14.0 \\
Furfural & 1.0 & 5.9 & 6.0 \\
\hline
\end{tabular}

along with the respective product formation predictions from the present model, calibration curves were constructed to estimate a product distribution at any torrefaction severity. These calibration relations are shown in Figure 4.2. The most abundant products, then, are water and carbon dioxide, followed by acetic acid. Using these calibration values in the kinetic model yields a dynamic gas-phase removal signal of these species on a mass basis, and by difference, the mass loss observed in the biomass.

\subsubsection{Elemental Composition and Heating Value}

Recent literature was surveyed to collect elemental composition, heating value, and mass and energy yield data for a comparison base for the torrefaction model prediction of elemental changes and energy densification(Pach et al. 2002; Bridgeman et al. 2008; Phanphanich and Mani 2011; Wannapeera et al. 2011; Broström et al. 2012; Sarvaramini et al. 2013; Sarvaramini and Larachi 2014). This literature data ranged from $200-310^{\circ} \mathrm{C}$ torrefaction, and represented 8-900 minute residence times. The scope for comparison with the model was narrowed to only include woody biomass sources over a mass loss of up to $30 \%$. To directly compare to these empirical data, the mass-calibrated kinetic model was converted to predict elemental composition by performing an elemental balance. The 


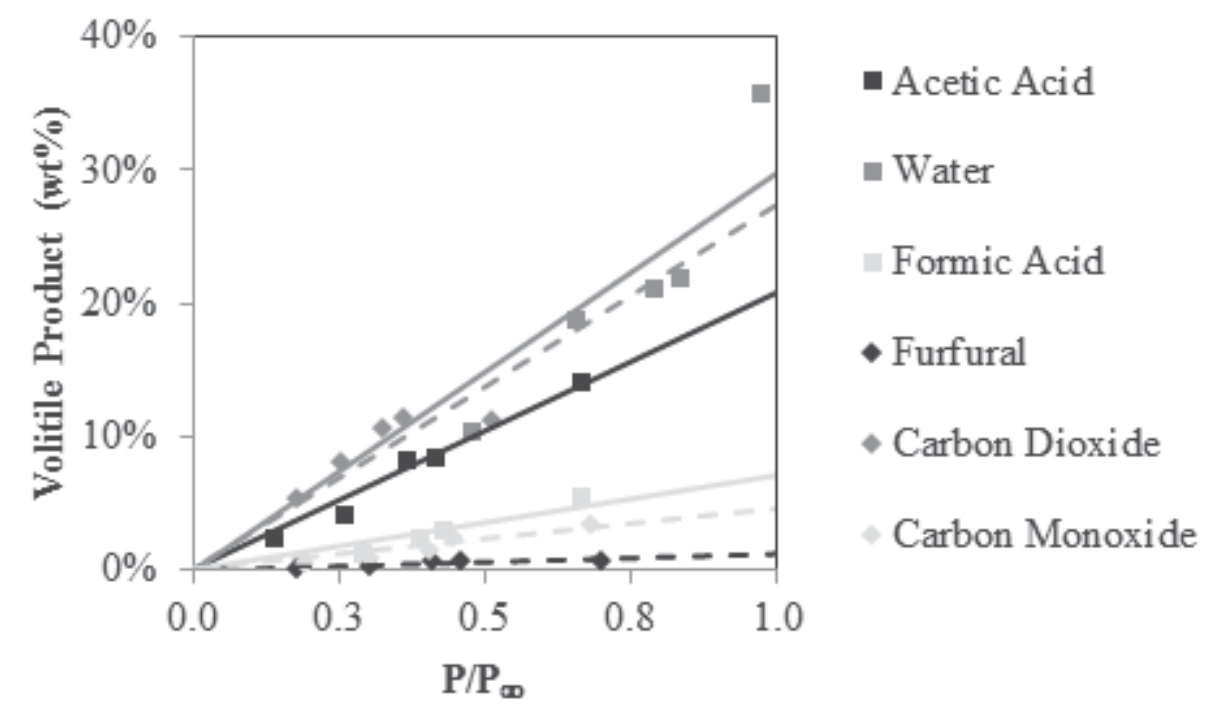

Figure 4.2: Model calibration of volatile product yield. Solid linear trends are paired with series with square markers and dash linear trends are paired with diamond series. Experimental data from (Prins et al., 2006a,b).

elemental compositions of the predicted gas/vapor products were removed from the initial biomass composition (average of $48 \%$ carbon, $6 \%$ hydrogen, and $45 \%$ oxygen from literature), resulting in a torrefied biomass composition by difference. Knowing the elemental composition can lead to estimates of the fuel's heating value, and the potential improvements of torrefaction.

Friedl et al., examined 154 different biomass samples in their development and discussion of an empirical relationship to estimate the heating value of biomass from elemental composition(Friedl et al. 2005). They determined that the best correlation across a subset of 122 samples was $H H V=3.55 C^{2}-232 C-2230 H+51.2 C \times H+131 N+$ 20600 where $\mathrm{C}, \mathrm{H}$, and $\mathrm{N}$ are the elemental weight percent contributions from carbon, hydrogen, and nitrogen, and HHV is expressed in $\mathrm{kJ} / \mathrm{kg}$. This correlation was chosen for 
this study due to its demonstrated robustness for varying feedstock. When this correlation is coupled with the elemental composition discussed above, the HHV for the torrefied material was calculated directly. Other heating value correlations for coal and other alternative solid fuels were tested and found to predict values within $1.0 \%$ difference(Gumz and Hardt 1962; Kathiravale et al. 2003). Process energy yield, or energy retained in the solid material, was calculated as $E Y=\left(m_{p} / m_{0}\right)\left(H H V_{p} / H H V_{0}\right)$ where $m_{p}$ and $m_{0}$ are the mass of the product and original material, and $H H V_{p}$ and $H H V_{0}$ are the higher heating values of the product and original material respectively.

\subsection{Results and Discussion}

\subsubsection{Modeling Torrefied Biomass Properties}

After the kinetic model was calibrated to predict mass loss and elemental composition, it was interpreted and compared against similar literature data. Figure 4.3 shows the comparison between model predictions for changes in absolute and relative elemental composition. The model predicts that the initial $26.5 \%$ mass loss is comprised of a $5.9 \%$ mass loss from carbon (48.0 to $42.1 \%$ ), a $19.1 \%$ mass loss from oxygen (45.0 to $25.9 \%)$, and a $1.5 \%$ mass loss from hydrogen $(6.0$ to $4.5 \%)$. On a relative elemental mass basis, the carbon increases from $48 \%$ to approximately $57 \%$, oxygen decreases from $45 \%$ to approximately $35 \%$, and hydrogen first decreases from the initial $6 \%$, but has a slight inflection and arrives back around 6\%. This represents an increase in $\mathrm{C} / \mathrm{O}$ ratio from approximately 1.1 to 1.6 , and an increase in $\mathrm{H} / \mathrm{O}$ ratio from 2.1 to 2.7 . On a mass basis, 

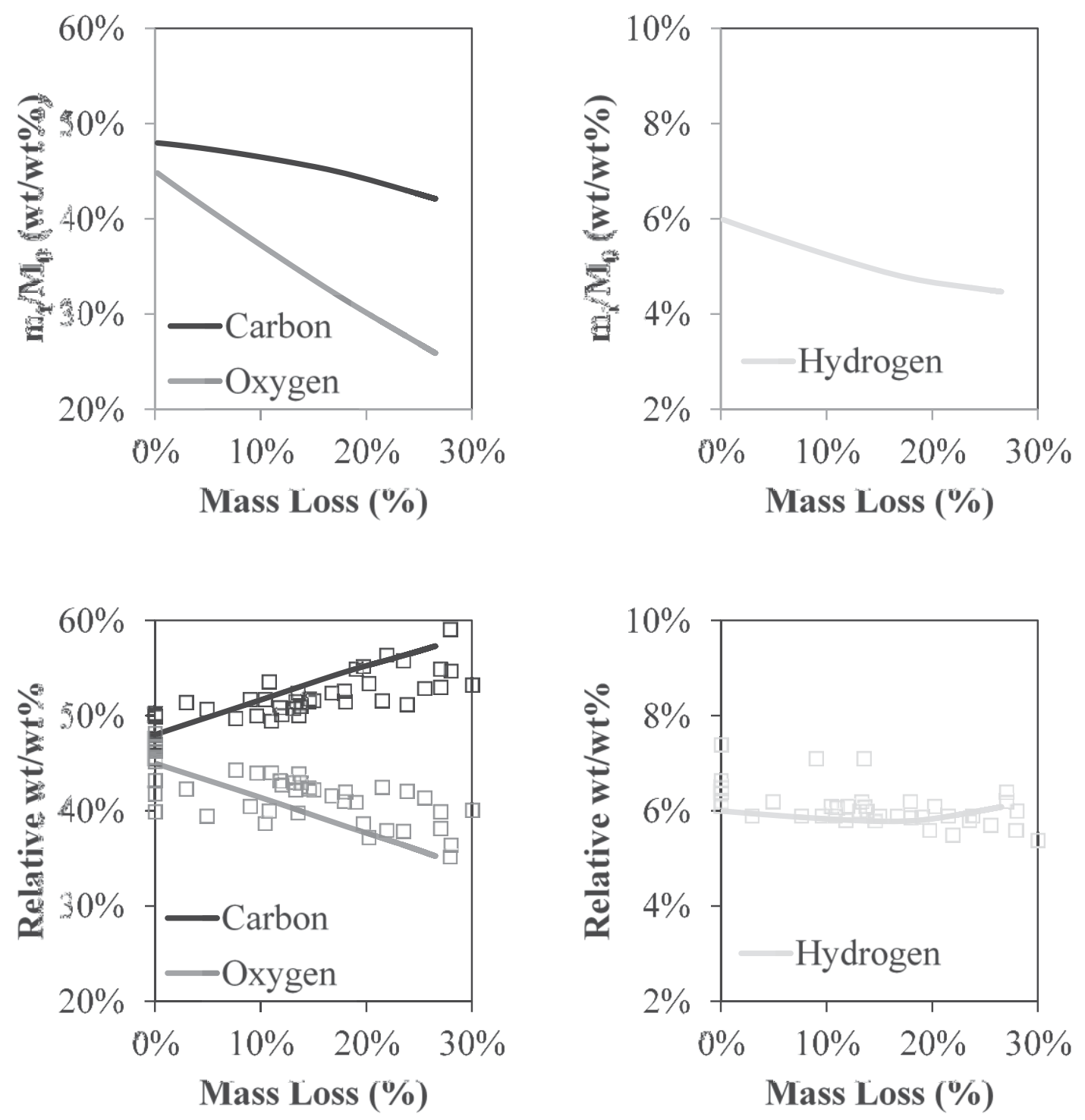

Figure 4.3: Model predictions (solid lines) of absolute elemental mass loss(top), and changes in relative elemental composition with comparison to literature data(bottom). Experimental data are represent by data points from (Pach et al. 2002; Bridgeman et al. 2008; Phanphanich and Mani 2011; Wannapeera et al. 2011; Broström et al. 2012; Sarvaramini et al. 2013; Sarvaramini and Larachi 2014).

the relative loss of oxygen is paired with a nearly mirrored relative increase in carbon. This relative decrease in oxygen is due to high relative oxygen content in the detached products. As discussed earlier, the major torrefaction products are water, carbon dioxide, and acetic 
acid, making oxygen and hydrogen released more when compared on a simple molar(or mass) basis. The model's inflection prediction in hydrogen content is due to a large initial decrease, due to the production of water, and a much slower hydrogen loss after approximately $20 \%$ mass loss relative to continued loss of oxygen. When compared to literature, the model predictions are well within the spread of corresponding empirical torrefaction data for woody biomass. The relative carbon projection estimates values slightly higher than those measured, and conversely the oxygen trend is slightly low. In addition, both traces have slopes that are slightly more aggressive than the empirical centerlines. Overall the model's prediction has a mean absolute error of $1.7 \%$ for carbon, $0.28 \%$ for hydrogen, and $2.4 \%$ for oxygen.

The elemental predictions were then translated to predictions in heating value of the torrefied material and compared to literature data in Figure 4.4. The HHV predictions closely follow the trend of relative carbon increase. The trend fits well within the experimental data, but has a slightly higher prediction then the data centerline due to slightly higher carbon prediction (or slightly lower oxygen projections). If these heating values are coupled with mass loss into the energy yield, or energy retained by the solid material, the prediction is again within the experimental spread but estimated slightly above the data centerline. The mean absolute error was $1.4 \mathrm{MJ} / \mathrm{kg}$ for the prediction of energy density, and $2.9 \%$ for the energy yield. Over the initial $26.5 \%$ mass loss, approximately $90 \%$ of the initial energy is still present in the torrefied material. 

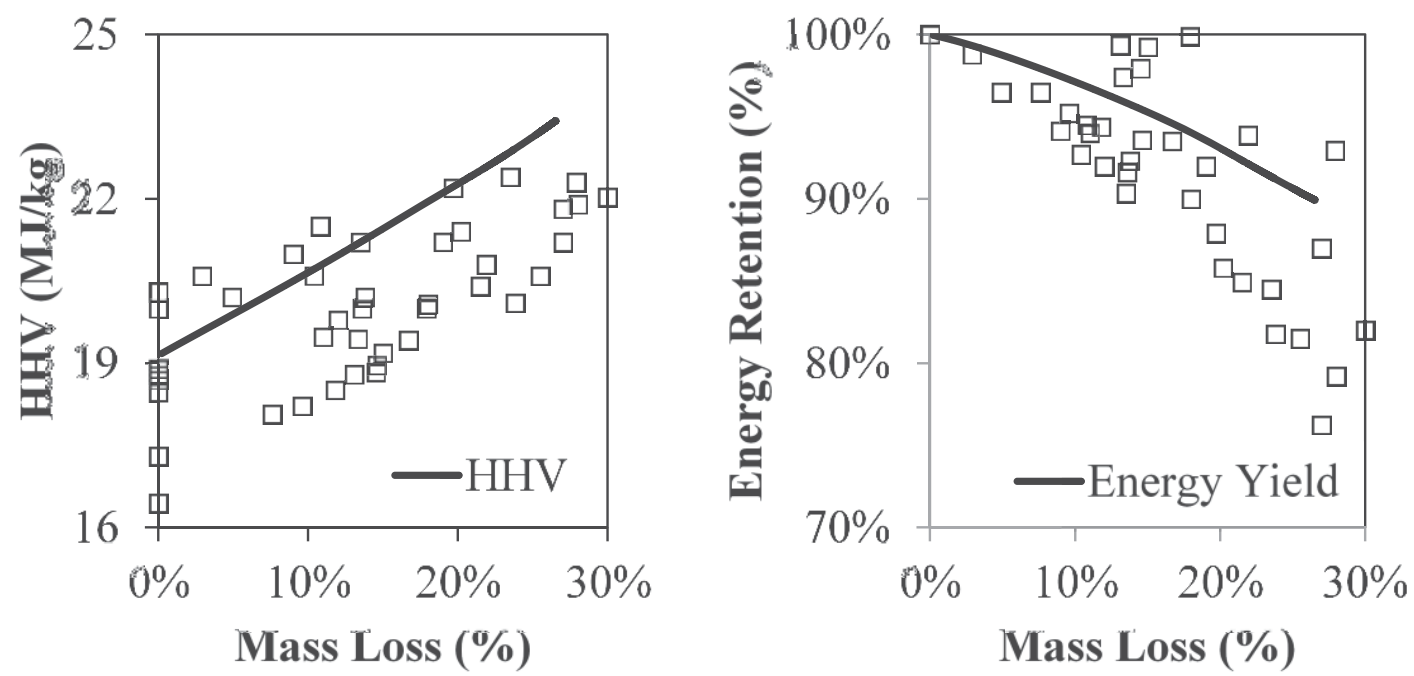

Figure 4.4: Model prediction (solid lines) of energy density, and energy retention in the torrefied biomass. Experimental data are represent by data points from (Pach et al. 2002; Bridgeman et al. 2008; Phanphanich and Mani 2011; Wannapeera et al. 2011; Broström et al. 2012; Sarvaramini et al. 2013; Sarvaramini and Larachi 2014).

As heavily oxygenated species are released from the raw biomass materials due to degradation of the hemicellulose, the resulting torrefied materials are compositionally more favorable as a fuel (increasing carbon, decreasing oxygen) and retain a significant portion $(>90 \%)$ of the extractable energy. Even though the kinetic parameters and product distribution used here in the model prediction were specific to a wood species, overall the modeling approach used here is able to reasonably predict the bulk literature trends observed by others with many woody feedstocks. This is a positive indication that the intrinsic molecular detachment model discussed here is a step toward a fundamental understanding of torrefaction. This fundamental model can then be used to represent torrefaction on any scale, and with future developments be incorporated into future models to predict heat and mass transfer considerations due to reactor design, particle sizes, heating rates, etc. 


\subsubsection{Future Model Extension}

As shown in Figures 5 and 6, when the literature data survey here is extended to include data covering a larger mass loss regime, it is clear that the same trends that are observed in torrefaction continue uninterrupted. In fact, it appears that these same trends extend for all volatile matter content in the biomass and leave just fixed carbon. New data are included from analysis of chars from pyrolysis over $600-900^{\circ} \mathrm{C}$, and a data point for fixed carbon(Mohan et al. 2006). Because the three stage intrinsic model used here was able to predict the solid properties over the mass loss region typically associated with torrefaction $(<30 \%)$ and the degradation of hemicellulose, we propose that this model can be extended to predict these behaviors all the way to fixed carbon on a fundamental level. To accomplish this, future work will examine the addition of more reaction stages, and the kinetic characterization of additional chemical species originating primarily from the cellulose and lignin biomass components. 

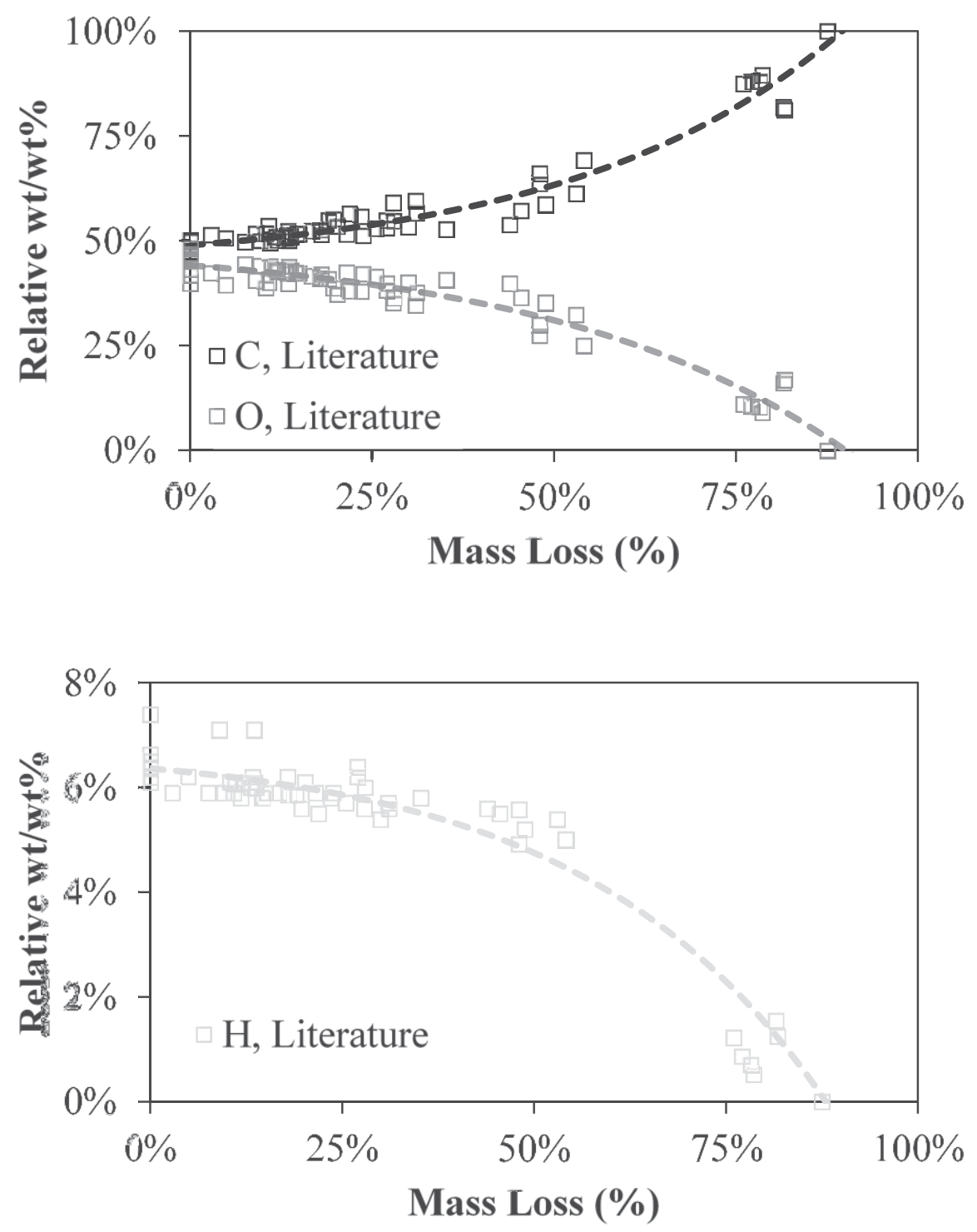

Figure 4.5: Literature data for carbon and oxygen (top) and hydrogen (bottom) composition over the entire mass loss regime in an inert atmosphere. Data from (Pach et al. 2002; Mohan et al., 2006; Bridgeman et al. 2008; Phanphanich and Mani 2011; Wannapeera et al. 2011; Broström et al. 2012; Sarvaramini et al. 2013; Sarvaramini and Larachi 2014). Dashed lines are arbitrary trends simply to illustrate data connection. 

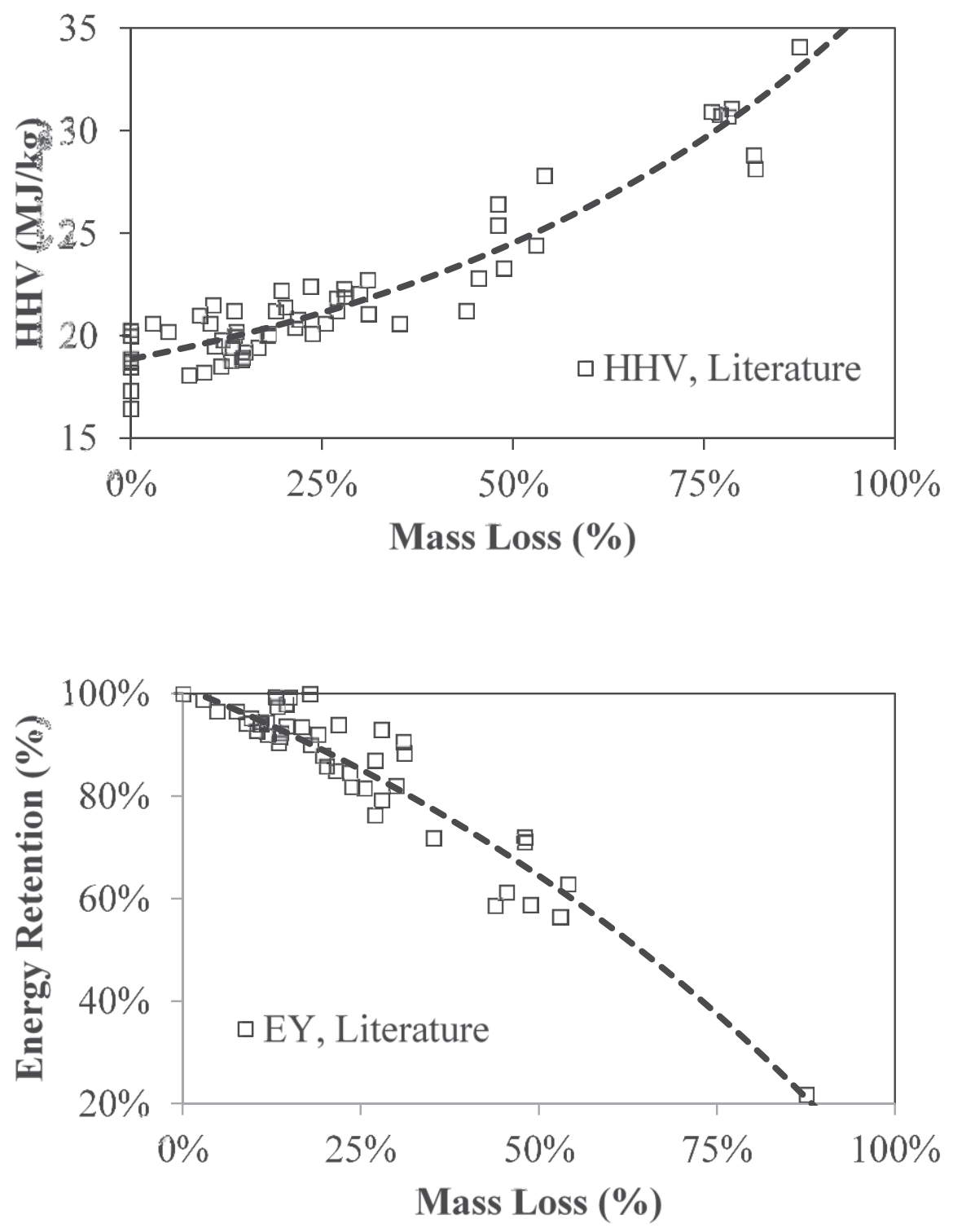

Figure 4.6: Literature data for energy density (top) and yield (bottom) over the entire mass loss regime in an inert atmosphere. Data from (Pach et al. 2002; Mohan et al., 2006; Bridgeman et al. 2008; Phanphanich and Mani 2011; Wannapeera et al. 2011; Broström et al. 2012; Sarvaramini et al. 2013; Sarvaramini and Larachi 2014). Dashed lines are arbitrary trends simply to illustrate data connection. 


\subsection{Conclusions}

The three stage torrefaction model studied here was able to accurately predict the changes observed in elemental composition and energy content observed by others (mean error of $1.7 \%$ for carbon, $0.28 \%$ for hydrogen, and $2.4 \%$ for oxygen). The model predicts on a relative basis that the carbon content increases by approximately $9 \%$, oxygen decreases by around $10 \%$, and the relative amount of hydrogen is relatively constant over the initial $26.5 \%$ mass loss observed during torrefaction. Over this mass loss region, approximately $90 \%$ of the original available energy is retained in the solid material leading to an increase in heating value from 19.1 to $23.4 \mathrm{MJ} / \mathrm{kg}$. Because this model was developed around examining the primary gas-vapor product evolution on a molecular level, it provides intrinsic insights that can lend detailed understanding during process design and analysis. 


\subsection{Works Cited}

Almeida G, Brito JO, Perré P. 2010. Alterations in energy properties of eucalyptus wood and bark subjected to torrefaction: The potential of mass loss as a synthetic indicator. Bioresource Technology 101(24):9778-9784.

Arias B, Pevida C, Fermoso J, Plaza MG, Rubiera F, Pis JJ. 2008. Influence of torrefaction on the grindability and reactivity of woody biomass. Fuel Processing Technology 89(2):169-175.

Ayhan D. 2008. Importance of biomass energy sources for Turkey. Energy Policy 36(2):834-842.

Bar-Ziv E, Chudnovsky B. Evaluation of co-firing of raw-biomass and torrefied-biomass with bituminous coals in $575 \mathrm{MW}$ tangentially-fired and $550 \mathrm{MW}$ opposite-wall boilers. Electric Power 2011; 2011; Rosemont, IL.

Bates RB, Ghoniem AF. 2012. Biomass torrefaction: Modeling of volatile and solid product evolution kinetics. Bioresource Technology 124(0):460-469.

Bates RB, Ghoniem AF. 2013. Biomass torrefaction: Modeling of reaction thermochemistry. Bioresource Technology 134(0):331-340.

Bergman PCA. 2005. Combined torrefaction and pelletisation, the TOP process. ECN Biomass, DEN programme of SenterNovem, Dutch Ministry of Economic Affairs, Report ECN-C-05-073. 
Boardman RD, Hess JR, Sokhansanj S, Tumuluru JS, Wright CT. 2011. A review on biomass torrefaction process and product properties for energy applications. Industrial Biotechnology 7(5):384+.

Bridgeman TG, Jones JM, Shield I, Williams PT. 2008. Torrefaction of reed canary grass, wheat straw and willow to enhance solid fuel qualities and combustion properties. Fuel 87(6):844-856.

Bridgeman TG, Jones JM, Williams A, Waldron DJ. 2010. An investigation of the grindability of two torrefied energy crops. Fuel 89(12):3911-3918.

Broström M, Nordin A, Pommer L, Branca C, Di Blasi C. 2012. Influence of torrefaction on the devolatilization and oxidation kinetics of wood. Journal of Analytical and Applied Pyrolysis 96(0):100-109.

Carrasco JC, Oporto GS, Zondlo J, Wang J. 2013. Torrefaction kinetics of red oak (Quercus rubra) in a fluidized reactor. BioResources 8(4):5067-5082.

Chang S, Zhao Z, Zheng A, He F, Huang Z, Li H. 2012. Characterization of products from torrefaction of sprucewood and bagasse in an auger reactor. Energy \& Fuels 26(11):7009-7017.

Chen Q, Zhou J, Liu B, Mei Q, Luo Z. 2011a. Influence of torrefaction pretreatment on biomass gasification technology. Chinese Science Bulletin 56(14):1449-1456. 
Chen W-H, Cheng W-Y, Lu K-M, Huang Y-P. 2011b. An evaluation on improvement of pulverized biomass property for solid fuel through torrefaction. Applied Energy 88(11):3636-3644 .

Chew JJ, Doshi V. 2011. Recent advances in biomass pretreatment - Torrefaction fundamentals and technology. Renewable and Sustainable Energy Reviews 15(8):4212-4222.

Ciolkosz D, Wallace R. 2011. A review of torrefaction for bioenergy feedstock production. Biofuels, Bioproducts and Biorefining 5(3):317-329.

Conti JJ, Holtberg PD, Diefenderfer JR, Napolitano SA, Schaal AM, Turnure JT, Westfall LD. 2014. Annual Energy Outlook 2014 with projections to 2040, Report \#: DOE/EIA-0383(2014). Report \#: DOE/EIA-0383. US Department of Energy.

Couhert C, Salvador S, Commandré JM. 2009. Impact of torrefaction on syngas production from wood. Fuel 88(11):2286-2290.

Dai J, Sokhansanj S, Grace JR, Bi X, Lim CJ, Melin S. 2008. Overview and some issues related to co-firing biomass and coal. The Canadian Journal of Chemical Engineering 86(3):367-386.

Devi L, Ptasinski KJ, Janssen FJJG. 2003. A review of the primary measures for tar elimination in biomass gasification processes. Biomass and Bioenergy 24(2):125140. 
Friedl A, Padouvas E, Rotter H, Varmuza K. 2005. Prediction of heating values of biomass fuel from elemental composition. Analytica Chimica Acta 544(1-2):191-198.

Gumz W, Hardt L. 1962. Kurzes Handbuch der Brennstoff- und Feuerungstechnik. Berlin, Heidelberg: Springer Berlin Heidelberg.

Kathiravale S, Muhd Yunus MN, Sopian K, Samsuddin AH, Rahman RA. 2003. Modeling the heating value of Municipal Solid Waste放. Fuel 82(9):1119-1125.

Khazraie Shoulaifar T, DeMartini N, Willför S, Pranovich A, Smeds AI, Virtanen TAP, Maunu S-L, Verhoeff F, Kiel JHA, Hupa M. 2014. Impact of Torrefaction on the Chemical Structure of Birch Wood. Energy \& Fuels 28(6):3863-3872.

Klinger J, Bar-Ziv E, Shonnard D. 2013. Kinetic study of aspen during torrefaction. Journal of Analytical and Applied Pyrolysis 104(0):146-152.

Klinger J, Klemetsrud B, Bar-Ziv E, Shonnard D. 2014. Temperature Dependence of Aspen Torrefaction Kinetics. Journal of Analytical and Applied Pyrolysis.

Lee J-W, Kim Y-H, Lee S-M, Lee H-W. 2012. Optimizing the torrefaction of mixed softwood by response surface methodology for biomass upgrading to high energy density. Bioresource Technology 116(0):471-476.

Medic D, Darr M, Shah A, Potter B, Zimmerman J. 2012a. Effects of torrefaction process parameters on biomass feedstock upgrading. Fuel 91(1):147-154. 
Medic D, Darr M, Shah A, Rahn S. 2012b. Effect of Torrefaction on Water Vapor Adsorption Properties and Resistance to Microbial Degradation of Corn Stover. Energy \& Fuels 26(4):2386-2393.

Mohan D, Pittman CU, Steele PH. 2006. Pyrolysis of Wood/Biomass for Bio-oil: A Critical Review. Energy \& Fuels 20(3):848-889.

Ohliger A, Förster M, Kneer R. 2013. Torrefaction of beechwood: A parametric study including heat of reaction and grindability. Fuel 104(0):607-613.

Pach M, Zanziand R, Björnbom E. 2002. Torrefied Biomass a Substitute for Wood and Charcoal. 6th Asia-Pacific International Symposium on Combustion and Energy Utilization. Kuala Lumpur, Malaysia.

Phanphanich M, Mani S. 2011. Impact of torrefaction on the grindability and fuel characteristics of forest biomass. Bioresource Technology 102(2):1246-1253.

Prins MJ, Ptasinski KJ, Janssen FJJG. 2006a. Torrefaction of wood: Part 2. Analysis of products. Journal of Analytical and Applied Pyrolysis 77(1):35-40.

Prins MJ, Ptasinski KJ, Janssen FJJG. 2006b. Torrefaction of wood: Part 1. Weight loss kinetics. Journal of Analytical and Applied Pyrolysis 77(1):28-34.

Prins MJ, Ptasinski KJ, Janssen FJJG. 2007. From coal to biomass gasification: Comparison of thermodynamic efficiency. Energy 32(7):1248-1259.

Reichling JP, Kulacki FA. 2011. Comparative analysis of Fischer-Tropsch and integrated gasification combined cycle biomass utilization. Energy 36(11):6529-6535. 
Sarvaramini A, Assima GP, Larachi F. 2013. Dry torrefaction of biomass - Torrefied products and torrefaction kinetics using the distributed activation energy model. Chemical Engineering Journal 229(0):498-507.

Sarvaramini A, Larachi F. 2014. Integrated biomass torrefaction - Chemical looping combustion as a method to recover torrefaction volatiles energy. Fuel 116(0):158167.

Stelte W, Clemons C, Holm JK, Sanadi AR, Ahrenfeldt J, Shang L, Henriksen UB. 2011. Pelletizing properties of torrefied spruce. Biomass and Bioenergy 35(11):46904698.

van der Stelt MJC, Gerhauser H, Kiel JHA, Ptasinski KJ. 2011. Biomass upgrading by torrefaction for the production of biofuels: A review. Biomass and Bioenergy 35(9):3748-3762.

Wannapeera J, Fungtammasan B, Worasuwannarak N. 2011. Effects of temperature and holding time during torrefaction on the pyrolysis behaviors of woody biomass. Journal of Analytical and Applied Pyrolysis 92(1):99-105.

Yang H, Yan R, Chen H, Lee DH, Zheng C. 2007. Characteristics of hemicellulose, cellulose and lignin pyrolysis. Fuel 86(12-13):1781-1788.

Yin C, Rosendahl L, Kær SK. 2012. Towards a better understanding of biomass suspension co-firing impacts via investigating a coal flame and a biomass flame in a swirl- 
stabilized burner flow reactor under same conditions. Fuel Processing Technology 98(0):65-73.

Zheng A, Zhao Z, Chang S, Huang Z, He F, Li H. 2012. Effect of Torrefaction Temperature on Product Distribution from Two-Staged Pyrolysis of Biomass. Energy \& Fuels 26(5):2968-2974. 


\section{Development of a Unified Torrefaction-Pyrolysis Kinetic Model}

Reprinted with permission from KLINGER J, BAR-ZIV E, SHONNARD D. 2015. UNIFIED KINETIC MODEL FOR TORREFACTION-PYROLYSIS. FUEL PROCESSING TECHNOLOGY 138(0):175-183. Copyright 2015 Elsivier B.V. ${ }^{4}$

\subsection{Abstract}

Thermochemical conversion is a promising pathway to renewable fuels. Torrefaction is the low temperature conversion to a primarily solid fuel, and pyrolysis is a higher temperature process that produces mainly a liquid bio-oil product. Though these processes are both thermal degradation routes in an inert atmosphere, they are often presented as different processes. A novel six stage consecutive model is proposed to describe a unified view of torrefaction and pyrolysis. The reactions lump chemical species formation in the six reaction stages and represent decomposition of cellulose, hemicellulose, and lignin. Activation energies of 104, 129, 154, 217, 256, and $285 \mathrm{~kJ} / \mathrm{mol}$ were found through modeling of 32 unique gas-phase species fragments and weight loss dynamics for degradation from $260-425^{\circ} \mathrm{C}$. It is demonstrated that there is a unified process

\footnotetext{
${ }^{4}$ The material contained in this chapter was previously published in Fuel Processing Technology.
} 109 
that occurs, and can describe the degradation of the structural components in biomass. These dynamics yield important insight into the thermal degradation mechanism such as the chemical product detachment dynamics, and the influence of process severity.

\subsection{Introduction}

In 2013, the United States consumed approximately 97.4 quadrillion BTUs of primary energy, of which approximately $83 \%$ was derived from fossil energy sources (35.1 quads as petroleum, 26.6 quads as natural gas, 18.1 quads as coal) primarily to satisfy demand for heat, power, and transportation fuels (Fichman 2015). These three fossil fuel categories make up approximately $95 \%, 89 \%, 91 \%$, and $66 \%$ of the energy consumption of the transportation, industrial, residential and commercial, and electric power sectors respectively (Fichman 2015). As a result of these activities in 2012, 6,526 million metric tons of $\mathrm{CO}_{2}$-eqivalence ( $82 \%$ as direct $\mathrm{CO} 2,9 \%$ methane, $6 \%$ nitrous oxide, $3 \%$ fluorinated gases) were released by these U.S. activities alone (EPA 2014). These emissions can be linked to electricity generation (38\%), transportation (32\%), industry (14\%), and residential and commercial applications (9\%) (EPA 2014). From this simple high-level look at the energy patterns of the U.S. it is clear that more emphasis needs to be placed on the meeting the objectives set forth by renewable energy initiatives such as the renewable fuel standard (and subsequent updates in the RFS II) to address fossil consumption in the transportation sector and the state mandated renewable energy portfolios to address fossil fuel use for heat and power in the electric utility and industrial sectors. Though there are many possible ways to address these energy requirements in a more sustainable way, the 
most compelling near-term solution may be to develop a renewable drop-in fuel replacement. Such a fuel will permit the retention of existing infrastructure and distribution/consumption practices. The thermochemical conversion of biomass can offer drop-in solutions to these three most prevalent fossil fuels.

Thermal conversion in an oxygen free environment at mild temperatures (200$300^{\circ} \mathrm{C}$ ) results primarily in a more carbonaceous solid fuel and is referred to as torrefaction (Chew and Doshi 2011; van der Stelt et al. 2011). At slightly higher temperatures (350$500^{\circ} \mathrm{C}$ ) the thermal depolymerization of material is referred to as pyrolysis and mainly produces a liquid biocrude oil comprised of many different organic compounds (Mohan et al. 2006). As temperature increases further $\left(>700^{\circ} \mathrm{C}\right)$ biomass in an oxidative environment can produce a mainly gaseous fuel (syngas) (Mohan et al. 2006). Though these conversion processes can produce promising alternative fuels and much work is being done to model the decomposition and provide mechanistic insight, there is still no clear understanding of the fundamental mechanisms that occur during torrefaction and pyrolysis (van der Stelt et al. 2011; Nocquet et al. 2014a; 2014b).

Proposed mechanisms for torrefaction and pyrolysis are generally represented as the structural polymers (cellulose, hemicellulose, and lignin) in lignocellullosic biomass degrading through a series of smaller macro-molecule polymer units intermediates, to smaller trimer, dimer, and monomer units, and ultimately a suite of distinct organic products formed through decomposition of polymer end units, or monomer/dimer scission/fragmentations (Patwardhan et al. 2009; Shen and Gu 2009; Huang et al. 2010; Patwardhan et al. 2011a; 2011b; Isahak et al. 2012; Collard and Blin 2014; Kelkar et al. 
2014). Of these components cellulose is studied most often perhaps due to its' uniform nature. Shen and Gu looked at further developing mechanistic understanding of cellulose pyrolysis through 3-D TG-FTIR and GC-MS (Shen and Gu 2009). They found that in the absence of secondary reactions levoglucosan, the main product from cellulose pyrolysis, is consistently formed through first the depolymerization of cellulose chains to monomer units, and then to levoglucosan through hydrogen abstraction and formation of a hydroxyl radical at the broken $\beta(1 \rightarrow 4)$ glycosidic linkage sites and reforming (Shen and Gu 2009). This type of formation pathway for levoglucosan and other cellulose based organics is also supported by other works, and has been studied in the presence of alkali-based minerals that act as catalysts (Ponder et al. 1992; Li et al. 2001; Patwardhan et al. 2009; Collard and Blin 2014; Kelkar et al. 2014; Trendewicz et al. 2015). More recently in support of this Sánchez-Jiménez et al. found that cellulose pyrolysis most closely obeys kinetic laws governed by a random chain scission mechanism (Sánchez-Jiménez et al. 2013). These results suggest that there is a progressive degradation of biomass polymers during pyrolysis to smaller chains and ultimately gas-phase chemical species, indicative of consecutive-type chemical reactions.

Previously, our group proposed such a lumped consecutive kinetic model to describe the gas-phase evolution of species during torrefaction (Klinger et al. 2013; Klinger et al. 2014b). It was found that a minimum of three first order reactions were required to describe the transient characteristics of the formed volatile species: water, carbon monoxide, carbon dioxide, acetic acid, formic acid, and furfural(Klinger et al. 2014b). Though the degradation process was found to be consistent over the temperature ranges 
studied (up to $300^{\circ} \mathrm{C}$ ), it was found that mechanistic interpretations through mass loss alone are not sufficient to gain chemical mechanistic insights (Klinger et al. 2014a; Klinger et al. 2014b).

To gain further insight into the mechanisms of biomass degradation, this type of lumped chemical species analysis is extended in this work to include pyrolysis-ranged processing conditions. Though pyrolysis and torrefaction are often studied independently or presented as separate processes, it is asserted here that they are a single unified process that occur at kinetically different rates. This idea that torrefaction and pyrolysis are similar processes can be observed in other modeling studies, combined torrefaction-pyrolysis processing experiments, and works that investigate chemical species distribution (Carmen Branca et al. 2003; Westerhof et al. 2012; Di Blasi et al. 2013; Eseltine et al. 2013; Westover et al. 2013; C. Branca et al. 2014). In this work, thermal degradation of biomass is investigated through a proposed unified model to describe both torrefaction and pyrolysis. This work is novel in that it moves beyond weight-loss measurements and discrete product distributions, and uses a series of dynamic chemical species to establish kinetic parameters. In addition to an approximate weight-loss measurement, 32 individual molecular ions were traced as transient species to obtain chemical dynamics during the degradation process. This type of approach can effectively be used to describe and model the process on a chemical level, but also be used to provide insights to other mechanistic works. 


\subsection{Materials and Methods}

Micro-torrefaction and pyrolysis experiments carried out in this work used debarked aspen wood. A knife mill (Thomas Wiley ®, NR. 3557524 359264) was used to reduce particles with a $1 \mathrm{~mm}$ screen. The whole samples were then sieved (W.S. Tyler Rotap, RX-29) and particles between 500-600 $\mu$ m (32-28 Tyler mesh) were isolated to maintain uniform, repeatable thermochemical conversion. Proxies used for pure carbohydrate/fiber components were similar to commercially available products through a supplier such as Sigma-Aldrich (cellulose: Avicel® $\mathrm{PH}-101, \sim 50 \mu \mathrm{m}$ particle microcrystalline cellulose powder; hemicellulose: Poly(beta-D-xylopyranose[1 $\rightarrow 4]$, xylan from beechwood; lignin: Sigma-Aldrich 471003, low sulfonate kraft lignin, 10,000 average molecular weight). Before experiments were carried out, all samples were dried at $105^{\circ} \mathrm{C}$ until no difference in mass was observed.

\subsubsection{Pyrolysis Experiments}

A resistive filament pyrolyzer (CDS 5200HP Pyroprobe) was used to process the aspen samples. The pyrolysis unit was connected to an in-line gas chromatograph (Trace GC Ultra, ThermoFisher) and mass spectrometer (Trace DSQII, ThermoFisher) for gasphase product detection and characterization. The GC was fit with a non-retentive fused silica guard column (Restek, Rxi Guard Column, 10m). The GC oven was maintained at the same temperature as the system transfer lines $\left(300^{\circ} \mathrm{C}\right)$, and transferred the materials from the GC inlet to the MS with minimal interaction as described in previous work (Klinger et al. 2013; Klinger et al. 2014b). 
Biomass samples were loaded in quartz reaction tubes (25 mm x $2 \mathrm{~mm}$ OD) and were surrounded by the resistive heating coil for radiative heat transfer $\left(1000^{\circ} \mathrm{C} / \mathrm{s}\right)$. The biomass was held in the center of the coil's heating zone by minimal amounts of quartz wool. A sample size of 0.10-0.20 mg was used, and measured by a microbalance accurate to $1 \mu \mathrm{g}$ (Citizen Scales Inc., Model CM5). High purity helium (99.999\%) acted as the carry gas throughout the system, and a flow rate of $1.5 \mathrm{~mL} / \mathrm{min}$ was maintained through the GC column $(50.9 \mathrm{~cm} / \mathrm{s}$ superficial velocity). Molecular fragments in the range $15-350 \mathrm{~m} / \mathrm{z}$ were recorded at a rate of $\sim 5 \mathrm{~Hz}$ over the course of 90 minute experiments. The Total Ion Current (TIC) chromatogram is a summation of all molecular fragment intensities at each time point, and was recorded as a proxy for total sample mass loss.

Previously, our group investigated the kinetics of thermal degradation in the range of traditional low-temperature pyrolysis (torrefaction) temperatures up to $300^{\circ} \mathrm{C}$ (Klinger et al. 2013; Klinger et al. 2014b). In transition into pyrolysis-ranged processing, six temperatures were studied here: $315,330,350,375,400$, and $425^{\circ} \mathrm{C}$. To model pyrolysis in this range molecular fragments relating to cellulose, hemicellulose, and lignin (described below) were used along with the overall weight loss proxy, the TIC signal.

\subsubsection{Product Distribution and Molecular Fragmentation}

Pyrolysis is well-known to produce a complex mixture of organic compounds that is dependent on feedstock properties, sample sizes, and processing severity (heating rates, temperature, and duration) among other factors. To understand the chemical speciation from the carbohydrate/fiber fractions of biomass, studies have been performed on pure samples of cellulose, hemicellulose, and lignin (Patwardhan et al. 2009; Patwardhan et al. 
2011a; 2011b). Major products from each of the three components are shown in Table 5.1 along with their major molecular ions produced in a mass spectrometer according to the National Institute of Standards and Technology (NIST). The major ion fragments presented are from highest abundance to lowest, and the compounds are listed in order of typical retention times. The most prominent species produced from pyrolysis of cellulose are non-condensable gases ( $\mathrm{CO}$ and $\mathrm{CO} 2)$, water, levoglucosan, and smaller amounts of other anhydrosugars and furans (Patwardhan et al. 2009). The major species from the pyrolysis of hemicellulose are non-condensable gases, water, organic acids (formic and acetic), and smaller amounts of other anhydrosugars, aldehydes, etc. (Patwardhan et al. 2011b). The pyrolysis of lignin results primarily in formation isomers of methylated or ethylated phenolic compounds, along with non-condensable gases and smaller organic compounds (Patwardhan et al. 2011a).

To determine the sensitivity of the experimental system, pure components (cellulose, hemicellulose, lignin) were run in the Py-GC-MS system described above at $350^{\circ} \mathrm{C}$. Average mass spectral fingerprints across the major production time $(0-3 \mathrm{~min})$ were extracted for comparison with major ion fragments observed by others (Table 5.1), and for interpretation of chemical species evolution. When major ions observed in this empirical work were combined with major product ions observed by others, 32 unique mass-tocharge fragments were identified to describe the degradation of cellulose, hemicellulose, and lignin within the biomass structure during pyrolysis. A summary of these ions are discussed later in section 3.2. 
Table 5.1: Major products formed from pyrolysis of pure component species.

\begin{tabular}{|c|c|c|c|c|c|}
\hline \multicolumn{2}{|c|}{$\begin{array}{c}\text { Cellulose } \\
\text { (Patwardhan et al. 2009) }\end{array}$} & \multicolumn{2}{|c|}{$\begin{array}{c}\text { Hemicellulose } \\
\text { (Patwardhan et al. 2011b) }\end{array}$} & \multicolumn{2}{|c|}{$\begin{array}{c}\text { Lignin } \\
\text { (Patwardhan et al. 2011a) }\end{array}$} \\
\hline Product & Major Ions & Product & Major Ions & Product & Major Ions \\
\hline $\mathrm{CO}$ & 28 & $\mathrm{CO}$ & 28 & $\mathrm{CO}$ & 28 \\
\hline $\mathrm{CO}_{2}$ & 44 & $\mathrm{CO}_{2}$ & 44 & $\mathrm{CO}_{2}$ & 44 \\
\hline $\mathrm{H}_{2} \mathrm{O}$ & 18,17 & $\mathrm{H}_{2} \mathrm{O}$ & 18,17 & $\mathrm{H}_{2} \mathrm{O}$ & 18,17 \\
\hline Formic acid & $29,46,45$ & Formic acid & $29,46,45$ & Acetaldehyde & $29,44,43$ \\
\hline Furan/acetone & $68,39,40$ & 2-methylfuran & $82,53,81$ & Acetic acid & $43,45,60$ \\
\hline Glycolaldehyde & $31,32,29$ & Acetic acid & $43,45,60$ & Phenol & $94,66,65$ \\
\hline 2-Methyl furan & $82,53,81$ & Acetol & 43,31 & $\begin{array}{l}\text { 2-methoxyphenol (o- } \\
\text { guaiacol) }\end{array}$ & $109,124,81$ \\
\hline 2-Furaldehyde & $96,95,39$ & 2-furaldehyde & $96,95,39$ & 4-vinyl phenol & $63,91,107,120$ \\
\hline 2-Furan methanol & $98,41,53$ & $\begin{array}{l}\text { Dianhydro- } \\
\text { xylopyranose } 1\end{array}$ & $27,43,55,86,114$ & $\begin{array}{l}\text { 2-methoxy-4-vinyl } \\
\text { phenol }\end{array}$ & $135,150,107,77$ \\
\hline $\begin{array}{l}\text { 5-(Hydroxymethyl)-2- } \\
\text { furancarboxaldehyde }\end{array}$ & $69,29,57$ & $\begin{array}{l}\text { Dianhydro- } \\
\text { xylopyranose } 2\end{array}$ & $29,58,85,114$ & $\begin{array}{l}\text { 2,6-dimethoxy } \\
\text { phenol }\end{array}$ & 154,139 \\
\hline Anhydroxylopyranose & $39,69,98,144$ & $\begin{array}{l}\text { Anhydro- } \\
\text { xylopyranose }\end{array}$ & $29,43,73,86,114$ & $\begin{array}{l}\text { 4-methyl- } \\
\text { 2,6,dimethoxyphenol }\end{array}$ & $107,125,153,168$ \\
\hline $\begin{array}{l}\text { 1,6-Anhydro-b-D- } \\
\text { glucopyranose(Levoglucosan) }\end{array}$ & $60,57,73$ & $\begin{array}{l}\text { Other } \\
\text { Anhydro- } \\
\text { xylopyranose }\end{array}$ & $29,57,73,86,114$ & $\begin{array}{l}\text { 3', 4'-dimethoxy } \\
\text { acetophenone }\end{array}$ & 165,180 \\
\hline $\begin{array}{l}\text { 1,6-Anhydro-b-D- } \\
\text { glucofuranose }\end{array}$ & $73,44,69$ & Xylose & $73,60,31,43$ & Sinapyl alcohol & 168,210 \\
\hline
\end{tabular}

\subsubsection{Modeling Approach}

Previously, a model for low-temperature pyrolysis was proposed to describe the process based on removal of gas-phase species in a three consecutive reaction mechanism (Klinger et al. 2013; Klinger et al. 2014b). The model assumes that the same basic lumped parameter reactions occur at all temperatures, but at different rates as governed by temperature. The chemistry of the process, then, is independent of temperature and a desired processing severity can be obtained through either time or temperature. As the temperature of pyrolysis was increased, the structure of the biomass is degraded more quickly, and more completely as the more recalcitrant portions of the biomass are broken 
down at an observable rate. To address this production in the extended temperature range, more consecutive reactions were added to describe this progressive structural deformation. As the temperature was increased to the highest temperature studied $\left(425^{\circ} \mathrm{C}\right)$, it was determined that a minimum of three additional reactions were needed to predict the evolution of gas-phase species observed. This model can be summarized as:

$$
\begin{gathered}
\text { Biomass } \stackrel{k_{1, i}}{\rightarrow} R_{1}+\sum \alpha_{1, i} P_{1, i} \\
R_{j-1} \stackrel{k_{j, i}}{\rightarrow} R_{j}+\sum \alpha_{j, i} P_{j, i}
\end{gathered}
$$

for reaction $j$ from $(2,3, \ldots, 6)$, where $k_{j, i}$ is the reaction specific rate coefficient for species $i, R$ is a solid reaction intermediate that represents a partially degraded biomass with fragmented carbohydrate/fiber fractions, $\alpha_{j, i}$ is a stoichiometry factor for reaction $j$ and species $i$, and $P_{j, i}$ is a gas-phase product, species $i$ for reaction $j$. For each reaction stage, there is a single rate coefficient, and a unique stoichiometry factor for each chemical species. As discussed above, however, the stoichiometry parameters are proposed to be independent of temperature - meaning that a single stoichiometric parameter applies across all six reaction stages for each chemical product. For each species there are six stoichiometric parameters, one for each reaction. The six rate coefficients were fit independently for each species. The reaction rate constants are responsible for describing the dynamics of each gas-phase species in the lumped chemical reactions, and the quantity of species produced by each of the consecutive reactions is dictated by the stoichiometry parameters. These stoichiometry variables relate to the mechanistic chemistry that occurs in a lumped set of reactions. Each of the six proposed stages likely represent many near- 
parallel reactions that occur at, or near, the same observable rate to produce the many organic products of pyrolysis. These lumped reactions may, for example, represent the suite of probable reactions at a carbohydrate polymer chain end or the result of a random scission along the backbone. The reactions with similar dynamics, then, give an aggregated result for the respective degradation stage.

It is important to note that the proposed novel unified torrefaction-pyrolysis applies over the entire temperature range $\left(260-425^{\circ} \mathrm{C}\right)$, however the sensitivity of the process to system temperature masks several reaction stages and makes them unmeasurable due to very slow or fast kinetics. A reaction was classified as having very slow kinetics when the characteristic time was greater than two hours, and very fast kinetics when the characteristic time was less than fifteen seconds. When a reaction fell in either of these regimes, an extrapolated value obtained over a range of the valid temperatures was used during the fitting procedure. A matrix showing the temperature-reaction linkages during the model fitting procedure is shown in Table 5.2. As the reaction temperature increases, the initial reactions (Rxn 1-3) become kinetically very fast, and the later reactions (Rxn 46) are kinetically very slow over the initial temperature range. As discussed in our previous work (Klinger et al. 2013; Klinger et al. 2014b), the first three reaction steps apply up to $300^{\circ} \mathrm{C}$. Rxn 1 becomes very fast above $330^{\circ} \mathrm{C}$. Rxn 2 becomes very fast above $350^{\circ} \mathrm{C}$. Rxn 3 becomes very fast above $375^{\circ} \mathrm{C}$. Rxn 4 is observable from $330-400^{\circ} \mathrm{C}$. Rxn 5 is observable above $330^{\circ} \mathrm{C}$. Rxn 6 is observable above $350^{\circ} \mathrm{C}$.

The model fitting procedure was performed by minimizing the squared difference between the experimental data, and product profiles predicted by the model over the 90 
Table 5.2: Experimental matrix showing the temperature range for each reaction during model fitting.

\begin{tabular}{ccccccc}
\hline $\mathbf{R x n}$ & $\mathbf{3 1 5}^{\circ} \mathbf{C}$ & $\mathbf{3 3 0}^{\circ} \mathbf{C}$ & $\mathbf{3 5 0}^{\circ} \mathbf{C}$ & $\mathbf{3 7 5}^{\circ} \mathbf{C}$ & $\mathbf{4 0 0}^{\circ} \mathbf{C}$ & $\mathbf{4 2 5}^{\circ} \mathbf{C}$ \\
\hline 1 & $\mathrm{X}$ & $\mathrm{X}$ & Fast & Fast & Fast & Fast \\
2 & $\mathrm{X}$ & $\mathrm{X}$ & $\mathrm{X}$ & Fast & Fast & Fast \\
3 & $\mathrm{X}$ & $\mathrm{X}$ & $\mathrm{X}$ & $\mathrm{X}$ & Fast & Fast \\
4 & Slow & $\mathrm{X}$ & $\mathrm{X}$ & $\mathrm{X}$ & $\mathrm{X}$ & Fast \\
5 & Slow & Slow & $\mathrm{X}$ & $\mathrm{X}$ & $\mathrm{X}$ & $\mathrm{X}$ \\
6 & Slow & Slow & Slow & $\mathrm{X}$ & $\mathrm{X}$ & $\mathrm{X}$ \\
\hline
\end{tabular}

minute experiments. During the model fitting procedure a complete mass balance was maintained. As the solid mass product degrades, an equal total mass of volatile species was released. Because the dynamic traces are production rates, mass balance is ensured at any reaction time from a sum of profile integrals of biomass, intermediate solids, char, and volatile components in equality to the original mass. Product profiles were obtained using a forward finite difference numerical method with a similar time step of the experimental data $(5 \mathrm{~Hz})$. The model parameters were allowed to vary for the appropriate reactions according to the temperature-reaction dependence shown in Table 5.2.

\subsection{Results and Discussion}

Over the time-course of the pyrolysis experiments, the values for the TIC chromatogram were extracted as a proxy for the overall mass loss observed by the biomass sample. Sample traces over the range of torrefaction and pyrolysis temperatures for the TIC chromatogram are shown in Figure 5.1, and represent the total rate of volatile species production with time. The TIC signal represents a summation of all molecular fragments, and the overall trace is a convolution of the production rates from the proposed six reaction stages. The stoicheometeric parameters discussed represent the contribution from each 


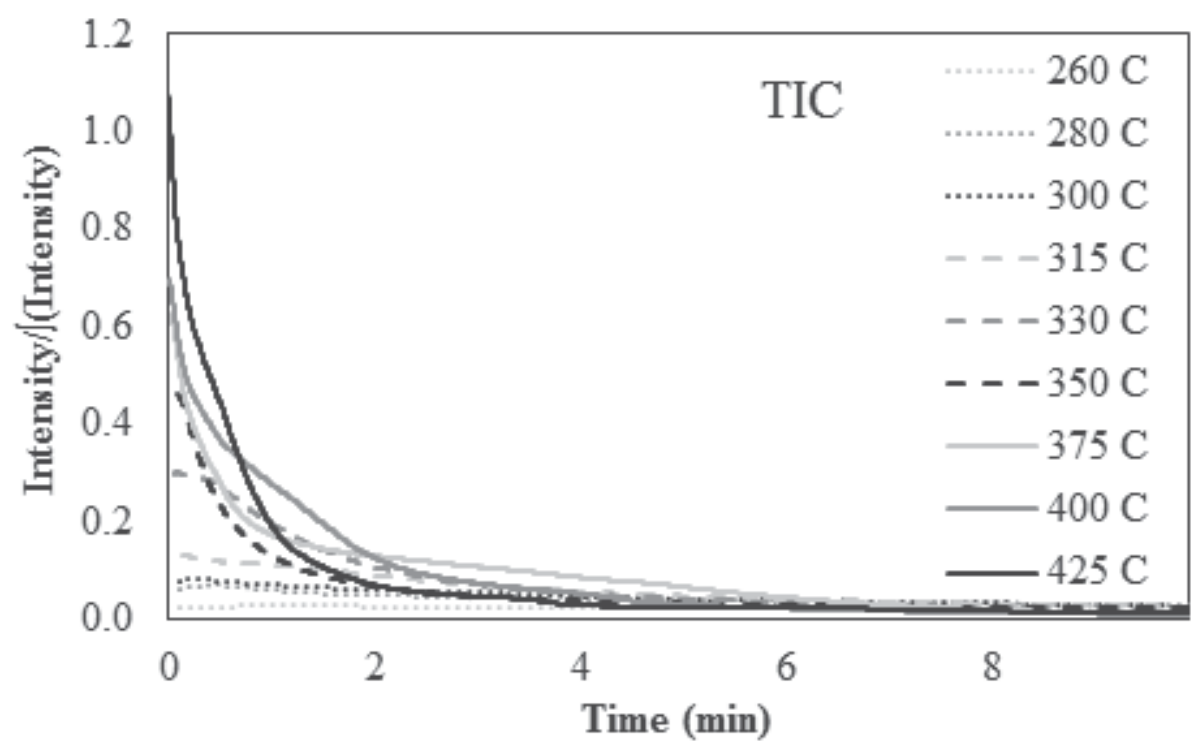

Figure 5.1: Experimental traces of the total chromatogram for a range of temperatures.

reaction stage for a given molecular fragment, and can be used to display the contribution from each stage without convolution. For this TIC signal, the stoicheometeric parameters do not have interpretable meaning, and instead the discussion is focused on the results of the rate constants. For comparison of the dynamics, the data in Figure 5.1 were normalized to unity production. When normalized to the same production quantity, the data present a clear temperature dependence of the process where relatively high temperatures $\left(425^{\circ} \mathrm{C}\right.$, $400^{\circ} \mathrm{C}$ ) result in production occurring almost entirely within the first two minutes with high initial production rate. Conversely, the lower temperatures $\left(<330^{\circ} \mathrm{C}\right)$ result in much smaller initial production rates, however, the production is sustained over a much longer duration to reach the same production intensity. Overall, the rates appear monotonic in nature as noted previously, but there are shifting contributions from late-time reactions to early-time reactions that need to be carefully traced with increasing temperature. The six consecutive 
reaction model was applied to these TIC traces to determine the rate constants associated with the overall mass loss observed by the biomass.

\subsubsection{Kinetic Model}

As discussed above, the TIC chromatograms were fit with the six consecutive reaction model. A summary of typical results for four temperatures are shown in Figure 5.2. The fit rate constants shown in the figures have units of $\min ^{-1}$. The model is able to predict the observed behavior of the signal well, with an average coefficient of determination of 0.98 at all temperatures and between duplicates. Although the model consists of six reactions, it is important to note that only a portion of them occur at an observable rate at the reported temperature as displayed in Table 5.2. At $280^{\circ} \mathrm{C}$, the experimental trace is explained almost entirely with $\operatorname{Rxn} 1\left(\mathrm{k}^{-1} \sim 2.4 \mathrm{~min}\right)$ and $\operatorname{Rxn} 2\left(\mathrm{k}^{-1} \sim\right.$ $10 \mathrm{~min}$ ), with small contributions from $\operatorname{Rxn} 3$. At $330^{\circ} \mathrm{C}$, the first four reactions define the observed behavior with characteristic times of $0.34,0.91,3.7$, and 50 minutes respectively. Four reactions (Rxn 3-6) were also fit from the $375^{\circ} \mathrm{C}$ traces with characteristic times of 0.52, 2.3, and 14 minutes for Rxn 3-5 and small contributions from Rxn 6. As the temperature is increased to the $425^{\circ} \mathrm{C}$, only Rxn 5 and 6 were fit with characteristic times of 0.44 and 2.4 minutes respectively.

Average fitting results for the TIC chromatograms are displayed in an Arrhenius

plot as Figure 5.3. Error bars showing deviation for the fit kinetic rate constants between replicate experiments fall within the data symbols, and were omitted. Linear regression of the parameters from the six reactions yields activation energies of 104, 129, 154, 217, 256, and $285 \mathrm{~kJ} / \mathrm{mol}$ respectively, with coefficient of determination values (from data in Figure 

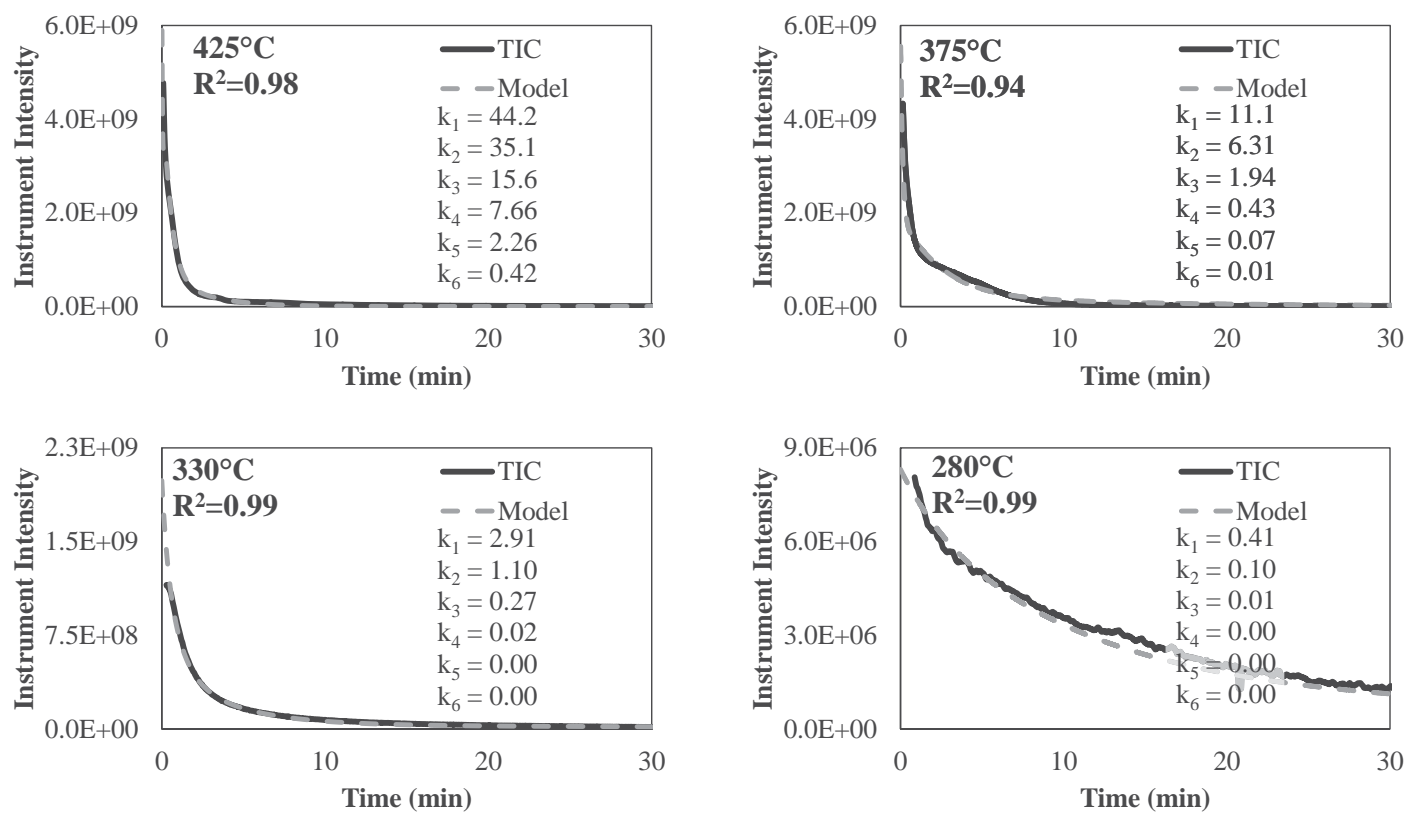

Figure 5.2: Typical model fits for TIC traces.

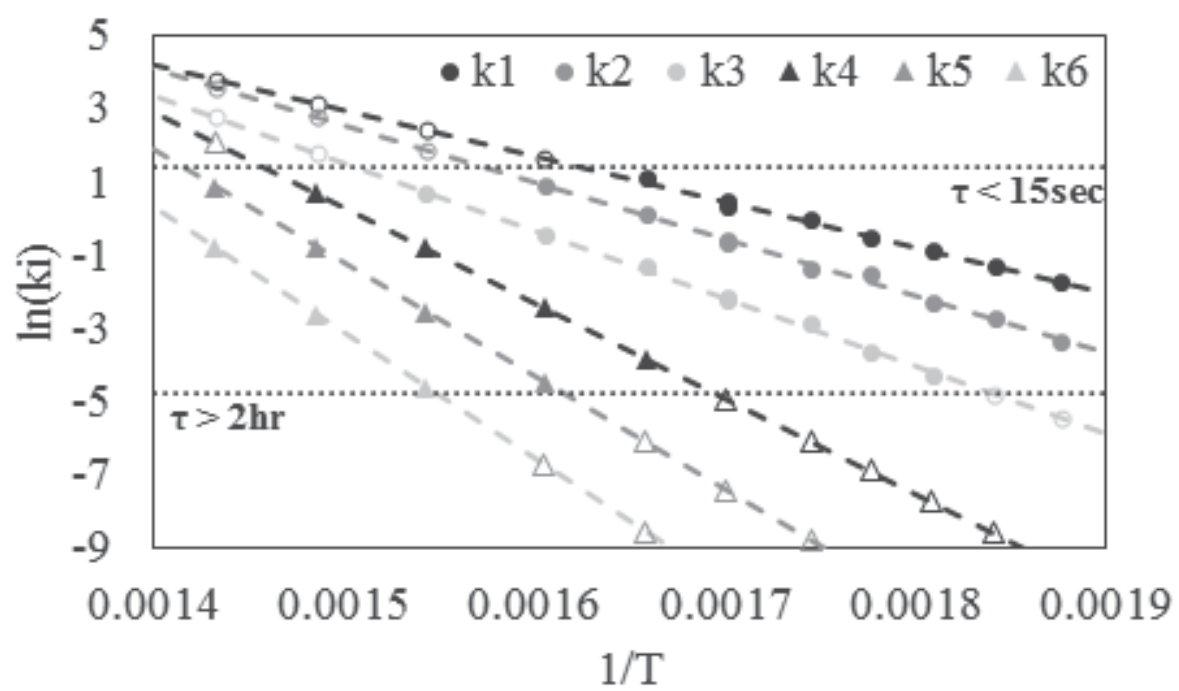

Figure 5.3: Arrhenius plot for kinetic modeling of TIC signal. Solid symbols represent modeling results. Empty symbols represent values used in modeling as predicted by straight line trends (dashed lines). 
5.3 ) of $0.99,0.99,0.99,1.00,1.00$, and 0.99 respectively. This suggests that as the degradation continues through the consecutive stages, the remaining solids become more recalcitrant and require more energy to continue degrading. Though these values do not give any direct insight into the structure of the intermediates, they can be used in process modeling and may provide insight to probing the structural changes observed during biomass degradation. Such solid state work has also concluded that scission reactions occur early in pyrolysis processing on weaker oxygen and hydrogen bonds, leading to a more rigid and carbonaceous structure (Kim et al. 2011; Westover et al. 2013; Azargohar et al. 2014). This mechanistic insight can be combined for greater understanding of thermal degradation, or use in quantum simulations.

\subsubsection{Component-based Model Fitting}

As discussed earlier, pure wood components of cellulose, hemicellulose, and lignin were processed to interpret the major chemical species formed during pyrolysis at $350^{\circ} \mathrm{C}$. Sample sizes were maintained around the same sizes of aspen of $0.10-0.20 \mathrm{mg}$. Through many of the same molecular ions listed in Table 5.1 above were consistently observed, the ten molecular fragments with the highest relative abundance were targeted for qualitative comparison. The data were normalized to the intensity of the maximum fragment. These fragments are related to their respective carbohydrate parent-fraction, and the modeling of their gas-phase evolutions is then directly related to their parent fraction's degradation. The most abundant molecular fragments are shown in Table 5.3. Major fragments identified from cellulose primarily includes $59.9 \mathrm{~m} / \mathrm{z}$ (C2H4O2-), $72.9 \mathrm{~m} / \mathrm{z}$ (C3H5O2-), and $56.9 \mathrm{~m} / \mathrm{z}$ (C3H5O-). These three fragments can all be related to levoglucosan, and 
agrees with major product formation identified in literature (Patwardhan et al. 2009). Other fragments identified $(42.9 \mathrm{~m} / \mathrm{z}, \mathrm{C} 2 \mathrm{H} 3 \mathrm{O}-$; $68.9 \mathrm{~m} / \mathrm{z}, \mathrm{C} 3 \mathrm{HO} 2-$; $28.9 \mathrm{~m} / \mathrm{z}, \mathrm{CHO}-$; etc. $)$ are primarily related to other anyhydrosugars, glycolaldehyde, and carbon dioxide. The hemicellulose results show the most abundant fragments include $43.9 \mathrm{~m} / \mathrm{z}(\mathrm{CO} 2-), 17.9$ $\mathrm{m} / \mathrm{z}(\mathrm{H} 2 \mathrm{O}-), 27.9 \mathrm{~m} / \mathrm{z}(\mathrm{CO}-), 42.9 \mathrm{~m} / \mathrm{z}(\mathrm{C} 2 \mathrm{H} 3 \mathrm{O}-)$, and $30.9 \mathrm{~m} / \mathrm{z}$ (CH3O-) relating to water, carbon dioxide, organic acids, and furan/xylopyranose species. These identified fragments also agree with major chemical species observed by others (Patwardhan et al. 2011b). Molecular fragments with the highest intensity from lignin include fragments similar to others mentioned above as well as $46.9 \mathrm{~m} / \mathrm{z}$ (CH3S-), $63.8 \mathrm{~m} / \mathrm{z}$ (C5H4-), and $54.9 \mathrm{~m} / \mathrm{z}$ (C4H7-) relating to aliphatic linkages containing sulfur, and benzene-ring and hydrocarbon

Table 5.3: Top ten most abundant ions formed during pyrolysis at $350^{\circ} \mathrm{C}$.

\begin{tabular}{cccc}
\hline Rank & Cellulose $(\mathrm{m} / \mathrm{z})$ & Hemicellulose $(\mathrm{m} / \mathrm{z})$ & Lignin $(\mathrm{m} / \mathrm{z})$ \\
\hline 1 & 59.9 & 43.9 & 43.8 \\
2 & 72.9 & 17.9 & 17.9 \\
3 & 56.9 & 27.9 & 46.9 \\
4 & 42.9 & 42.9 & 47.9 \\
5 & 68.9 & 30.9 & 44.9 \\
6 & 28.9 & 136.9 & 63.8 \\
7 & 69.9 & 108.9 & 56.9 \\
8 & 55.9 & 28.9 & 59.9 \\
9 & 43.9 & 123.9 & 72.9 \\
10 & 54.9 & 56.9 & 54.9 \\
\hline
\end{tabular}


containing species. These observations can also be related to major phenolic compounds observed in literature (Jackson et al. 2009; Patwardhan et al. 2011a; Zhang et al. 2014). To investigate the degradation of structural components of biomass during pyrolysis, the molecular fragments present in the highest intensity were combined with those observed by others (presented in Table 5.1) in a set of 32 representative fragments related primarily to cellulose $(\mathrm{C})$, hemicellulose $(\mathrm{H})$, and/or lignin $(\mathrm{L}): 18 \mathrm{~m} / \mathrm{z}(\mathrm{C}, \mathrm{H}, \mathrm{L}), 19 \mathrm{~m} / \mathrm{z}(\mathrm{C}, \mathrm{H}), 28$ m/z (C, H, L), 29 m/z (C, H, L), 31 m/z (H), 39 m/z (C), 43 m/z (C, H), 44 m/z (C, H, L), $45 \mathrm{~m} / \mathrm{z}(\mathrm{L}), 47 \mathrm{~m} / \mathrm{z}(\mathrm{L}), 48 \mathrm{~m} / \mathrm{z}(\mathrm{L}), 53 \mathrm{~m} / \mathrm{z}(\mathrm{C}, \mathrm{H}), 55 \mathrm{~m} / \mathrm{z}(\mathrm{C}, \mathrm{L}), 56 \mathrm{~m} / \mathrm{z}(\mathrm{C}), 57 \mathrm{~m} / \mathrm{z}(\mathrm{C}$, H, L), 60 m/z (C, H, L), 64 m/z (L), 69 m/z (C), 70 m/z (C), 73 m/z (C, H, L), 94 m/z (L), 95 m/z (H), 96 m/z (C), 98 m/z (C), 107 m/z (L), 109 m/z (H, L), 124 m/z (H), 137 m/z (H), $153 \mathrm{~m} / \mathrm{z}(\mathrm{L}), 154 \mathrm{~m} / \mathrm{z}(\mathrm{L}), 165 \mathrm{~m} / \mathrm{z}(\mathrm{L})$, and $168 \mathrm{~m} / \mathrm{z}(\mathrm{L})$.

The six consecutive reactions were also applied to the dynamic traces of the 32 unique ion fragment independently from the weight loss proxy. A summary of these data traces along with the model fits at a processing temperature of $350^{\circ} \mathrm{C}$ are shown in Figure 5.4. Because of the nature of tracing molecular fragments instead of a unique chemical compound, the magnitude of fragments in Figure 5.4 were not mass calibrated and are therefore on an arbitrary scale as detected by the instrument. The production rate traces for the molecular fragments appear to have similar behaviors with slightly varying weights given to reactions occurring at early, middling, and late times. If individuals ions that are both primarily related to a single structural component of biomass and produced in a large quantity from that fraction, then some general observations about the degradation of cellulose, hemicellulose, and lignin can be extracted: (1) unique hemicellulose fragments 
observed within the pure component studies such as $124 \mathrm{~m} / \mathrm{z}$ and $137 \mathrm{~m} / \mathrm{z}$ are produced at very early times, and that indicates a relatively lower reaction energy requirement for
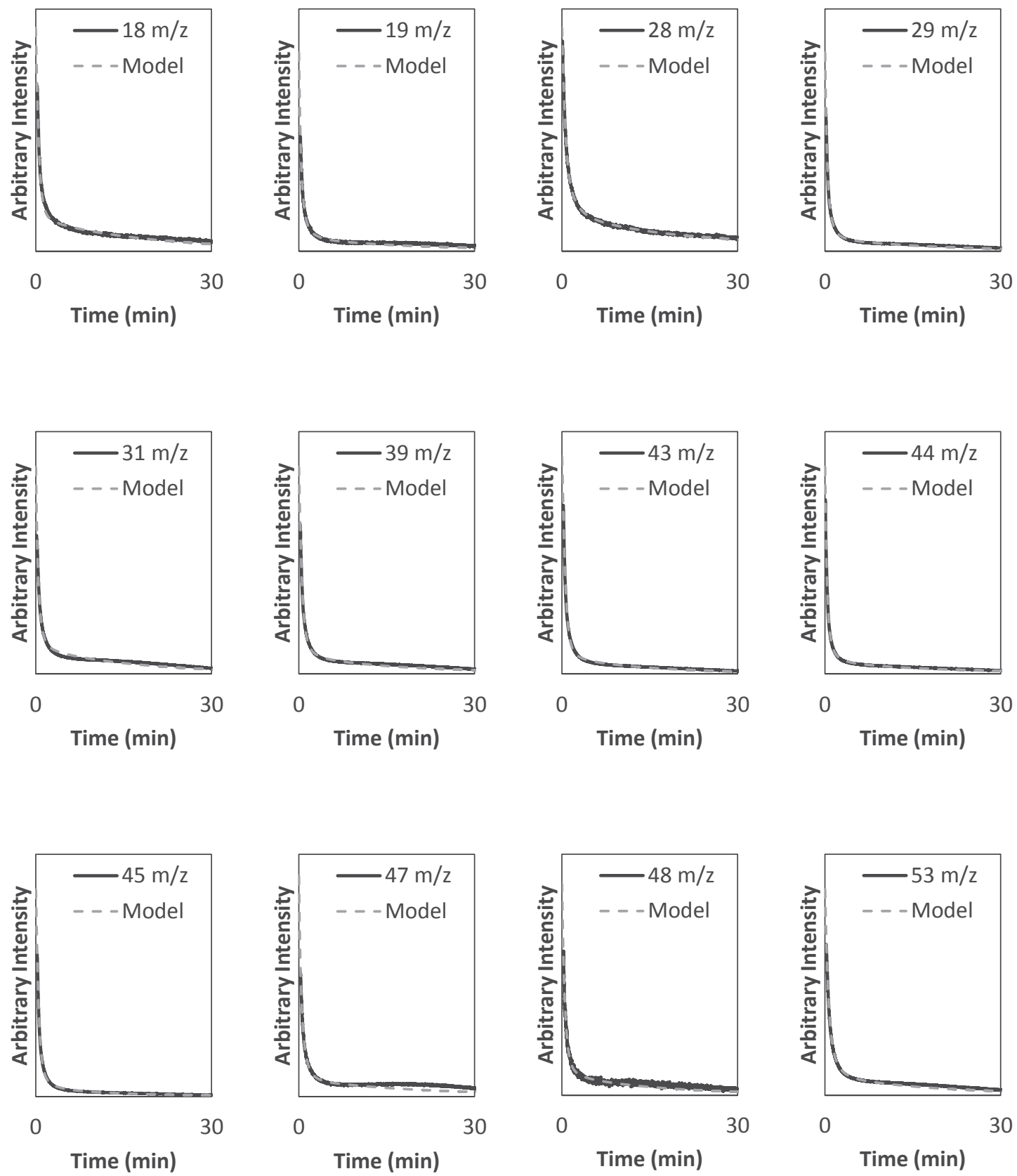

Figure 5.4: Typical experimental traces for 32 mass fragment traces and model fits. Data shown were taken at $350^{\circ} \mathrm{C}$. 
Figure 5.4 Continued
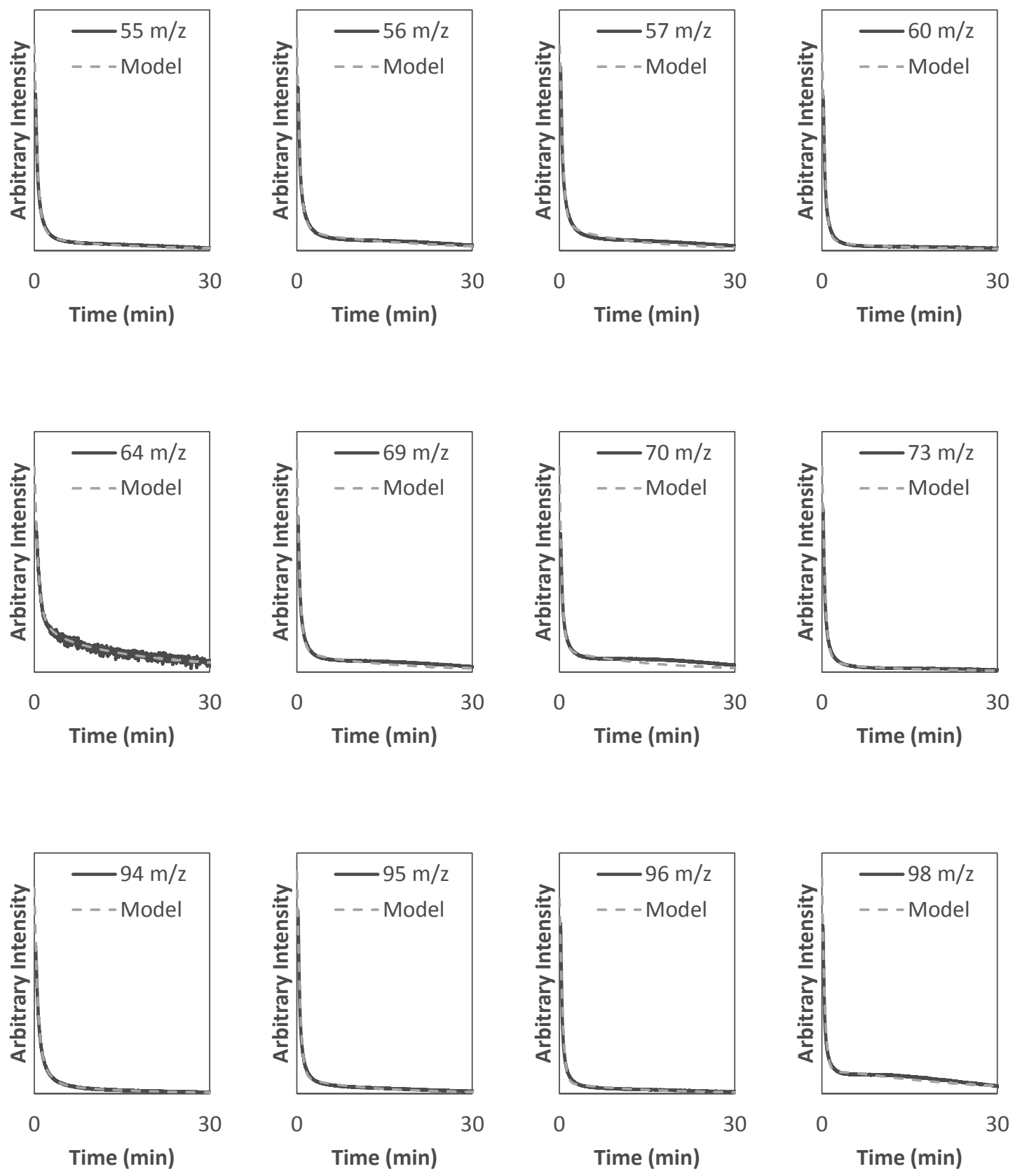
Figure 5.4 Continued
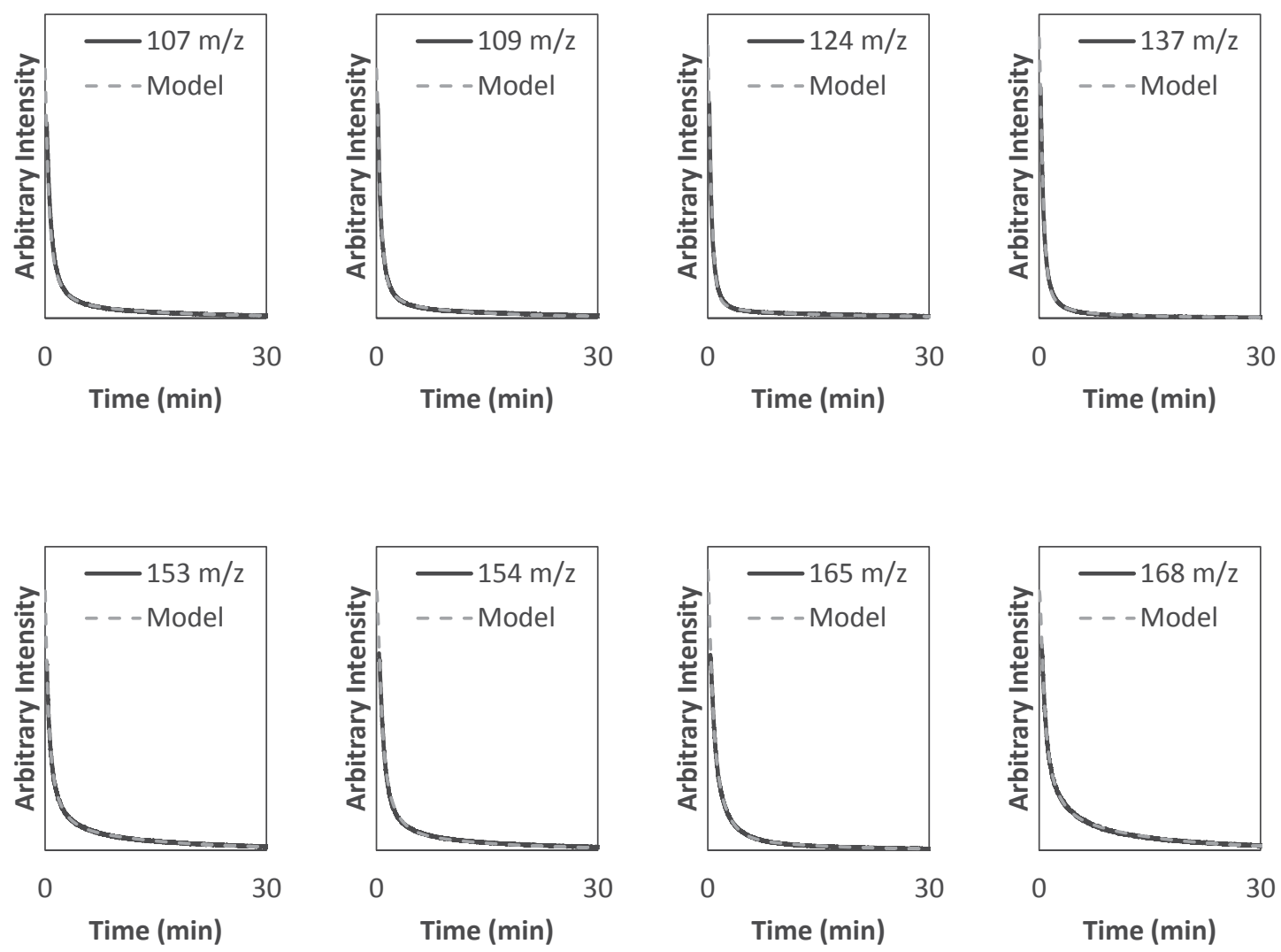

degradation, (2) fragments uniquely related to phenolic compounds such as $168 \mathrm{~m} / \mathrm{z}$ have a production rate that occur over a longer duration indicating a higher energy required for product formation, and (3) cellulose-based fragments such as $39 \mathrm{~m} / \mathrm{z}, 56 \mathrm{~m} / \mathrm{z}$ have production rates between the other components, and likely a middling decomposition energy. These observations are also noted in other literature works (Yang et al. 2007; Sarvaramini et al. 2013; Collard and Blin 2014). To interpret the distribution of production between the six reaction steps, Figure 5.5 shows the average stoichiometry parameters for 


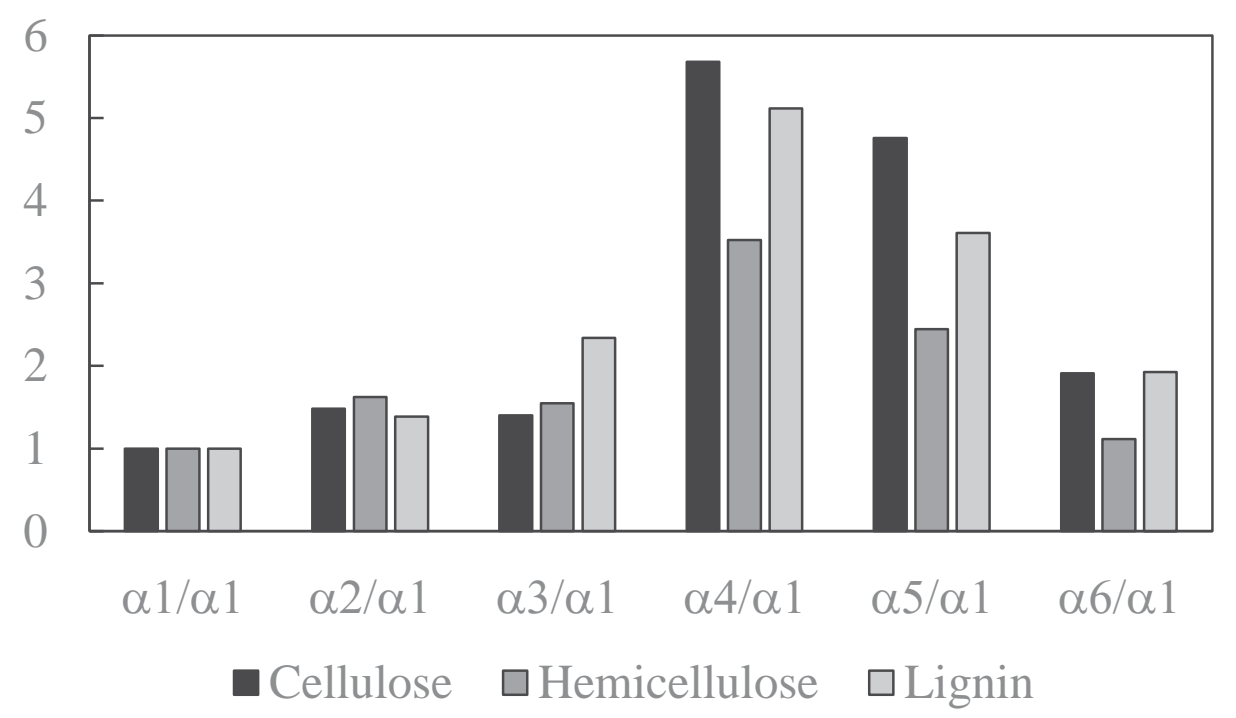

Figure 5.5: Average stoichiometry factor ratios for unique structural component fragments.

the molecular fragments that were identified uniquely to either cellulose, hemicellulose, or lignin in ratio to the first reaction parameter. This demonstrates the relative production attributed to the parent fraction as pyrolysis severity increases. There is significant product from all portions in all reactions, however, hemicellulose qualitatively demonstrated relatively lower production in Rxn 4-6 (high production in Rxn 1-3), cellulose exhibits the highest relative production from late-time reactions (4-6), and the distribution of lignin is middling. This again supports the observations that hemicellulose has a relatively smaller required decomposition energy compared to the high energy required for cellulose noted above, and by others. Table 5.4 lists the average stoichiometry factor ratios obtained for all molecular fragments across all temperatures. These values show the relative distribution of production between the six reaction stages. From the values In Table 5.4 obtained from the fitting procedure, it is demonstrated that some of the various organic fragments are 
produced even at lower processing temperatures, as the earlier reaction have lower activation energies (as shown above for TIC, and following). In general, these early reactions would dominate at lower temperatures (torrefaction) as the rates for the later reactions would be very slow in comparison. This predicts that although more product is formed a higher temperatures, there will be formation of a liquid oil product during torrefaction or slow (conventional) pyrolysis.

Although the production of the various chemical species are distributed between reactions with different characteristic times within the consecutive model, the dynamic behaviors of all species are captured with a 0.99 average coefficient of determination. The time-dependent traces of the chemical species removal provide direct insight to changes in the parent biomass and can yield mechanistic insight. The molecular fragment traces were fit independently from the TIC chromatogram results presented previously. Molecular fragment traces were fit at all pyrolysis temperatures. 
Table 5.4: Stoichiometry parameters for the 32 modeled molecular fragments.

\begin{tabular}{ccccccc}
\hline $\begin{array}{c}\text { Fragment } \\
(\mathbf{m} / \mathbf{z})\end{array}$ & $\boldsymbol{\alpha} \mathbf{1} / \boldsymbol{\alpha} \mathbf{1}$ & $\boldsymbol{\alpha} \mathbf{2} / \boldsymbol{\alpha} \mathbf{1}$ & $\boldsymbol{\alpha} \mathbf{3} / \boldsymbol{\alpha} \mathbf{1}$ & $\boldsymbol{\alpha} \mathbf{4} / \boldsymbol{\alpha} \mathbf{1}$ & $\boldsymbol{\alpha} \mathbf{5} / \boldsymbol{\alpha} \mathbf{1}$ & $\boldsymbol{\alpha} \mathbf{6} / \boldsymbol{\alpha} \mathbf{1}$ \\
\hline 18 & 1.0 & 1.2 & 3.6 & 7.5 & 2.4 & 0.8 \\
19 & 1.0 & 1.5 & 1.7 & 4.9 & 5.8 & 2.7 \\
28 & 1.0 & 1.5 & 3.7 & 12.2 & 8.4 & 1.7 \\
29 & 1.0 & 1.4 & 1.5 & 4.0 & 3.1 & 0.3 \\
31 & 1.0 & 1.5 & 1.8 & 6.7 & 4.9 & 0.3 \\
39 & 1.0 & 1.6 & 1.6 & 5.6 & 4.6 & 1.6 \\
43 & 1.0 & 1.3 & 1.3 & 3.6 & 1.8 & 0.2 \\
44 & 1.0 & 0.9 & 1.1 & 3.2 & 2.4 & 0.4 \\
45 & 1.0 & 1.3 & 1.3 & 1.7 & 1.4 & 0.3 \\
47 & 1.0 & 1.4 & 1.7 & 6.2 & 7.3 & 2.0 \\
48 & 1.0 & 1.3 & 1.4 & 5.0 & 4.0 & 1.4 \\
53 & 1.0 & 1.5 & 2.5 & 6.3 & 5.8 & 2.2 \\
55 & 1.0 & 1.6 & 1.4 & 3.3 & 3.5 & 1.3 \\
56 & 1.0 & 1.4 & 1.6 & 5.9 & 4.4 & 1.8 \\
57 & 1.0 & 1.7 & 1.7 & 4.8 & 4.1 & 2.7 \\
60 & 1.0 & 1.4 & 1.1 & 1.7 & 2.0 & 0.8 \\
64 & 1.0 & 1.5 & 3.4 & 10.3 & 7.9 & 5.3 \\
69 & 1.0 & 1.5 & 1.5 & 5.5 & 6.0 & 2.3 \\
70 & 1.0 & 1.3 & 1.5 & 5.1 & 7.1 & 3.8 \\
73 & 1.0 & 1.3 & 1.7 & 2.1 & 2.9 & 3.4 \\
94 & 1.0 & 1.0 & 1.9 & 2.3 & 1.5 & 2.3 \\
95 & 1.0 & 1.6 & 1.1 & 3.2 & 1.9 & 1.1 \\
96 & 1.0 & 1.5 & 1.0 & 2.4 & 1.7 & 0.7 \\
98 & 1.0 & 1.5 & 1.2 & 9.5 & 4.7 & 1.2 \\
107 & 1.0 & 1.6 & 2.2 & 4.9 & 3.0 & 2.5 \\
109 & 1.0 & 1.4 & 1.8 & 3.7 & 2.4 & 2.2 \\
124 & 1.0 & 1.6 & 1.3 & 2.1 & 1.8 & 1.9 \\
137 & 1.0 & 1.8 & 2.0 & 2.2 & 1.1 & 1.1 \\
153 & 1.0 & 0.5 & 1.5 & 2.8 & 1.7 & 1.3 \\
154 & 1.0 & 2.1 & 3.7 & 6.7 & 4.2 & 1.8 \\
165 & 1.0 & 1.6 & 2.8 & 3.1 & 1.7 & 0.7 \\
168 & 1.0 & 1.5 & 3.5 & 8.0 & 3.5 & 1.7 \\
\hline & & & & & &
\end{tabular}


A summary of the reaction rate constants fit for the 32 molecular fragments with the six stage consecutive model is shown in Figure 5.6. Values fit for the molecular fragments are shown as data points, and the dashed lines represent the average value obtained from the TIC chromatogram fitting discussed previously. The values for rate constants here were obtained independently, and are independent of fragment type/origin. Further, they are in agreement with the values that were obtained from the previous fitting routine with the mass loss proxy. This agreement validates that: (1) the six stage consecutive model predicts the formation of chemical species from the lumped reactions, and (2) there is a close linkage between the total degradation of the biomass and the evolution of any specific chemical species. It is supported that there is an underlying mechanism responsible for the degradation of all species, such as chain scission kinetics. This type of model is also hypothesized for the pyrolysis of cellulose and other polymers in recent literature (Sánchez-Jiménez et al. 2013; Pérez-Maqueda et al. 2014).

These kinetic rate constant fitting values are also summarized in Arrhenius plots in Figure 5.6. Data points are the average rate constant value from all molecular fragments, and the dashed lines are produced with the TIC chromatogram fitting in a previous section. Data for pyrolysis-range temperatures are shown in the bottom left plot, and torrefactionrange temperatures are shown in the bottom right plot. This demonstrated that the proposed lumped six consecutive reaction model is able to describe torrefaction, and pyrolysis on both a weight loss basis and for chemical speciation. This kinetic model unifies the ideas 

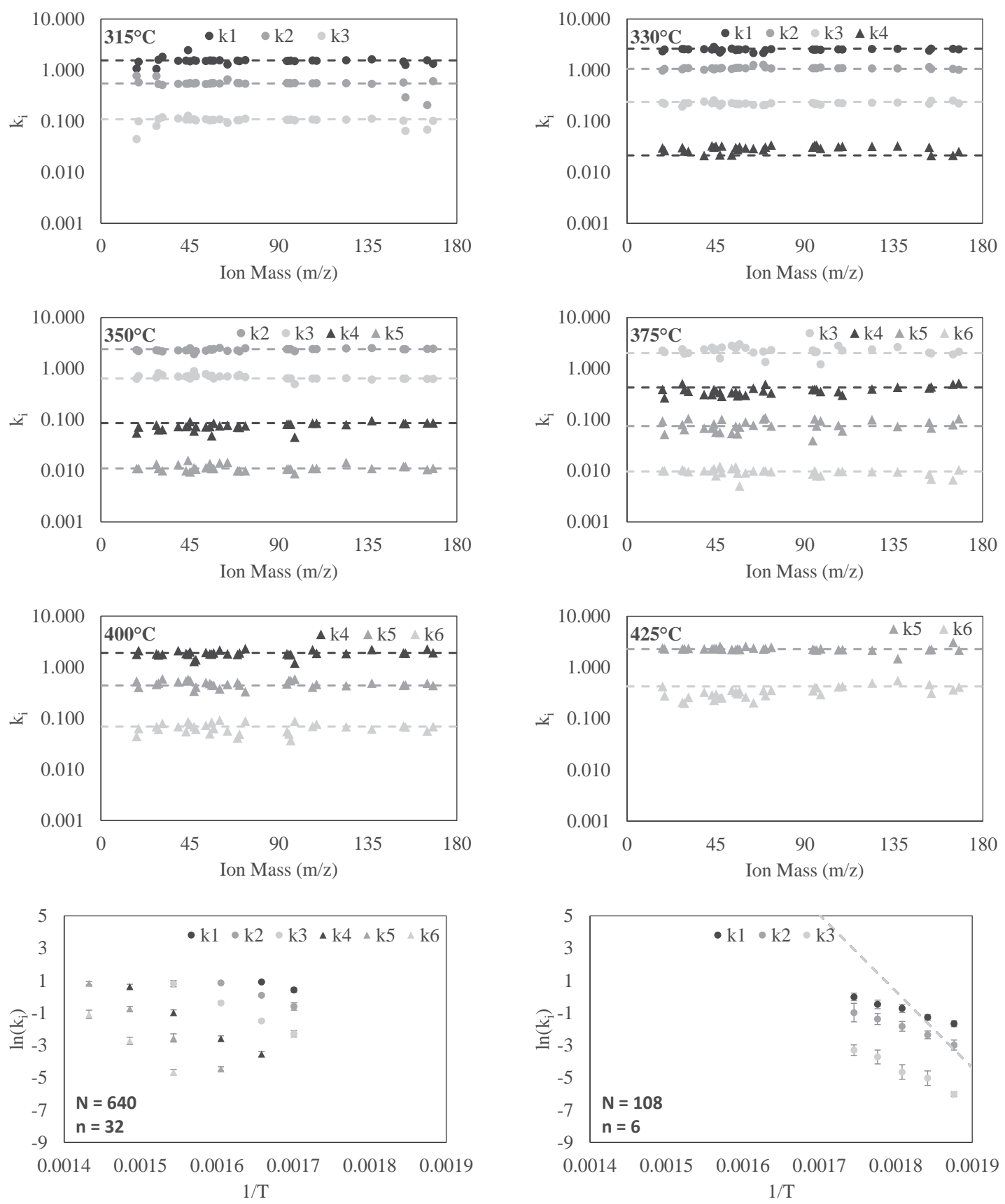

Figure 5.6: Summary of fit rate constants (data points) for molecular fragments at $315^{\circ} \mathrm{C}$ (Top, Left), $330^{\circ} \mathrm{C}$ (Top, Right), $350^{\circ} \mathrm{C}$ (Middle Top, Left), $375^{\circ} \mathrm{C}$ (Middle Top, Right), $400^{\circ} \mathrm{C}$ (Middle Bottom, Left), $425^{\circ} \mathrm{C}$ (Middle Bottom, Right), Arrhenius Plot for the 32 fragments for pyrolysis (Bottom, Left), and Torrefaction (Bottom, Right). Dashed lines show the respective average value obtained from the TIC chromatogram 
of torrefaction and pyrolysis in a single lumped parameter model. Further, this validates that the processes have similar mechanisms that occur at different kinetic rates due to the system temperature.

The rate constants for product formation can also be aggregated back to their parent component fraction (as discussed above). The fragments related to cellulose in ratio to the respective TIC value yield (rate constant from fragment trace fitting/rate constant from TIC fitting) an average value of $0.99 \pm 0.04$, while hemicellulose and lignin have average values of $1.02 \pm 0.04$ and $1.00 \pm 0.05$ respectively. This again validates that there is an underlying mechanism, or set of mechanisms, that are responsible for the removal of each chemical species and the overall changes observed by the biomass. Further, it is asserted that these data are representation that a single process is occurring over the investigated temperature range, any observed differences are from changes in temperature induced reaction rate changes.

The close agreement between the proposed kinetic model and empirical data suggests validity for predicting the chemical dynamics of torrefaction and pyrolysis. Though the instrument was not mass calibrated for the experimental work, normalized data were used to extract qualitative and quantitative data. The kinetic data were collected under conditions where the chemical reactions were rate limiting, using small biomass particles and very fast heating/product quenching rates. These ideal experimental conditions allow for collection of intrinsic reaction data. These intrinsic parameters are a basis for obtaining predictions at any desired processing condition. The model, though, does not attempt to include any effects that heat and mass transport (from large particles), or secondary 
cracking reactions (from mineral content or long gas residence times) have on the product distribution. In addition, the lumped solid reaction intermediates compositions are unknown and act as quasi-species in the reactions. Further model developments such as the effect of conductive heat transport and effects of alkali mineral content are needed in future work to apply the presented chemical dynamics in process-scale reactors.

\subsection{Conclusions}

A novel six consecutive reaction model is presented that can describe a unified view of torrefaction and pyrolysis from $260-425^{\circ} \mathrm{C}$. Fitting torrefaction and pyrolysis data for weight loss and chemical species gas-phase removal to a six stage consecutive model yields kinetic parameters of $104,129,154,217,256$, and $285 \mathrm{~kJ} / \mathrm{mol}$ respectively. It was also demonstrated that there is an underlying mechanism responsible for the degradation of the structural components of biomass. The dynamic chemical species traces presented here can be used to describe torrefaction and pyrolysis in a set of lumped reactions, and also yield mechanistic insight. 


\subsection{Works Cited}

Azargohar R, Nanda S, Kozinski JA, Dalai AK, Sutarto R. 2014. Effects of temperature on the physicochemical characteristics of fast pyrolysis bio-chars derived from Canadian waste biomass. Fuel 125(0):90-100.

Branca C, Giudicianni P, Di Blasi C. 2003. GC/MS Characterization of Liquids Generated from Low-Temperature Pyrolysis of Wood. Industrial \& Engineering Chemistry Research 42(14):3190-3202.

Branca C, Di Blasi C, Galgano A, Broström M. 2014. Effects of the Torrefaction Conditions on the Fixed-Bed Pyrolysis of Norway Spruce. Energy \& Fuels 28(9):5882-5891.

Chew JJ, Doshi V. 2011. Recent advances in biomass pretreatment - Torrefaction fundamentals and technology. Renewable and Sustainable Energy Reviews 15(8):4212-4222.

Collard F-X, Blin J. 2014. A review on pyrolysis of biomass constituents: Mechanisms and composition of the products obtained from the conversion of cellulose, hemicelluloses and lignin. Renewable and Sustainable Energy Reviews 38(0):594608.

Di Blasi C, Branca C, Masotta F, De Biase E. 2013. Experimental Analysis of Reaction Heat Effects during Beech Wood Pyrolysis. Energy \& Fuels 27(5):2665-2674. 
EPA. 2014. Inventory of U.S. Greenhouse Gas Emissions and Sinks 1990-2012. U.S. Environmental Protection Agency EPA 430-R-14-003.

Eseltine D, Thanapal SS, Annamalai K, Ranjan D. 2013. Torrefaction of woody biomass (Juniper and Mesquite) using inert and non-inert gases. Fuel 113(0):379-388.

Fichman BT. 2015. Monthly Energy Review DOE/EIA-0035(2015/01). In: U.S.EIA, editor. 1 ed. Washington, DC: Office of Energy Statistics. p. DOE/EIA0035(2015/01).

Huang J, Liu C, Wei S, Huang X, Li H. 2010. Density functional theory studies on pyrolysis mechanism of $\beta$-d-glucopyranose. Journal of Molecular Structure: THEOCHEM 958(1-3):64-70.

Isahak WNRW, Hisham MWM, Yarmo MA, Yun Hin T-y. 2012. A review on bio-oil production from biomass by using pyrolysis method. Renewable and Sustainable Energy Reviews 16(8):5910-5923.

Jackson MA, Compton DL, Boateng AA. 2009. Screening heterogeneous catalysts for the pyrolysis of lignin. Journal of Analytical and Applied Pyrolysis 85(1-2):226-230.

Kelkar S, Li Z, Bovee J, Thelen KD, Kriegel RM, Saffron CM. 2014. Pyrolysis of NorthAmerican grass species: Effect of feedstock composition and taxonomy on pyrolysis products. Biomass and Bioenergy 64(0):152-161.

Kim KH, Eom IY, Lee SM, Choi D, Yeo H, Choi I-G, Choi JW. 2011. Investigation of physicochemical properties of biooils produced from yellow poplar wood 
(Liriodendron tulipifera) at various temperatures and residence times. Journal of Analytical and Applied Pyrolysis 92(1):2-9.

Klinger J, Bar-Ziv E, Shonnard D. 2013. Kinetic study of aspen during torrefaction. Journal of Analytical and Applied Pyrolysis 104(0):146-152.

Klinger J, Bar-Ziv E, Shonnard D. 2014a. Predicting Properties of Torrefied Biomass by Intrinsic Kinetics. Energy \& Fuels 29(1):171-176.

Klinger J, Klemetsrud B, Bar-Ziv E, Shonnard D. 2014b. Temperature dependence of aspen torrefaction kinetics. Journal of Analytical and Applied Pyrolysis 110(0):424-429.

Li S, Lyons-Hart J, Banyasz J, Shafer K. 2001. Real-time evolved gas analysis by FTIR method: an experimental study of cellulose pyrolysis. Fuel 80(12):1809-1817.

Mohan D, Pittman CU, Steele PH. 2006. Pyrolysis of Wood/Biomass for Bio-oil: A Critical Review. Energy \& Fuels 20(3):848-889.

Nocquet T, Dupont C, Commandre J-M, Grateau M, Thiery S, Salvador S. 2014a. Volatile species release during torrefaction of wood and its macromolecular constituents: Part 1 - Experimental study. Energy 72(0):180-187.

Nocquet T, Dupont C, Commandre J-M, Grateau M, Thiery S, Salvador S. 2014b. Volatile species release during torrefaction of biomass and its macromolecular constituents: Part 2 - Modeling study. Energy 72(0):188-194. 
Patwardhan PR, Satrio JA, Brown RC, Shanks BH. 2009. Product distribution from fast pyrolysis of glucose-based carbohydrates. Journal of Analytical and Applied Pyrolysis 86(2):323-330.

Patwardhan PR, Brown RC, Shanks BH. 2011a. Understanding the Fast Pyrolysis of Lignin. ChemSusChem 4(11):1629-1636.

Patwardhan PR, Brown RC, Shanks BH. 2011b. Product Distribution from the Fast Pyrolysis of Hemicellulose. ChemSusChem 4(5):636-643.

Pérez-Maqueda LA, Sánchez-Jiménez PE, Perejón A, García-Garrido C, Criado JM, Benítez-Guerrero M. 2014. Scission kinetic model for the prediction of polymer pyrolysis curves from chain structure. Polymer Testing 37:1-5.

Ponder GR, Richards GN, Stevenson TT. 1992. Influence of linkage position and orientation in pyrolysis of polysaccharides: A study of several glucans. Journal of Analytical and Applied Pyrolysis 22(3):217-229.

Sánchez-Jiménez PE, Pérez-Maqueda LA, Perejón A, Criado JM. 2013. Generalized master plots as a straightforward approach for determining the kinetic model: the case of cellulose pyrolysis. Thermochimica Acta 552:54-59.

Sarvaramini A, Assima GP, Larachi F. 2013. Dry torrefaction of biomass - Torrefied products and torrefaction kinetics using the distributed activation energy model. Chemical Engineering Journal 229(0):498-507. 
Shen DK, Gu S. 2009. The mechanism for thermal decomposition of cellulose and its main products. Bioresource Technology 100(24):6496-6504.

Trendewicz A, Evans R, Dutta A, Sykes R, Carpenter D, Braun R. 2015. Evaluating the effect of potassium on cellulose pyrolysis reaction kinetics. Biomass and Bioenergy 74(0):15-25.

van der Stelt MJC, Gerhauser H, Kiel JHA, Ptasinski KJ. 2011. Biomass upgrading by torrefaction for the production of biofuels: A review. Biomass and Bioenergy 35(9):3748-3762.

Westerhof RJ, Brilman DWF, Garcia-Perez M, Wang Z, Oudenhoven SR, Kersten SR. 2012. Stepwise fast pyrolysis of pine wood. Energy \& Fuels 26(12):7263-7273.

Westover TL, Phanphanich M, Clark ML, Rowe SR, Egan SE, Zacher AH, Santosa D. 2013. Impact of thermal pretreatment on the fast pyrolysis conversion of southern pine. Biofuels 4(1):45-61.

Yang H, Yan R, Chen H, Lee DH, Zheng C. 2007. Characteristics of hemicellulose, cellulose and lignin pyrolysis. Fuel 86(12-13):1781-1788.

Zhang M, Resende FLP, Moutsoglou A. 2014. Catalytic fast pyrolysis of aspen lignin via Py-GC/MS. Fuel 116(0):358-369. 


\section{Application of a Kinetic Pyrolysis Model}

Reprinted with permission from ENERGY \& FUELS, submitted for publication. Unpublished work Copyright 2015 American Chemical Society. ${ }^{5}$

\subsection{Abstract}

Pyrolysis has the potential to create a bio-crude oil from biomass sources that can be used a fuel or feedstock for subsequent upgrading to hydrocarbon fuels or other chemicals. The product distribution/composition, however, is linked to the biomass source. This work investigates the products formed from pyrolysis of woody biomass with a previously developed chemical kinetics model. Different woody feedstocks reported in prior literature are placed on a common basis (moisture, ash, fixed carbon free) and normalized by initial elemental composition through ultimate analysis. Observed product distributions over the full devolatilization range are explored, reconstructed by the model, and verified with independent experimental data collected with a microwave-assisted pyrolysis system. These trends include production of permanent gas $\left(\mathrm{CO}, \mathrm{CO}_{2}\right)$, char, and condensable (oil, water) species. Elementary compositions of these streams are also investigated. Close agreement between literature data, model predictions, and independent experimental data indicate that the proposed model/method is able to predict the ideal

\footnotetext{
${ }^{5}$ The material contained in this chapter has been submitted to Energy \& Fuels.
} 
distribution from fast pyrolysis given reaction temperature, residence time, and feedstock composition.

\subsection{Introduction}

Thermal degradation of polymers in an inert atmosphere can selectively degrade the structure based on the processing severity (temperature and residence time). At mild conditions $\left(400-600{ }^{\circ} \mathrm{C}\right)$, this process is referred to as pyrolysis and detaches many smaller species that originate from the parent structure. In the case of biomass, pyrolysis creates a solid carbonaceous char, permanent gases (mainly $\mathrm{CO}$, and $\mathrm{CO} 2$ ), many organic molecules such as ketones, organic acids, aldehydes, phenolics, cyclics, saccharide based fragments, and larger polyphenolic polymers collectively referred to as pyrolytic tars(Meier and Faix 1999; Mohan et al. 2006). Because of the processing temperature, most of the original mass is partitioned into species that are condensable at ambient temperatures. This condensed mixture, bio-oil, is typically very viscous, acidic, and has a composition that is reflective of the parent biomass(Bridgwater et al. 1999; Mohan et al. 2006). Bio-oil can be used as a fuel oil for heating or electricity generation, or it can be upgraded to produce chemicals or hydrocarbon fuels. Due to the nature of utilizing biomass for energy, many sources of feedstock are needed to meet the large modern day energy consumption - and subsequently brings about process considerations due to heterogeneity of biomass feedstock sources and resulting bio-oil(Tumuluru et al. 2012; Kenney et al. 2013; Carpenter et al. 2014). To ensure product consistency and quality, processing conditions must be carefully controlled, or tailored to the specific biomass source being processed. Establishing correlations or 
models to predict these properties is essential for efficient utilization of feedstock resources.

Numerous review and experimental articles study the properties of pyrolysis products and their impact on fuel quality or applications(Bridgwater et al. 1999; Oasmaa and Czernik 1999; Czernik and Bridgwater 2004; Mohan et al. 2006; M Garcia-Perez et al. 2007; Ingram et al. 2007; Qi Zhang et al. 2007b; Manuel Garcia-Perez et al. 2008; Lu et al. 2009; Bridgwater 2012). Many of the current studies are parametric in nature, and reportedly change based on many factors such as temperature, residence time, particle size, vapor residence time, biomass feedstock composition, and moisture, among others. For example, in 2008 Garcia-Perez et al.(Manuel Garcia-Perez et al. 2008) performed a comprehensive study on the pyrolysis of mallee wood and the resulting product properties. They found that as processing temperature increased (severity), the solid yield from the process decreased (almost linearly). Furthermore, the decrease in solid yield is associated with a linear decrease in solid volatile matter as oxygen decreases from 25 to $10 \%$ and carbon increases from approximately 70 to $87 \%$, which also leads to an increased heating value. The overall decrease in solid yield is balanced between increased liquid and gas phase yields. The main gas phase species, $\mathrm{CO} 2$ and $\mathrm{CO}$, increase in a similar ratio over the processing conditions with minimal contribution from hydrocarbons. These same trends are observed in other literature sources across feedstock type and processing conditions(Agblevor et al. 1995; Manuel Garcia-Perez et al. 2008; RW Nachenius et al. 2015a), suggesting an underlying relationship that has yet to be described. This paper uses 
a kinetic model to further elucidate the relationship between processing conditions and product properties.

Previously, our group developed a kinetic model to describe torrefaction through a series of three consecutive reactions(Klinger et al. 2013). During these lumped pseudochemical reactions, the solid biomass breaks down into a series of intermediates and a set of gas/vapor phase species. The solid intermediates are assumed to be a partially degraded form of the original biomass where the carbohydrate and fiber fractions of the material have gone through scission reactions. The fiber/carbohydrates are then represented by smaller amount of the original cellulose, hemicellulose, and lignin at shorter average degrees of polymerization. The solid intermediates become progressively more recalcitrant with higher activation energies as weakly bound compounds are broken and removed from the chemical structure.

This lumped model approach was then extended into the pyrolysis range from 300$425{ }^{\circ} \mathrm{C}$ using a series of size pseudo-reactions(Klinger et al. 2015). At these increased temperatures, more chemical production was observed from more complete degradation of the cellulose and lignin fractions in particular. This increased degradation of cellulose and lignin at higher temperatures has also been observed by others(Yang et al. 2007; Sarvaramini et al. 2013; Collard and Blin 2014). These six pseudo-reactions also proceeded through a set of five solid intermediates that require increasing energies to degrade until only the fixed carbon and mineral content, or non-volatile mass, remains. These six reactions, likely representing many near-parallel reactions across the consecutive stages, were able to accurately describe dynamic gas-vapor species production. The model was 
based upon the identification of 32 unique chemical masses that were volatized as well as upon measurements of total weight loss. Stoichiometry factors were used to partition the relative production of the species through the six reactions. These reactions and parameters are summarized in Reactions 1-6 below where $j$ denotes intermediate reaction stage $(2,3,4$, or 5), $R_{j}$ is a degraded solid intermediate during reaction $j, \alpha_{j, i}$ is a stoichiometric parameter for species $i$ in reaction $j, P_{j, i}$ is product $i$ formed in reaction $j$. The activation energies were found to be $104,129,154,217,256$, and $285 \mathrm{~kJ} / \mathrm{mol}$ respectively with frequency factors of 2.6E9, 1.6E11, 5.0E12, 1.2E17, 3.6E19, and 9.3E20 $\mathrm{min}^{\wedge}-1$ respectively(Klinger et al. 2015). This work showed that torrefaction and pyrolysis can be explained by a single unified model and are similar processes. The activation energies for the progressive stages of degradation increase and can explain the differences in product production rate and component (cellulose, hemicellulose, lignin) degradation within the different temperature regimes.

$$
\begin{gathered}
\text { Biomass } \stackrel{k_{1}}{\rightarrow} R_{1}+\sum \alpha_{1, i} P_{1, i} \\
R_{j-1} \stackrel{k_{j}}{\rightarrow} R_{j}+\sum \alpha_{j, i} P_{j, i} \\
R_{5} \stackrel{k_{6}}{\rightarrow} \text { Char }+\sum \alpha_{6, i} P_{6, i}
\end{gathered}
$$

In this work the applications of such a kinetic model were explored for understanding the products of fast pyrolysis. Throughout this manuscript, fast pyrolysis refers to pyrolysis processing in which the reactions are limited primarily by reaction kinetics, not heat transfer limitation. Importantly, because the reaction kinetics for processing temperatures colder than $300{ }^{\circ} \mathrm{C}$ (i.e. torrefaction) are relatively slow, in many 
cases, torrefaction can be considered mild fast pyrolysis. Consequently, torrefaction and fast pyrolysis reaction data from the literature are grouped together in this work. The justification for this grouping is discussed further below. Data for the elemental composition of pyrolytic chars at various extents of reactions are used to determine the composition of the solid pseudo-reactant intermediates in the model and calibrate the model predictions. The predictions of the yield of gaseous, liquid, and solid product were explored and compared to literature data, in addition to the distribution of permanent gases $(\mathrm{CO}, \mathrm{CO} 2)$, water, and the condensable pyrolysis oil. The retention of the embodied energy in the pyrolytic chars was also investigated. Model predictions are compared against a broad literature survey for fast pyrolysis and torrefaction data, in addition to experimental data gathered independently for model/method validation. Variation in feedstock composition is addressed through normalization as discussed below.

\subsection{Material and Methods}

Micropyrolsis experiments and development of the pyrolysis model were conducted at Michigan Tech, with experimental and modeling details described in previous

work(Klinger et al. 2014a; Klinger et al. 2014b; Klinger et al. 2015). The model was validated using experimental data from Idaho National Laboratory (INL) using an microwave-assisted pyrolysis system as well as data published in literature(Westover et al. 2013; Howe et al. 2015). The samples used in the microwave-assisted fast pyrolysis tests include clean and whole tree pine, hybrid poplar, and tulip poplar. Detailed characterization of the samples has been described in a previous publication(Westover et al. 2013; Howe et al. 2015). Brief experimental details are provided here for convenience. 


\subsubsection{Micropyrolysis Experiments}

Micropyrolysis experiments for kinetic model development were performed with a CDS 5200HP Pyroprobe resistive filament pyrolyzer. The unit is capable of achieving approximately $1000^{\circ} \mathrm{C} / \mathrm{s}$ heating rates with predominantly radiative transport to the biomass sample. Samples studied with the micropyrolysis unit were debarked aspen fibers (500-600 $\mu \mathrm{m}, 100-300 \mu \mathrm{g})$. The pyrolyzer was connected directly to a GC/MS unit (ThermoFisher trace GC, DSQII MS) with a heated transfer line that was maintained at $300{ }^{\circ} \mathrm{C}$ to prevent product vapors from condensing. The GC/MS was equipped with a short non-retentive guard column and maintained at $300{ }^{\circ} \mathrm{C}$ to minimize convolution of dynamic product traces before data acquisition.

\subsubsection{Modeling Approach}

The kinetic model is described in Reactions 1-6 above. To calibrate the modeling parameters, literature data were collected for the product distribution and composition from fast pyrolysis of woody biomass for the entire temperature range studied (Agblevor et al. 1995; Prins et al. 2006; Arias et al. 2008; Manuel Garcia-Perez et al. 2008; Salehi et al. 2011; Sinağ et al. 2011; Wannapeera et al. 2011; Broström et al. 2012; Westerhof et al. 2012; Zheng et al. 2012; Ren et al. 2013; Branca et al. 2014; Nocquet et al. 2014a; 2014b; Howe et al. 2015; RW Nachenius et al. 2015a; Robert W Nachenius et al. 2015b). In these studies, fast pyrolysis implies decoupled reaction kinetics to heat and mass transport effects, and therefore has negligible influence due to transport phenomena. This is achieved through fast heating rate/flux into the biomass particles and small overall particle size. Selected studies were chosen where data were present for weight distribution between 
solid, liquid, gas phase species, distribution of primary gas species $\left(\mathrm{CO}\right.$ and $\left.\mathrm{CO}_{2}\right)$, water formed during pyrolysis, elemental distribution $(\mathrm{C}, \mathrm{H}, \mathrm{O})$ through ultimate analysis, and/or proximate analysis and heating value data. These data were tabulated with their respective processing times and temperatures. At sufficiently fast heating rates as discussed above, sample particles are uniformly heated, and the process can be decoupled from heat transfer dynamics, and can be expressed in an extent of reaction through pyrolysis. For this work, the extent or reaction is expressed through mass loss observed by biomass sample, or the amount of volatile matter removed. For the woody feedstocks used in the studies above, the non-volatile matter (mineral content and fixed carbon) sum to approximately $10-15 \%$ (12\% average used during modeling) of the initial dry weight. Because of this, the extent of reaction (mass loss) ranges from $0-88 \%$ where remaining organic matter is the nonvolatile fixed carbon. Secondary reactions are primarily attributed to the presence of significant alkali mineral content or long gas-phase residence times but were not considered because the surveyed data were sourced from fast pyrolysis systems with short vapor-phase residence times and used woody biomass with insignificant mineral content(Wei et al. 2006; Jieling Zhang et al. 2007a; Shen and Gu 2009; Trendewicz et al. 2015).

These literature data were used to calibrate the composition of the solid intermediates of Rxn 1-5 from an assumed feed of 1 mole of hydrogen contained in the parent biomass ( 16.6 grams), and complete degradation to a solid char with only the nonvolatile mass remaining as char (solid product in $\mathrm{Rxn} 6$ ). The non-volatile mass is considered as the fixed carbon content $(\sim 12 \mathrm{wt} \%)$ and mineral content (negligible for 
woody biomass). An average initial composition from the literature sources of woody biomass was used to initiate the model (48\% carbon, $6.0 \%$ hydrogen, $46 \%$ oxygen). Fitting was performed by minimizing the squared difference between the bulk literature trends and the model predictions for composition $(\mathrm{C}, \mathrm{H}, \mathrm{O})$ of the solid reactant, the production of reaction-formed water, and the mass distribution between the $\mathrm{CO}$ and $\mathrm{CO} 2$ in the permanent gas stream. Predictions for the oil species (excluding water) are found through an elemental balance. The embodied energy of the solid products is found through a correlation developed to predict heating values of a wide range of biomass species(Friedl et al. 2005). From a set of 122 samples studied, an accurate and robust estimate of the heating value is given by $H H V=3.55 C^{2}-232 C-2230 H+51.2 C \times H+131 N+$ 20,600, where the heating value, $\mathrm{HHV}$, is expressed in $\mathrm{kJ} / \mathrm{kg}, \mathrm{C}, \mathrm{H}$, and $\mathrm{N}$ are the weight percent contributions from carbon, hydrogen and nitrogen respectively. Embodied energy in the produced water and $\mathrm{CO} 2$ are taken as zero by definition, and a typical value of 10.1 $\mathrm{MJ} / \mathrm{kg}$ was used for the HHV of carbon monoxide. The remaining embodied energy from the feedstock is attributed to the condensable oil product.

\subsubsection{Feedstock/Solid Product Characterization}

Feedstock for experimental validation of the model were four different wood species including clean pine (Bulter, AL), whole pine (Butler, AL), hybrid poplar (Morrow, OR), and tulip poplar (Knox, KY). Proximate analysis were carried out with a LECO TGA701 (LECO, St. Joseph, MI) according to ASTM D5142. Ultimate analysis (CHN) was performed using a modified ASTM D5373 method for a slightly shorter burn profile with a LECO TruSpec CHN Analyzer (LECO, St. Joseph, MI). Oxygen content was 
determined by difference. Heating values (HHV) were determined using ASTM D5865-10 with a LECO AC600 calorimeter (LECO, St. Joseph, MI). Average values of at least duplicate measurements were used in this study.

\subsubsection{Fast Pyrolysis}

A microwave-assisted fast pyrolysis reactor was used to obtain independent data for model validation. Here fast pyrolysis refers to processing in which reactions are limited by chemical reaction kinetics, not heat transfer. The lab-scale microwave pyrolysis unit was used for data collection from low to high severity levels (conditions described below). To enhance microwave absorption, samples were ground using a Retzch ZM200 fine grinder equipped with a $200 \mu \mathrm{m}$ screen and then doped with 5\% activated charcoal from Sigma Aldrich. The experimental apparatus consisted of a quartz tube surrounded by an insulated microwave cavity (furnace) that can be independently heated with resistive heaters to $550{ }^{\circ} \mathrm{C}$. A $3 \mathrm{~kW}$ SM1250D model microwave generator (MKS Instruments, Andover, MA) was used in combination with a waveguide and microwave auto-tuners to briefly focus a microwave beam onto samples inside the cavity to achieve fast pyrolysis heating rates. A PRO 82 pyrometer (Williamson, Concord, MA) was used to monitor sample temperature during the reaction. The sample temperature from the pyrometer and the performance of the microwave generator, including forward and reverse powers were tracked within LabVIEW (National Instruments, Austin, TX), which used that data other operator inputs to automatically control the microwave power to quickly reach the target reaction temperature and then turn off the microwave power. 
Each experiment was performed by following 6 steps. (1) Preheat the microwave cavity and a quartz tube to 300,375 , or $450{ }^{\circ} \mathrm{C}$ using resistive heating. (2) Load a sample into the end of the tube away from the heated furnace and start a nitrogen purge gas flow of $2 \mathrm{~L} / \mathrm{min}$. (3) After an inert atmosphere is achieved in the quartz tube, the sample is relocated to the center of the heated microwave cavity using a pushrod to maintain inert atmosphere. (4) The microwave beam is activated to rapidly heat the samples to the target reaction temperature, which 320,395 , and $470{ }^{\circ} \mathrm{C}$, and then the microwave power was automatically shut-off. All target reaction temperatures in these results were reached within $8.0 \mathrm{sec}$. (5) After a total residence time of 20 seconds, the quartz tube containing the samples is removed from the furnace and cooled using reverse N2 flow. (6) After the quartz tube and sample cools to approximately $100{ }^{\circ} \mathrm{C}$, the sample is removed, and sample and gas line components are weighed to determine solid and liquid yields. Each experimental condition was performed in triplicate.

Importantly, the feedstocks chosen for the microwave pyrolysis are identical to feedstocks that were previously prepared at Idaho National Laboratory (INL) and tested for fast pyrolysis conversion at the National Renewable Energy Laboratory (NREL) in a 2 inch fluidized bed fast pyrolysis system(Westover et al. 2013; Howe et al. 2015). Because the feedstocks chosen for the microwave tests are identical to feedstocks that have been tested in an established fluidized bed fast pyrolysis reactor, direct comparison of the product data can establish the relevance of the microwave approach to fluidized bed fast pyrolysis. Motivation for using a microwave-assisted fast pyrolysis system are (1) each test can be completed, including the weighing of products, in minutes, rather than hours or 
days; (2) because of microwave heating, heat transfer media, such as silica sand, is not necessary, greatly simplifying the process to weigh the solid products; (3) the microwave heats the samples internally allowing for potentially larger particles and slower surface heating rates while still achieving fast pyrolysis conditions.

\subsubsection{Pyrolysis Product Characterization}

Proximate and ultimate analyses of the bio-oil and char was performed using the same methods described above in Section 2.3. Water content of bio-oil was measured in accordance with ASTM D5530 by Karl Fisher titration, and was measured in triplicate and quantified against NIST traceable water standards. A Model300® NDIR (California Analytical Instruments) and three-channel (10m MS 5A, 10m PBQ, and 8m CP Sil 5) CP 4900 MicroGC (Varian) were used to measure and record permanent gas products.

\subsection{Results and Discussion}

\subsubsection{Model Calibration}

The kinetic model is displayed in Rxn 1-6 above and was previously developed from careful study of chemical dynamics(Klinger et al. 2015). In order to make mass-based predictions for pyrolysis products, several parameters were calibrated to literature data as discussed in section 2.2. The calibrated parameters include the elemental composition of the solid reaction intermediates, $R_{j}$, and the reaction stoichiometric parameters for noncondensable gases ( $\mathrm{CO}$ and $\mathrm{CO} 2)$ and water.

Figure 6.1 shows a comparison of relative elemental composition in solids from literature ("Literature") and the experimental data ("Experimental") gathered from the 
microwave assisted pyrolyzer over the mass loss observed by the original sample. Also highlighted are data reported by Howe et al. because the same feedstock was used. There is a general trend to the data, where the relative carbon content begins around $50 \%$, and increases to approximately $60 \%$ at $50 \%$ removal of initial sample mass. As mass is further removed, the rate of change in the relative carbon content increases to final value approaching 100\%, which consists almost exclusively of fixed carbon. The increase in carbon content is due to the selective removal of hydrogen and oxygen. At $50 \%$ mass removal, average oxygen content decreased from approximately $45 \%$ to $35 \%$ while average hydrogen content decreases only slightly from approximately $6.0 \%$ to $5.5 \%$. The relative amounts of both hydrogen and oxygen quickly decay to their final values near zero when the material is fully de-volatilized. Though these general trends apply across many different studies investigating woody feedstock, there is substantial scatter likely due to experimental uncertainties and, perhaps more substantially, due to variability in feedstock composition within woody feedstock. Evidence of the importance of feedstock variability is shown by the close agreement between the experiments using microwave-assisted fast pyrolysis and the fluidized bed results reported by (Howe et al.) using the same four feedstock.

Because of the large scatter in empirical data, a more uniform comparison was pursued. As previously stated, the scatter is thought to be primarily attributable to differences in feedstock composition. To account for this, two factors were considered: (1) results are considered on a fixed carbon free basis, and (2) results were normalized by 

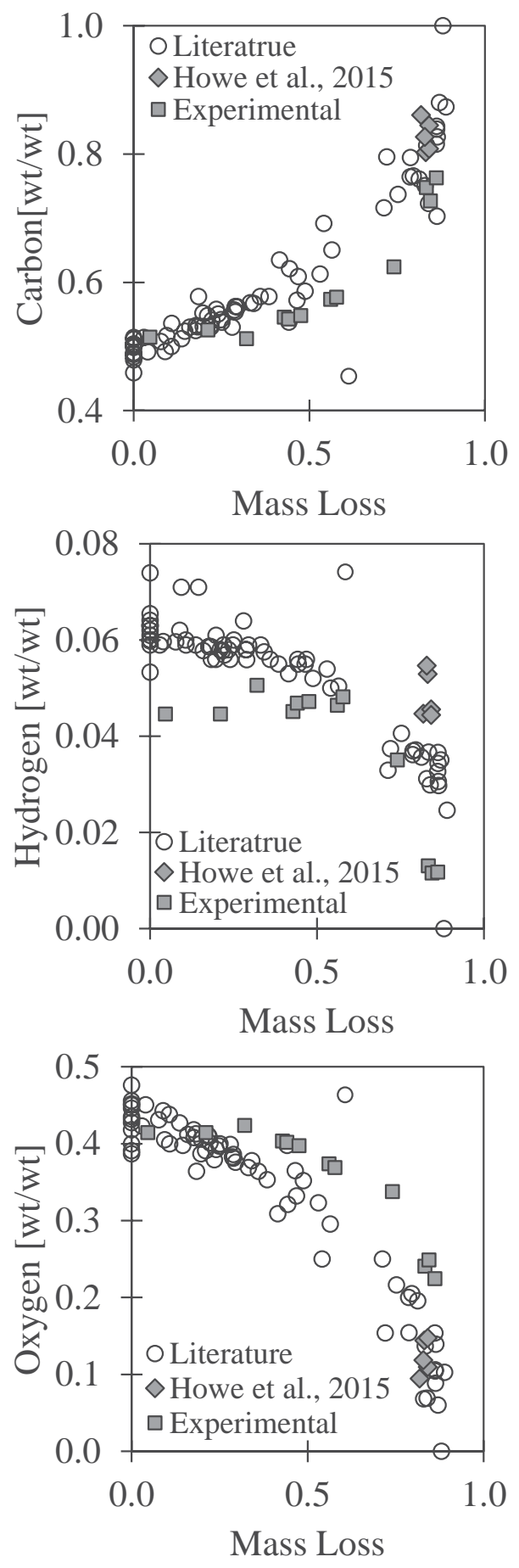

Figure 6.1: Experimental and literature data for relative composition of wood char through pyrolysis. Literature data from (Arias et al. 2008; Salehi et al. 2011; Wannapeera et al. 2011; Broström et al. 2012; Howe et al. 2015; RW Nachenius et al. 2015a). Mass Loss is on a moisture and ash free basis. 
the initial elemental distribution. Fixed carbon for the species studied here, and reported in literature, range from approximately $12-19 \%$. This mass is non-volatile by definition (although it can be catalytic) and impacts the relative composition measurements shown in Figure 6.1. The second consideration was to normalize the measured/predicted elemental mass with the initial mass of the element present in the sample. The hypothesis here is that if heat transport limitations and secondary reactions catalyzed by mineral content or fixed carbon are negligible, then fast pyrolysis products are qualitatively similar. The products may be quantitatively different, however, based upon their diverse carbohydrate/fiber distribution. Normalizing results based upon initial bio-polymer compositions (cellulose, hemicellulose, lignin) addresses the variability between different raw feedstocks, placing the data on similar bases. Figure 6.2 shows the agreement between reported experimental data and model predictions for carbon, hydrogen, and oxygen remaining in the solid product, reported on an ash, moisture, and fixed carbon free basis. This new basis is referred to as "volatile loss*". On this basis, there is much less scatter between the empirical data, and a general trend for degradation becomes more apparent. The literature data presented in Figure 6.2 were used to calibrate the solid intermediate compositions. From the process, it was found that the reaction begins as a solid material with approximate composition $\mathrm{C}_{0.67} \mathrm{H}_{1.00} \mathrm{O}_{0.48}$ and proceeds through intermediates of approximate relative compositions of $\mathrm{C}_{0.73} \mathrm{H}_{1.00} \mathrm{O}_{0.46}, \mathrm{C}_{0.76} \mathrm{H}_{1.00} \mathrm{O}_{0.46}, \mathrm{C}_{0.69} \mathrm{H}_{1.00} \mathrm{O}_{0.42}, \mathrm{C}_{1.00} \mathrm{H}_{0.76} \mathrm{O}_{0.36}$, and $C_{1.00} H_{0.60} \mathrm{O}_{0.27}$, and concludes with the final char (fixed carbon) of $\mathrm{C}_{1.00} \mathrm{H}_{0} \mathrm{O}_{0}$. Although the quasi-species cannot be isolated and characterized independently for verification, the 
resulting averaged elemental composition is consistent with observations in literature, as displayed in Figure 6.2.

The subplots on the left of Figure 6.2 show a comparison between measured and predicted elemental distribution, while the sub plots on the right show the data along with the model prediction as functions of volatile mass loss (volatile loss*) on the right. The model predicts the behavior of the observed literature data very closely $\left(R^{2}=0.99,0.98\right.$, and 0.99 respectively). Also shown are the translated experimental data from our trials that were gathered independently of the fitting procedure, for comparison and validation. The agreement of the model and the independent data are discussed in Section 3.2 below. The decay of carbon content with volatile mass loss appears to be slightly superlinear, while the oxygen is sublinear. The close fit between measured and predicted data across a wide range of woody feedstock suggest that these traces can apply to other similar feedstock without prior knowledge of their degradation pathway.

Additional calibration was needed to find the reaction stoichiometric parameters for carbon monoxide, carbon dioxide, and water. Results from this procedure are shown in Figure 6.3. The fitting procedure was performed using the same literature and experimental data as discussed above, except that $\mathrm{CO}$ and $\mathrm{CO} 2$ yields are not available from some source, including the microwave pyrolysis experiments (Howe et al. 2015, Westover et al. 2013). Although a smaller set of data is available for mass yields of these species over the progression of pyrolysis severity, the general trend is captured through the fitting procedure. The production behaviors for $\mathrm{CO}$ and $\mathrm{CO} 2$ are similar, and begin with modest production followed by increasing production rate with increasing process severity. These 

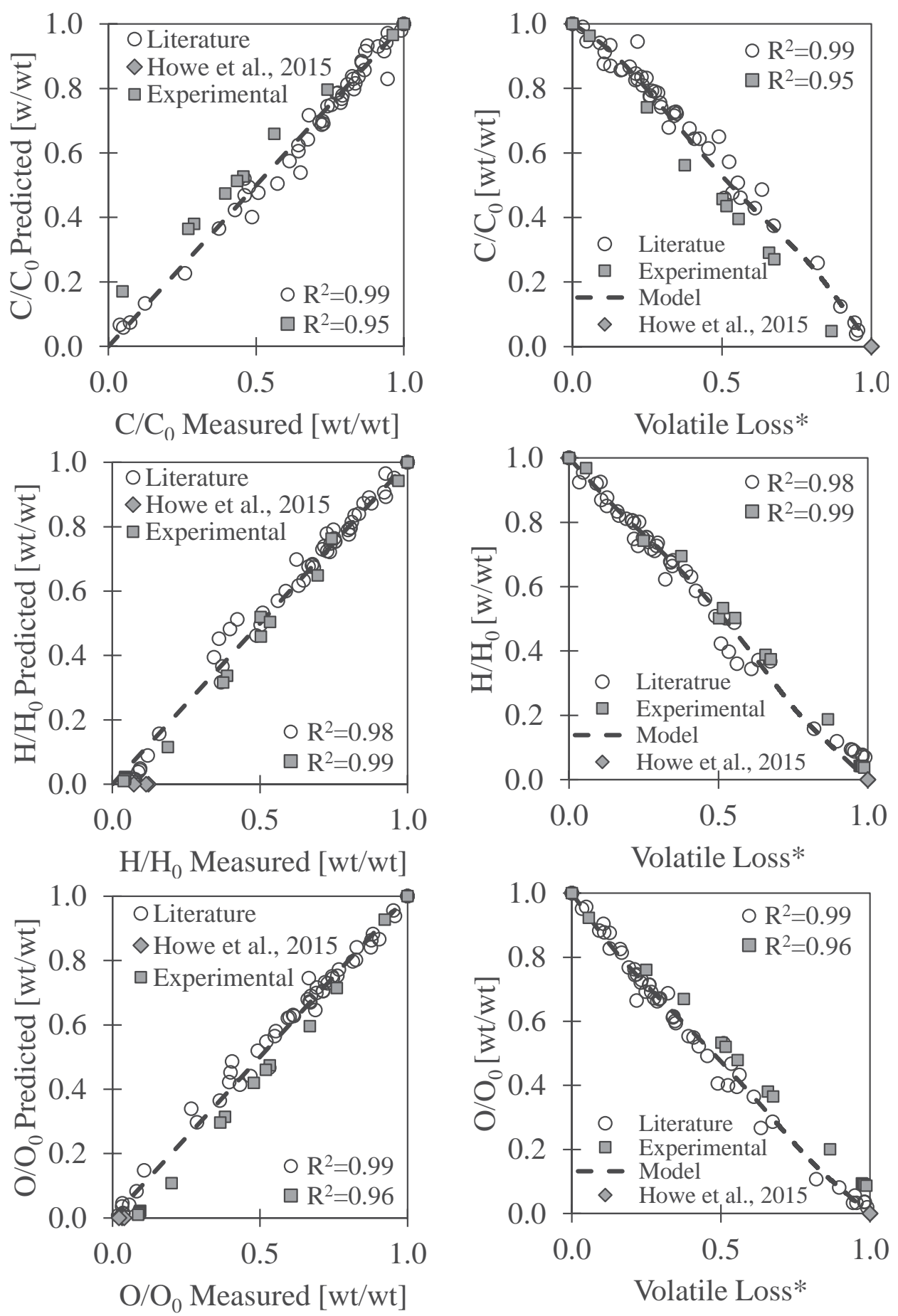

Figure 6.2: Comparison of experimental data and model prediction for normalized composition of wood char through pyrolysis. Volatile Loss* is on a moisture, ash, and fixed carbon free basis. Literature data from (Arias et al. 2008; Manuel Garcia-Perez et al. 2008; Salehi et al. 2011; Wannapeera et al. 2011; Broström et al. 2012; Howe et al. 2015; RW Nachenius et al. 2015a). 
behaviors for $\mathrm{CO}$ and $\mathrm{CO}_{2}$ are also commonly observed in literature, as noted above(Manuel Garcia-Perez et al. 2008; Nocquet et al. 2014b; RW Nachenius et al. 2015a). The behavior of water production is in stark contrast to the formation of fixed gases and exhibits the fastest production rate during mild pyrolysis. As severity increases, water formation decreases, and almost plateaus as it approaches $100 \%$ removal of the volatile mass. This likely corresponds to water formation from structural carbohydrates/fiber. From thermogravimetric analyses, it is known that hemicellulose degrades at the lowest severity conditions, cellulose at medium severity, and lignin degradation is portioned between medium and severe processing(Yang et al. 2007; Khelfa et al. 2013; Sarvaramini et al. 2013; Stefanidis et al. 2014). In addition, there is evidence that water production from thermal treatment of lignin is much lower than that of the carbohydrates, and that hemicellulose is the largest producer(Khelfa et al. 2013; Stefanidis et al. 2014). We hypothesize that these combined effects account for the observed trends and predictions. 

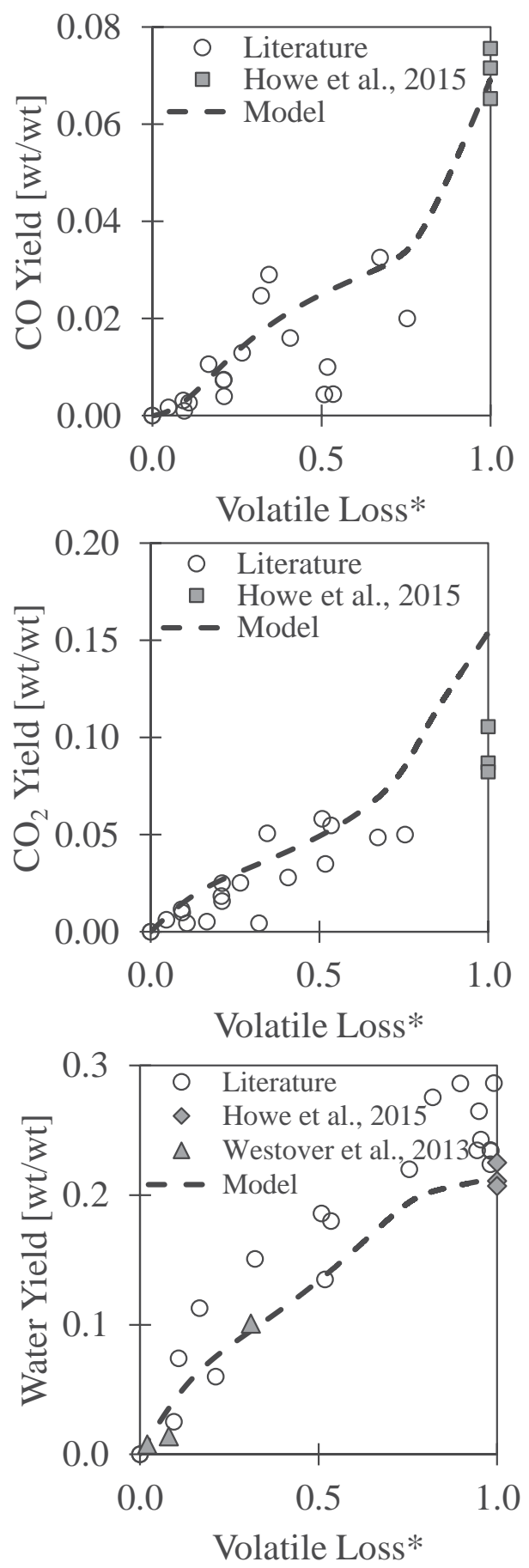

Figure 6.3: Comparison of carbon monoxide, carbon dioxide, and water yield to model predictions for mass calibration of reaction stoichiometry. Volatile Loss* is on a moisture, ash, and fixed carbon free basis. Literature data from (Manuel Garcia-Perez et al. 2008; Sinağ et al. 2011; Wannapeera et al. 2011; Westover et al. 2013; Howe et al. 2015; RW Nachenius et al. 2015a) 


\subsubsection{Validation}

\subsubsection{Char Composition}

As a result of the mass loss, the relative elemental composition of the pyrolytic char is altered. As described and shown in Figure 6.2 above, the solid composition of the pyrolytic chars collected from the microwave system are well predicted by the model. The coefficient of determination for the normalized carbon, hydrogen, and oxygen are 0.95 , 0.99 , and 0.96 respectively. This, combined with the magnitude of mass loss discussed above, validates that the model has accurate representation of experimental observations.

\subsubsection{Gross Calorific Value}

Figure 6.4 shows the model predictions and data for heating value of the solid char. The data presented were not used during the model calibration, and thus both literature and experimental data provide validation. There is a clear trend in the bulk literature data that is in agreement with the model. The gross calorific value increases with increasing severity. Beginning at approximately $19 \mathrm{MJ} / \mathrm{kg}$ in the original material, the heating value observes a modest increase to approximately $22 \mathrm{MJ} / \mathrm{kg}$ with $50 \%$ removal of the volatile mass. As more mass is removed, a higher proportion of carbon remains in the solid product and thereby increases the heating value. This trend is well within the scatter observed in literature, and agrees with data gathered in this study. Above $90 \%$ volatile mass removal, however, the model appears to predict a higher energy content than typically measured. This is likely a combined result of few data available at the most severe processing 
conditions during calibration, which skews the model toward higher accuracy at less severe conditions, and experimental error in collection/measurement of pyrolytic chars, as they are usually distributed between several unit operations in the collection train such as cyclones, electrostatic precipitators, hot vapor filters, or suspended in oil/tars. To the authors' knowledge, there is not a significant quantity of published data on the heating values of the produced liquid and gas-phase products over a wide range of processing severities. Because of the lack of comprehensive published data, their energy contents are not shown here. The predictions for gas and liquid-phase product energy densities, however, may be inferred from the elemental composition/distributions discussed in Section 3.3 Model Summary.

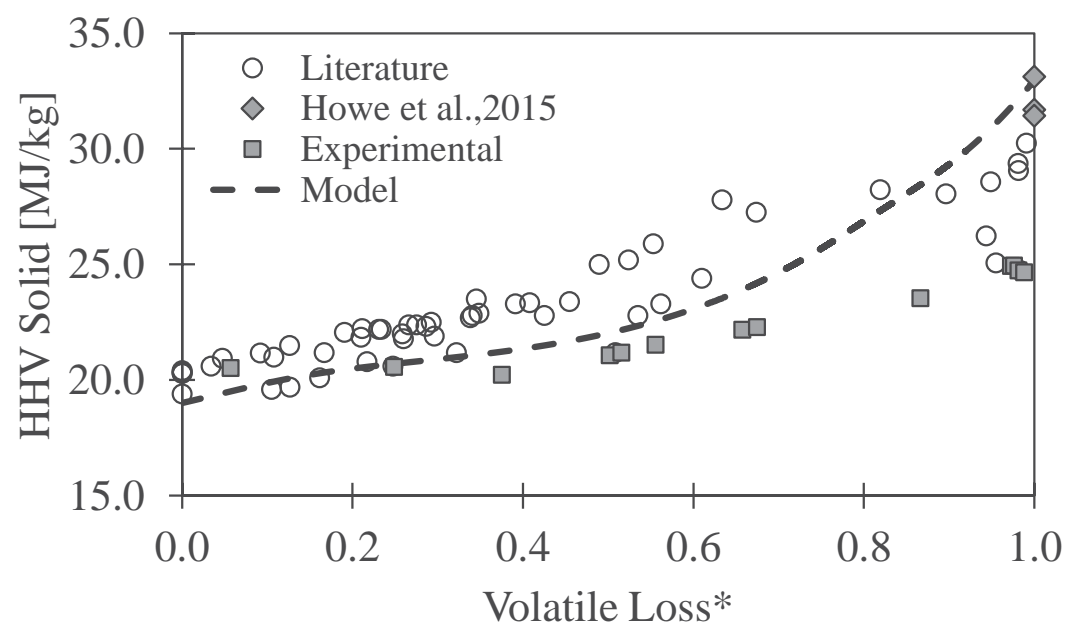

Figure 6.4: Higher heating value predictions and data for pyrolytic chars formed at varying process severity. Volatile Loss* is on a moisture, ash, and fixed carbon free basis. Literature data from (Arias et al. 2008; Salehi et al. 2011; Wannapeera et al. 2011; Broström et al. 2012; Howe et al. 2015; RW Nachenius et al. 2015a). 


\subsubsection{Product Phase Distribution}

Experimental data trends and model prediction for yield of total gas, total liquid, and oil products are shown in Figure 6.5. The data presented were not used in model calibration, and thus both literature and experimental data provide validation. The yields within all subplots are present as weight percent of the initial biomass sample. The gas species yield represents the combined production of carbon dioxide and carbon monoxide. The yield of gaseous species increases approximately linearly with volatile mass loss, reaching $10 \%$ of the total product mass around $70 \%$ volatile mass loss and increasing to $22 \%$ at total devolatilization. Liquid product yield represents the total production of condensable species or the combined production of bio-oil and water. There is an approximate linear increase in total liquid production to a product yield of $60 \%$ at $80 \%$ volatile mass loss, after which the production rate slows slightly, ending at approximately $66 \%$. The production of oil begins slowly through the initial volatile loss* zone, and begins to increase around $20 \%$ volatile mass loss (6\% oil yield). After this, there is an approximate linear increase in oil yield until $70 \%$ volatile mass loss (to $35 \%$ oil yield). The oil production with mass removal is slowed after 70 volatile loss*, and ends at a maximum of approximately $45 \%$ yield. Note that there is much greater scatter in the oil yield data than in the liquid yield data, presumably due to errors in determining the water content of the product liquids. The predictions of the model are validated by the observations of other researchers, and the experimental data collected, as shown by the agreement in the figure. 

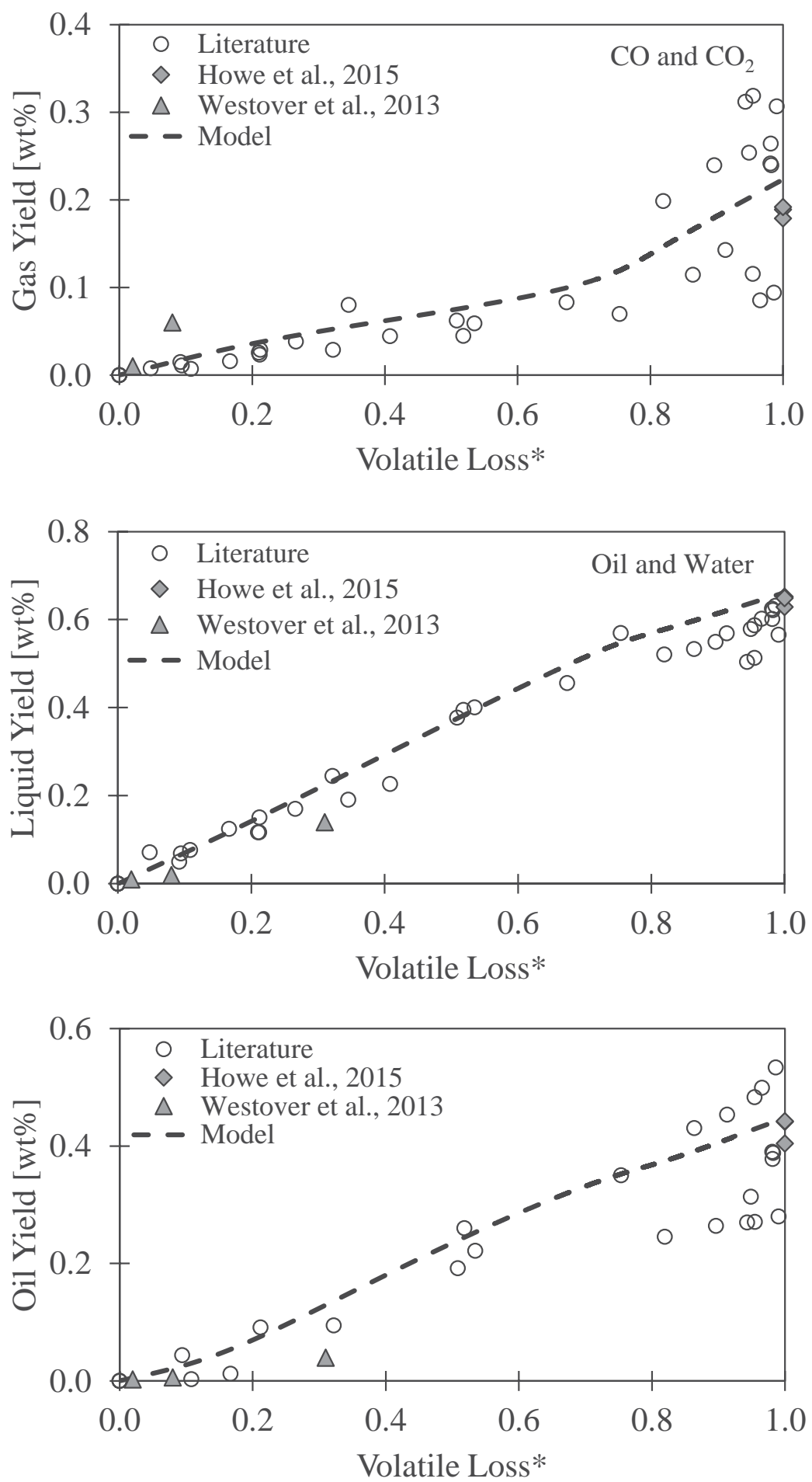

Figure 6.5: Model predictions and data for yield of total gas, total liquid, and oil products. Volatile Loss* is on a moisture, ash, and fixed carbon free basis. Literature data from (Manuel Garcia-Perez et al. 2008; Salehi et al. 2011; Sinağ et al. 2011; Wannapeera et al. 2011; Westover et al. 2013; Howe et al. 2015; RW Nachenius et al. 2015a). 


\subsubsection{Model Summary}

A summary of the mass distribution modeling results are shown in Figure 6. Subplots on the left detail distribution between solid, liquid, and gas, and subplots on the right show the predicted elemental distribution between the three product phases. The behaviors of product mass distribution are described in detail in Section 3.2. Initially $(<20 \%$ volatile loss $*$, the carbon distribution is favored toward the enhanced carbon content of the solid structure, while the carbon attributed to the gas follows closely the total mass allocated to the gas phase. The carbon enriched solid product comes at the expense of a carbon-lean liquid product. From the liquid-oil-water distribution, this is evident from the higher portion of mass attributed to water. Further, the oil formed during this region is known to be oxygen-rich, containing primarily organic acids, aldehydes, ketones, and some furans(Wannapeera et al. 2011; Westerhof et al. 2012; Branca et al. 2014; Nocquet et al. 2014b). This region is also associated with the hemicellulose region of biomass and has the lowest carbon (highest oxygen) content on a relative basis(Yang et al. 2007). In the middling region (up to $70 \%$ volatile loss*) primarily cellulose degrades and the elemental distribution closely follows the trends presented in the product mass distribution. In this region, much of the degraded mass is converted into pyrolysis oil that is similar in composition to the major chemical species: primarily levoglucosan, but also including organic acids, aldehydes, and other saccharide variants(Patwardhan et al. 2009). In this region, comparatively more $\mathrm{CO}_{2}$ is produced, shifting the oxygen distribution in higher favor of the gas-phase species. In the final degradation zone $(>70 \%)$, there is a reduced

production rate of liquid product, but an increased carbon composition. This is indicative 
of production of phenolic and cyclic species produced from the pyrolysis of lignin(Jackson et al. 2009; Patwardhan et al. 2011; Bai et al. 2014; Collard and Blin 2014; Min Zhang et al. 2014). The hydrogen distribution to the liquid phase is also favored at the expense of the gas phase in this region. The combined shift to greater carbon and hydrogen ratios with decreasing oxygen indicates that the lignin-based products are much closer to hydrocarbon based fuels, and are favorable for a high energy content liquid fuel. 

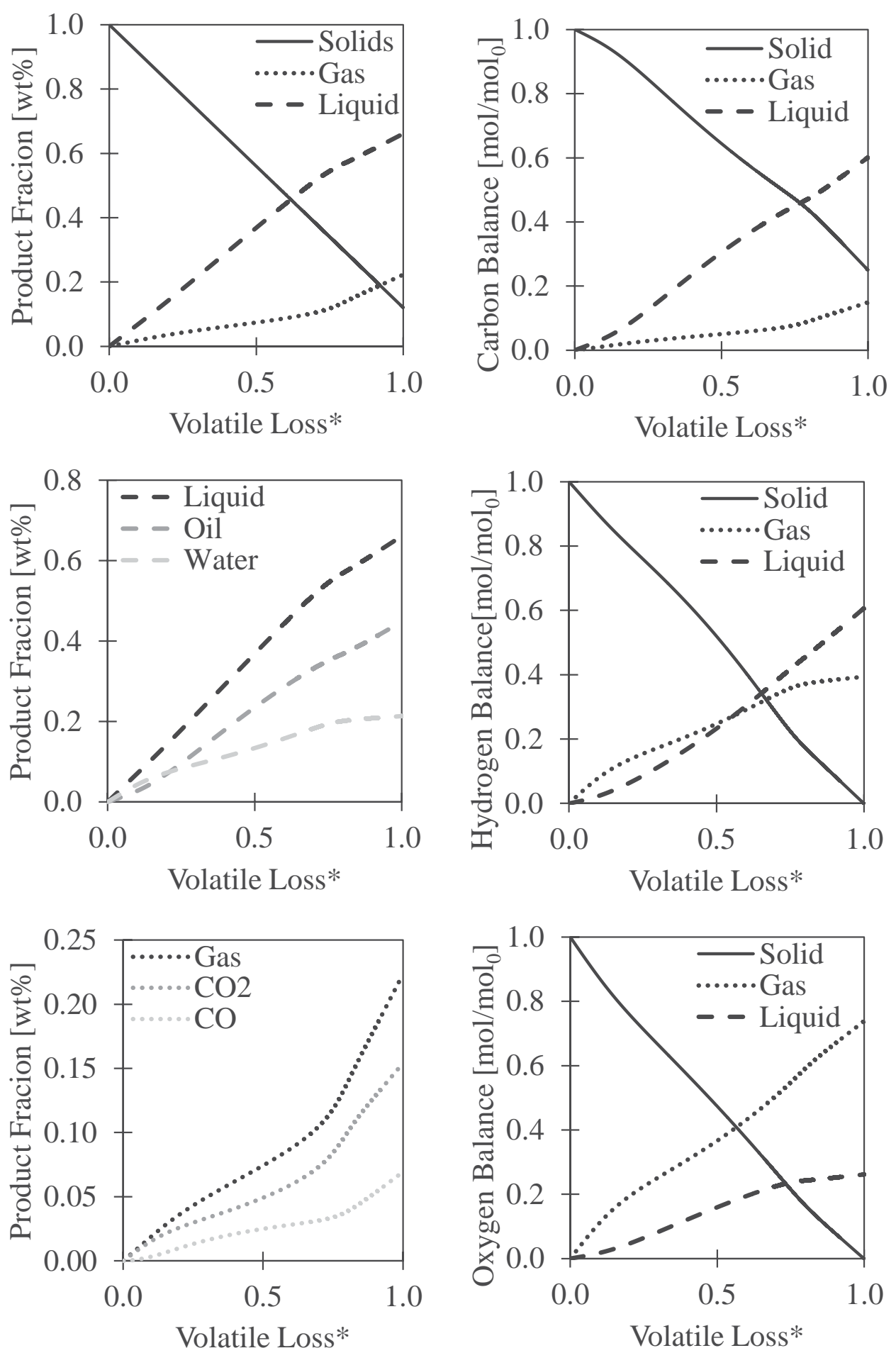

Figure 6.6: Model phase and elemental distribution predictions. Volatile Loss* is on a moisture, ash, and fixed carbon free basis. 


\subsection{Conclusions}

A kinetic model was used to describe the product evolution and distribution from fast pyrolysis of woody biomass. Because composition of the initial biomass is a controlling factor for the product distribution, the data were interpreted on an ash, moisture, and fixed carbon free basis to reduce the effect of raw feedstock variability. After calibration with a subset of data from literature, there was close agreement to other literature data and independent experimental data for the production of solid, liquid, and gas species. In addition, the distribution of carbon monoxide and carbon dioxide in the gas

phase, and water and oil produced in the liquid phase predicts the trends observed in literature data. A microwave assisted pyrolysis reactor was used to gather independent data that validated model predictions. These results were further strengthened by results from the same feedstocks in a separate fluidized bed fast pyrolysis system. Finally, bio-polymer compositions of all products were predicted, which demonstrated good agreement with other observations found in literature. Implementing such a model for the prediction of pyrolysis species can act as a screening tool for potential feedstocks or help in adjusting process parameters to create tailored products for advanced solid and liquid biofuels. 


\subsection{Works Cited}

Agblevor FA, Besler S, Wiselogel AE. 1995. Fast Pyrolysis of Stored Biomass Feedstocks. Energy \& Fuels 9(4):635-640.

Arias B, Pevida C, Fermoso J, Plaza MG, Rubiera F, Pis JJ. 2008. Influence of torrefaction on the grindability and reactivity of woody biomass. Fuel Processing Technology 89(2):169-175.

Bai X, Kim KH, Brown RC, Dalluge E, Hutchinson C, Lee YJ, Dalluge D. 2014. Formation of phenolic oligomers during fast pyrolysis of lignin. Fuel 128(0):170-179.

Branca C, Di Blasi C, Galgano A, Broström M. 2014. Effects of the Torrefaction Conditions on the Fixed-Bed Pyrolysis of Norway Spruce. Energy \& Fuels 28(9):5882-5891.

Bridgwater AV, Meier D, Radlein D. 1999. An overview of fast pyrolysis of biomass. Organic Geochemistry 30(12):1479-1493.

Bridgwater AV. 2012. Review of fast pyrolysis of biomass and product upgrading. Biomass and Bioenergy 38(0):68-94.

Broström M, Nordin A, Pommer L, Branca C, Di Blasi C. 2012. Influence of torrefaction on the devolatilization and oxidation kinetics of wood. Journal of Analytical and Applied Pyrolysis 96(0):100-109.

Carpenter D, Westover TL, Czernik S, Jablonski W. 2014. Biomass feedstocks for renewable fuel production: a review of the impacts of feedstock and pretreatment 
on the yield and product distribution of fast pyrolysis bio-oils and vapors. Green Chemistry 16(2):384-406.

Collard F-X, Blin J. 2014. A review on pyrolysis of biomass constituents: Mechanisms and composition of the products obtained from the conversion of cellulose, hemicelluloses and lignin. Renewable and Sustainable Energy Reviews 38(0):594608.

Czernik S, Bridgwater AV. 2004. Overview of Applications of Biomass Fast Pyrolysis Oil. Energy \& Fuels 18(2):590-598.

Friedl A, Padouvas E, Rotter H, Varmuza K. 2005. Prediction of heating values of biomass fuel from elemental composition. Analytica Chimica Acta 544(1-2):191-198.

Garcia-Perez M, Chaala A, Pakdel H, Kretschmer D, Roy C. 2007. Vacuum pyrolysis of softwood and hardwood biomass: comparison between product yields and bio-oil properties. Journal of Analytical and Applied Pyrolysis 78(1):104-116.

Garcia-Perez M, Wang XS, Shen J, Rhodes MJ, Tian F, Lee W-J, Wu H, Li C-Z. 2008. Fast Pyrolysis of Oil Mallee Woody Biomass: Effect of Temperature on the Yield and Quality of Pyrolysis Products. Industrial \& Engineering Chemistry Research 47(6):1846-1854.

Howe D, Westover T, Carpenter D, Santosa D, Emerson R, Deutch S, Starace A, Kutnyakov I, Lukins C. 2015. Field-to-Fuel Performance Testing of 
Lignocellulosic Feedstocks: An Integrated Study of the Fast PyrolysisHydrotreating Pathway. Energy \& Fuels 29(5):3188-3197.

Ingram L, Mohan D, Bricka M, Steele P, Strobel D, Crocker D, Mitchell B, Mohammad J, Cantrell K, Pittman Jr CU. 2007. Pyrolysis of wood and bark in an auger reactor: physical properties and chemical analysis of the produced bio-oils. Energy \& Fuels 22(1):614-625.

Jackson MA, Compton DL, Boateng AA. 2009. Screening heterogeneous catalysts for the pyrolysis of lignin. Journal of Analytical and Applied Pyrolysis 85(1-2):226-230.

Kenney KL, Smith WA, Gresham GL, Westover TL. 2013. Understanding biomass feedstock variability. Biofuels 4(1):111-127.

Khelfa A, Bensakhria A, Weber JV. 2013. Investigations into the pyrolytic behaviour of birch wood and its main components: Primary degradation mechanisms, additivity and metallic salt effects. Journal of Analytical and Applied Pyrolysis 101(0):111121.

Klinger J, Bar-Ziv E, Shonnard D. 2013. Kinetic study of aspen during torrefaction. Journal of Analytical and Applied Pyrolysis 104(0):146-152.

Klinger J, Bar-Ziv E, Shonnard D. 2014a. Predicting Properties of Torrefied Biomass by Intrinsic Kinetics. Energy \& Fuels 29(1):171-176. 
Klinger J, Klemetsrud B, Bar-Ziv E, Shonnard D. 2014b. Temperature dependence of aspen torrefaction kinetics. Journal of Analytical and Applied Pyrolysis 110(0):424-429.

Klinger J, Bar-Ziv E, Shonnard D. 2015. Unified kinetic model for torrefaction-pyrolysis. Fuel Processing Technology 138:175-183.

Lu Q, Li W-Z, Zhu X-F. 2009. Overview of fuel properties of biomass fast pyrolysis oils. Energy Conversion and Management 50(5):1376-1383.

Meier D, Faix O. 1999. State of the art of applied fast pyrolysis of lignocellulosic materials -- a review. Bioresource Technology 68(1):71-77.

Mohan D, Pittman CU, Steele PH. 2006. Pyrolysis of Wood/Biomass for Bio-oil: A Critical Review. Energy \& Fuels 20(3):848-889.

Nachenius R, van de Wardt T, Ronsse F, Prins W. 2015a. Torrefaction of pine in a benchscale screw conveyor reactor. Biomass and Bioenergy.

Nachenius RW, van de Wardt T, Ronsse F, Prins W. 2015b. Residence time distributions of coarse biomass particles in a screw conveyor reactor. Fuel Processing Technology 130:87-95.

Nocquet T, Dupont C, Commandre J-M, Grateau M, Thiery S, Salvador S. 2014a. Volatile species release during torrefaction of wood and its macromolecular constituents: Part 1 - Experimental study. Energy 72(0):180-187. 
Nocquet T, Dupont C, Commandre J-M, Grateau M, Thiery S, Salvador S. 2014b. Volatile species release during torrefaction of biomass and its macromolecular constituents: Part 2 - Modeling study. Energy 72(0):188-194.

Oasmaa A, Czernik S. 1999. Fuel Oil Quality of Biomass Pyrolysis OilsState of the Art for the End Users. Energy \& Fuels 13(4):914-921.

Patwardhan PR, Satrio JA, Brown RC, Shanks BH. 2009. Product distribution from fast pyrolysis of glucose-based carbohydrates. Journal of Analytical and Applied Pyrolysis 86(2):323-330.

Patwardhan PR, Brown RC, Shanks BH. 2011. Understanding the Fast Pyrolysis of Lignin. ChemSusChem 4(11):1629-1636.

Prins MJ, Ptasinski KJ, Janssen FJJG. 2006. Torrefaction of wood: Part 2. Analysis of products. Journal of Analytical and Applied Pyrolysis 77(1):35-40.

Ren S, Lei H, Wang L, Bu Q, Chen S, Wu J. 2013. Thermal behaviour and kinetic study for woody biomass torrefaction and torrefied biomass pyrolysis by TGA. Biosystems Engineering 116(4):420-426.

Salehi E, Abedi J, Harding T. 2011. Bio-oil from Sawdust: Effect of Operating Parameters on the Yield and Quality of Pyrolysis Products. Energy \& Fuels 25(9):4145-4154.

Sarvaramini A, Assima GP, Larachi F. 2013. Dry torrefaction of biomass - Torrefied products and torrefaction kinetics using the distributed activation energy model. Chemical Engineering Journal 229(0):498-507. 
Shen DK, Gu S. 2009. The mechanism for thermal decomposition of cellulose and its main products. Bioresource Technology 100(24):6496-6504.

Sınağ A, Uskan B, Gülbay S. 2011. Detailed characterization of the pyrolytic liquids obtained by pyrolysis of sawdust. Journal of Analytical and Applied Pyrolysis $90(1): 48-52$.

Stefanidis SD, Kalogiannis KG, Iliopoulou EF, Michailof CM, Pilavachi PA, Lappas AA. 2014. A study of lignocellulosic biomass pyrolysis via the pyrolysis of cellulose, hemicellulose and lignin. Journal of Analytical and Applied Pyrolysis 105(0):143150.

Trendewicz A, Evans R, Dutta A, Sykes R, Carpenter D, Braun R. 2015. Evaluating the effect of potassium on cellulose pyrolysis reaction kinetics. Biomass and Bioenergy $74(0): 15-25$.

Tumuluru JS, Hess JR, Boardman RD, Wright CT, Westover TL. 2012. Formulation, pretreatment, and densification options to improve biomass specifications for cofiring high percentages with coal. Industrial Biotechnology 8(3):113-132.

Wannapeera J, Fungtammasan B, Worasuwannarak N. 2011. Effects of temperature and holding time during torrefaction on the pyrolysis behaviors of woody biomass. Journal of Analytical and Applied Pyrolysis 92(1):99-105. 
Wei L, Xu S, Zhang L, Zhang H, Liu C, Zhu H, Liu S. 2006. Characteristics of fast pyrolysis of biomass in a free fall reactor. Fuel Processing Technology 87(10):863871.

Westerhof RJ, Brilman DWF, Garcia-Perez M, Wang Z, Oudenhoven SR, Kersten SR. 2012. Stepwise fast pyrolysis of pine wood. Energy \& Fuels 26(12):7263-7273.

Westover TL, Phanphanich M, Clark ML, Rowe SR, Egan SE, Zacher AH, Santosa D. 2013. Impact of thermal pretreatment on the fast pyrolysis conversion of southern pine. Biofuels 4(1):45-61.

Yang H, Yan R, Chen H, Lee DH, Zheng C. 2007. Characteristics of hemicellulose, cellulose and lignin pyrolysis. Fuel 86(12-13):1781-1788.

Zhang J, Toghiani H, Mohan D, Pittman CU, Toghiani RK. 2007a. Product analysis and thermodynamic simulations from the pyrolysis of several biomass feedstocks. Energy \& Fuels 21(4):2373-2385.

Zhang M, Resende FLP, Moutsoglou A. 2014. Catalytic fast pyrolysis of aspen lignin via Py-GC/MS. Fuel 116(0):358-369.

Zhang Q, Chang J, Wang T, Xu Y. 2007b. Review of biomass pyrolysis oil properties and upgrading research. Energy Conversion and Management 48(1):87-92.

Zheng A, Zhao Z, Chang S, Huang Z, He F, Li H. 2012. Effect of Torrefaction Temperature on Product Distribution from Two-Staged Pyrolysis of Biomass. Energy \& Fuels 26(5):2968-2974. 


\section{Conclusions and Recommendations for Future Work}

This work was focused on development of a unified kinetic model for torrefaction

and pyrolysis for woody biomass. Heartwood is an ideal feedstock for an analytical study due to its relative homogeneity and absence of minerals that are well-known to induce secondary catalytic reactions. Initially a three stage consecutive model was developed to describe the volatile species released from wood torrefaction at $300^{\circ} \mathrm{C}$. This work used gas chromatography and mass spectroscopy to monitor the gas-phase products in real time. This novel method considered the main products as acetic acid, formic acid, water, carbon monoxide and carbon dioxide. The resulting kinetic model was the first of its kind - a kinetic model that predicts specific gas-phase species evolution.

After initial proposal of the model, the reaction scheme was investigated over a range of torrefaction temperatures $\left(260-300^{\circ} \mathrm{C}\right)$. It was found that the model holds over the entire temperature range, and accurately predicts gas product evolution over the changing process conditions. Furfural was added as an additional gas-phase species to the consecutive mechanism. From this work it was discovered that careful consideration must be given to torrefaction conditions due to different observed behaviors of product evolution. Perhaps most importantly, careful consideration must be given to the removal of formed water (large production in early time reactions) and chemical formation of organic acids (dominated by late time reactions). From the extracted kinetic parameters and stoichiometry factory (process chemistry), the kinetic model could then be used to predict product distributions at various processing conditions. 
The model was then used in a predictive manner over a range of torrefaction conditions to gain insight into the solid phase biochar that is formed. Because of the potential application of this material as a replacement for traditional fossil coal, the work was focused around parameters that are of particular interest from an energy viewpoint energy content (density), elemental composition, process mass and energy yields (efficiencies). The kinetic model was mass-calibrated to predict gas/vapor products from wood feedstock, and an elemental balance was performed to estimate the remaining solid char. It was found that the torrefaction process removes relatively more mass than energy from the solid, making a more energy rich fuel. In addition, careful selection of process conditions can yield a fuel of tailored composition. For solid fuel applications, it is concluded that a minimum of $20 \%$ of the initial dry mass is removed through the process. This will ensure that there is significant removal of water and corrosive organic acids, and that the energy density is enhanced (nearing sub-bituminous coal levels).

The proposed kinetic model was then extended into a more traditional pyrolysis range (up to $425^{\circ} \mathrm{C}$ ), while still avoiding any significant secondary thermal reactions. Here the model was extended to six consecutive reactions to describe to observed product evolution of both weightloss (chromatographic TIC) and 32 unique molecular fragmentations from cellulose, hemicellulose, and lignin. Each reaction stage was only measurable over a range of reaction temperatures, and limited the fitting procedure to subset of the model parameters. In conclusion of this empirical work, it was found that the model not only describes the evolution of gas-phase species from cellulose, hemicellulose, and lignin, but also describes the entirety of torrefaction and pyrolysis within a single 
unified mechanism. Such a model can be used to predict the chemical composition from torrefaction, pyrolysis, or combined multi-stage torrefaction-pyrolysis. It was also shown that torrefaction and pyrolysis are the same follow the same thermal degradation mechanism at different kinetic rates due to the influence of processing temperature. The presented kinetic parameters and process chemistry parameters could be (through an admittedly very intense and concerted study of the presented data) distilled to a pyrolysis mechanism or probable chemical pathways.

The unified model was then calibrated to estimate products and product composition over the entire degradation mass range. These predictions were verified through independent empirical tests. It was found that there is reasonable prediction of solid, liquid, and gas species as well as their composition. Also of great importance, it was discovered that different woody biomass sources behave very similarly if interpreted on the relative ash, moisture, and fixed carbon free basis discussed. Highlighted from a different angle, the presented model may be able to account for variation in woody feedstock by accounting for the initial distribution of cellulose, hemicellulose, lignin, fixed carbon, and ash. The product and elemental balances predicted by the chemical kinetic model can be combined to estimate the ideal product distribution given any production configuration.

Looking to future work there are many areas that still need development and consideration. A specific topic that could enhance the development of the presented work is establishment of a relation between product mass quantification from cellulose, hemicellulose, and lignin to a wide range of processing conditions and in the absence of 
secondary thermal/mineral effects. Outside near-complete devolitalization (complete pyrolysis), there is very limited data available in current literature. Such quantified transient chemical information are vital to mass calibration of chemical kinetic models such as the one presented.

In-line with these proposed activities, the influence of mineral content, and heat/mass transport limitations are often only investigated at the most severe processing conditions. To understand how these impact the intrinsic mechanisms, they must be studied parametrically over the complete range of conditions. Because lignocellulosic biomasses are all comprised of essentially the same chemical building blocks, it stand to reason that they should all degrade in a similar fashion in the absence of secondary effects. Although the qualitative products may be shared across all biomass species, their various magnitudes are perhaps an artifact from the variable initial composition. From this single underlying mechanism, it may be possible to describe all observed/observable phenomena with convolution from secondary reaction from alkali minerals, and heat/mass transport effects, and variable feedstock composition.

Current process models and simulations should also be integrated with kinetic models that predict species distribution. Many current studies are based on end-point quantifications alone, assuming that complete processing is required for fuel production. As observed in the presented work, there may be many fuel quality factors that should be considered during optimization along with mass yield. Inclusion of such dynamic chemical models (and heat/mass transport, and mineral effects as developed) could provide greater understanding to producing tailored fuels or chemical feedstock. 
Beyond cellulose, there are few near-complete mechanistic theories of biomass/component degradation, and provide more avenues for future research. These mechanism could enhance the state-of-the-art kinetic understanding and provide a basis for model refinement beyond phenomenological studies. Conversely, further investigation of such work as presented here in Chapter 5 could enhance the mechanistic understanding of biomass or component degradation. 